\title{
Concocting Cholinergy
}

\section{Artur Kania ${ }^{1,2,3 *}$}

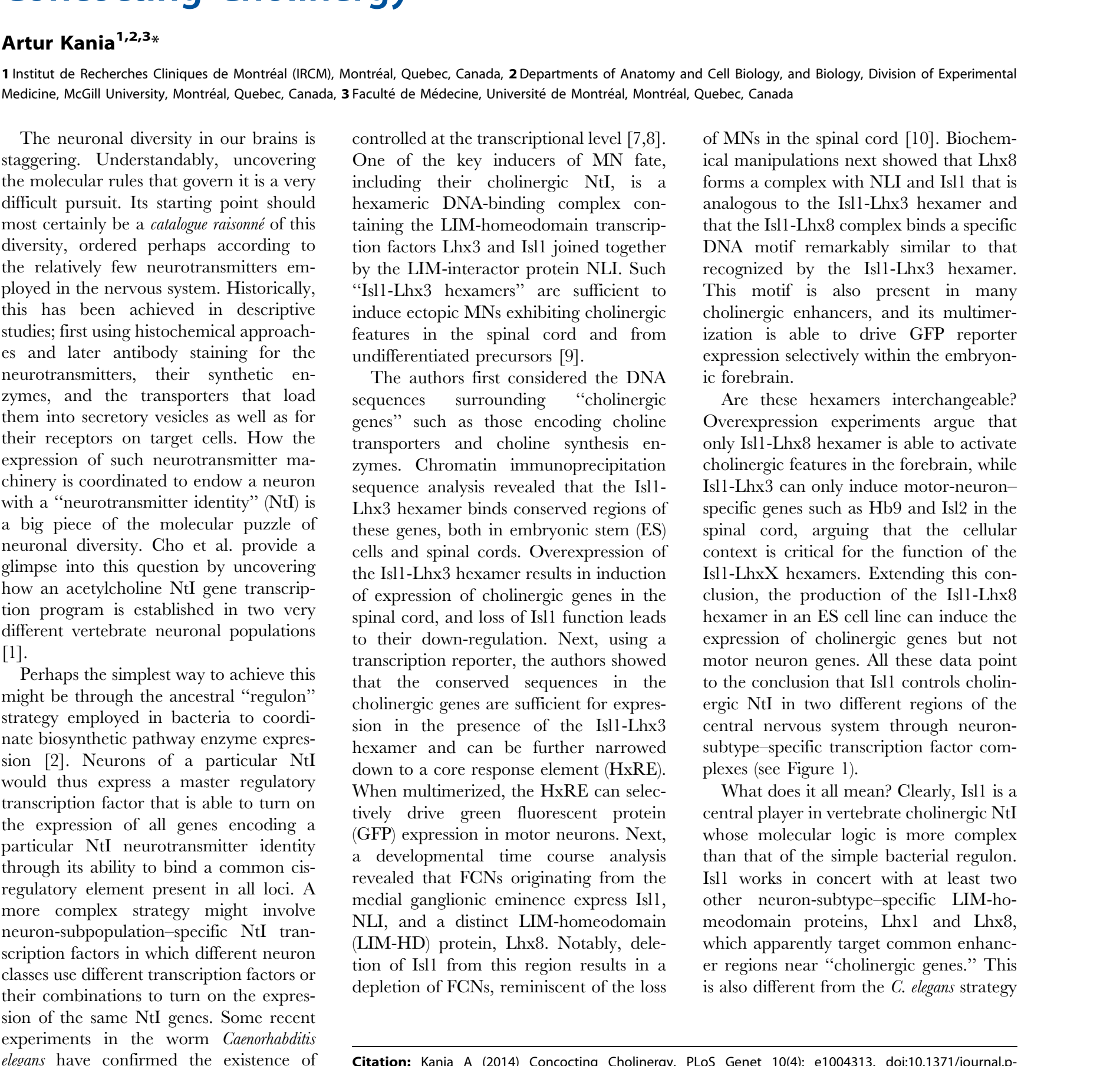
Medicine, McGill University, Montréal, Quebec, Canada, 3 Faculté de Médecine, Université de Montréal, Montréal, Quebec, Canada

The neuronal diversity in our brains is staggering. Understandably, uncovering the molecular rules that govern it is a very difficult pursuit. Its starting point should most certainly be a catalogue raisonné of this diversity, ordered perhaps according to the relatively few neurotransmitters employed in the nervous system. Historically, this has been achieved in descriptive studies; first using histochemical approaches and later antibody staining for the neurotransmitters, their synthetic enzymes, and the transporters that load them into secretory vesicles as well as for their receptors on target cells. How the expression of such neurotransmitter machinery is coordinated to endow a neuron with a "neurotransmitter identity" ( $\mathrm{NtI})$ is a big piece of the molecular puzzle of neuronal diversity. Cho et al. provide a glimpse into this question by uncovering how an acetylcholine NtI gene transcription program is established in two very different vertebrate neuronal populations [1].

Perhaps the simplest way to achieve this might be through the ancestral "regulon" strategy employed in bacteria to coordinate biosynthetic pathway enzyme expression [2]. Neurons of a particular NtI would thus express a master regulatory transcription factor that is able to turn on the expression of all genes encoding a particular NtI neurotransmitter identity through its ability to bind a common cisregulatory element present in all loci. A more complex strategy might involve neuron-subpopulation-specific NtI transcription factors in which different neuron classes use different transcription factors or their combinations to turn on the expression of the same NtI genes. Some recent experiments in the worm Caenorhabditis elegans have confirmed the existence of NtI master regulatory transcription factors [3-5], raising the question of whether a similar strategy is used in vertebrates. Cho et al. show in vertebrates that such regulatory factors exist but work in a combinatorial manner. The study focuses on two cholinergic neuronal populations: spinal motor neurons (MNs) and forebrain cholinergic neurons (FCNs) [6]. MNs are an ideal starting point for this analysis as much is known about how their genesis is

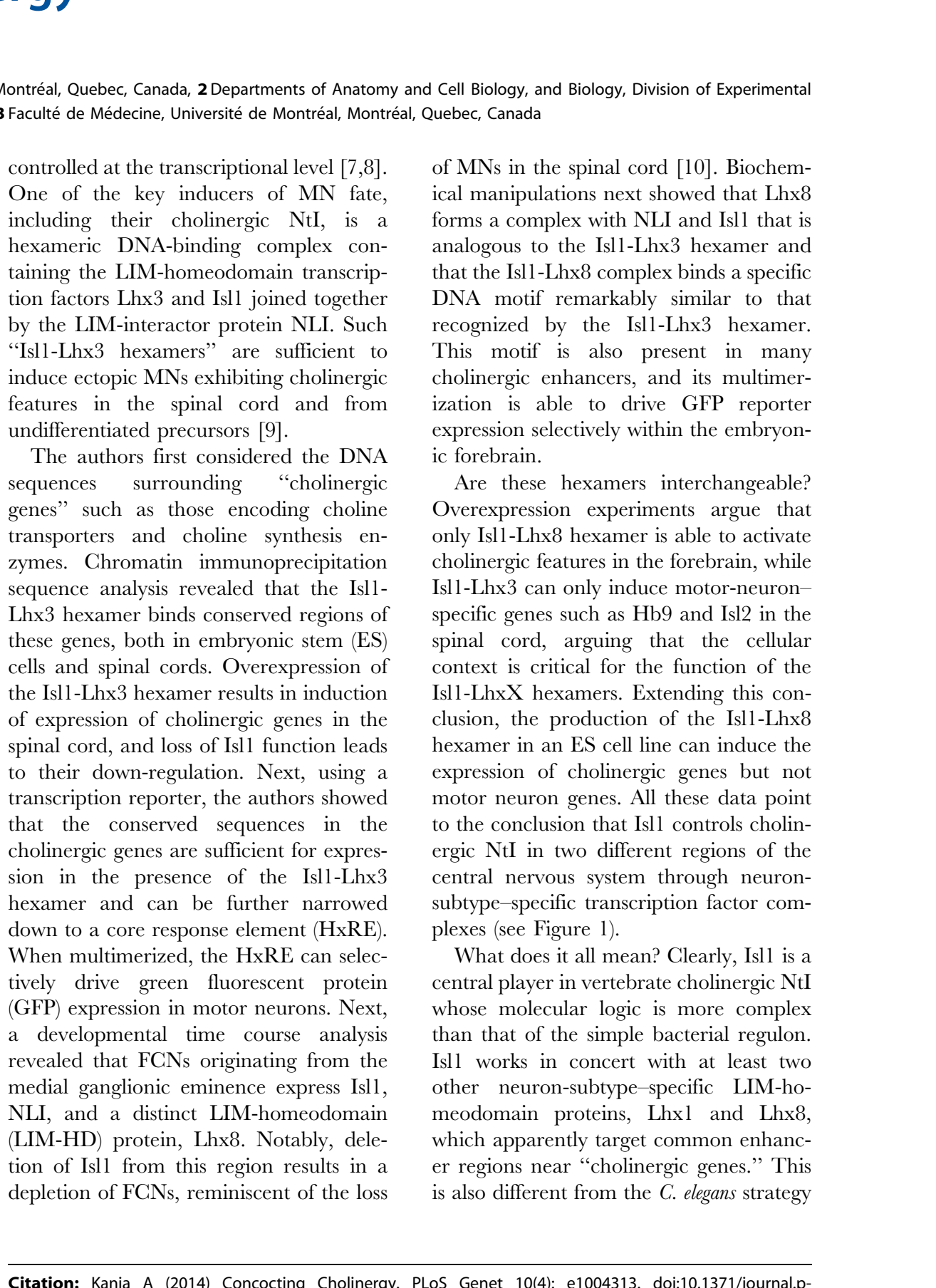

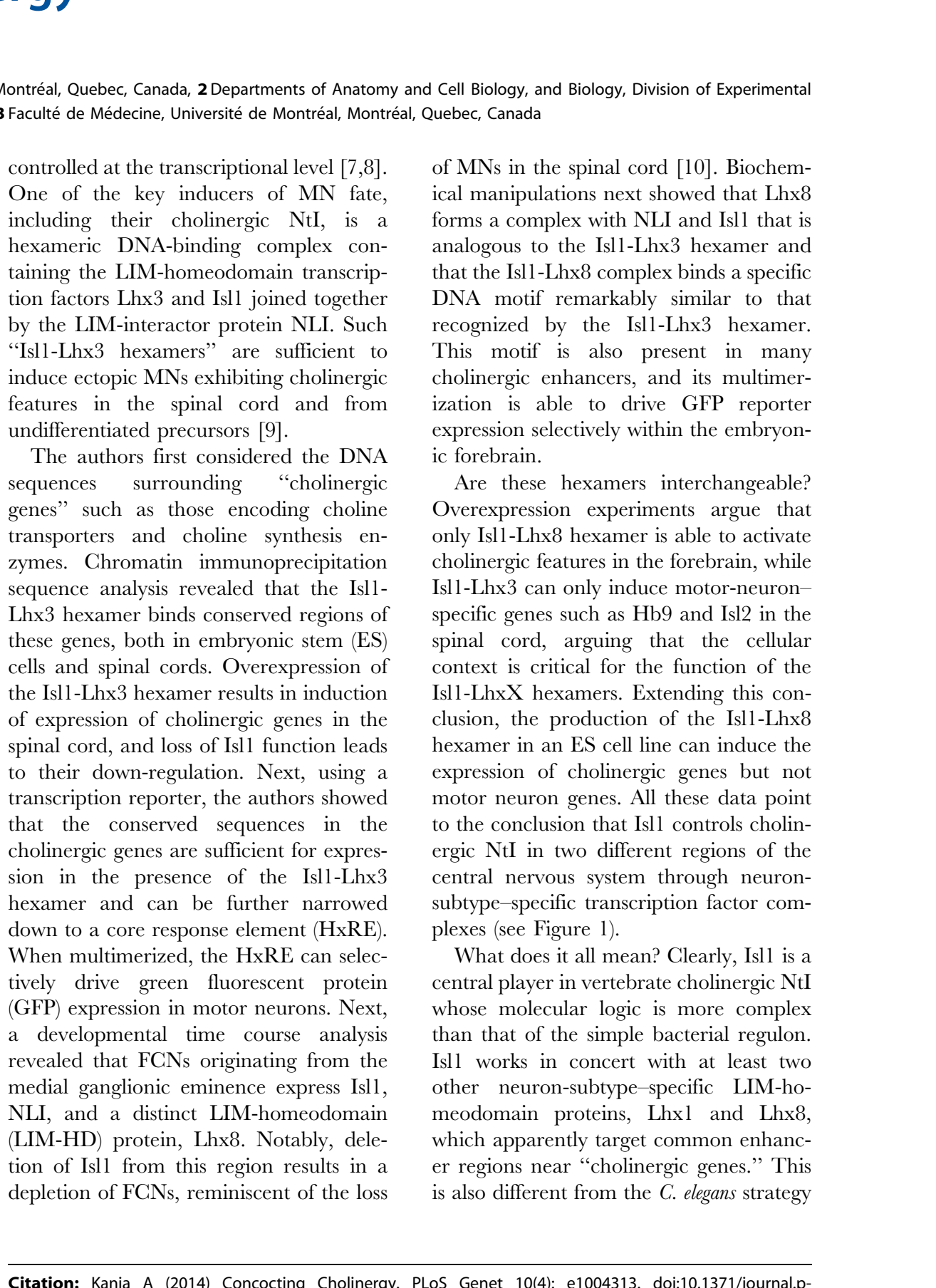

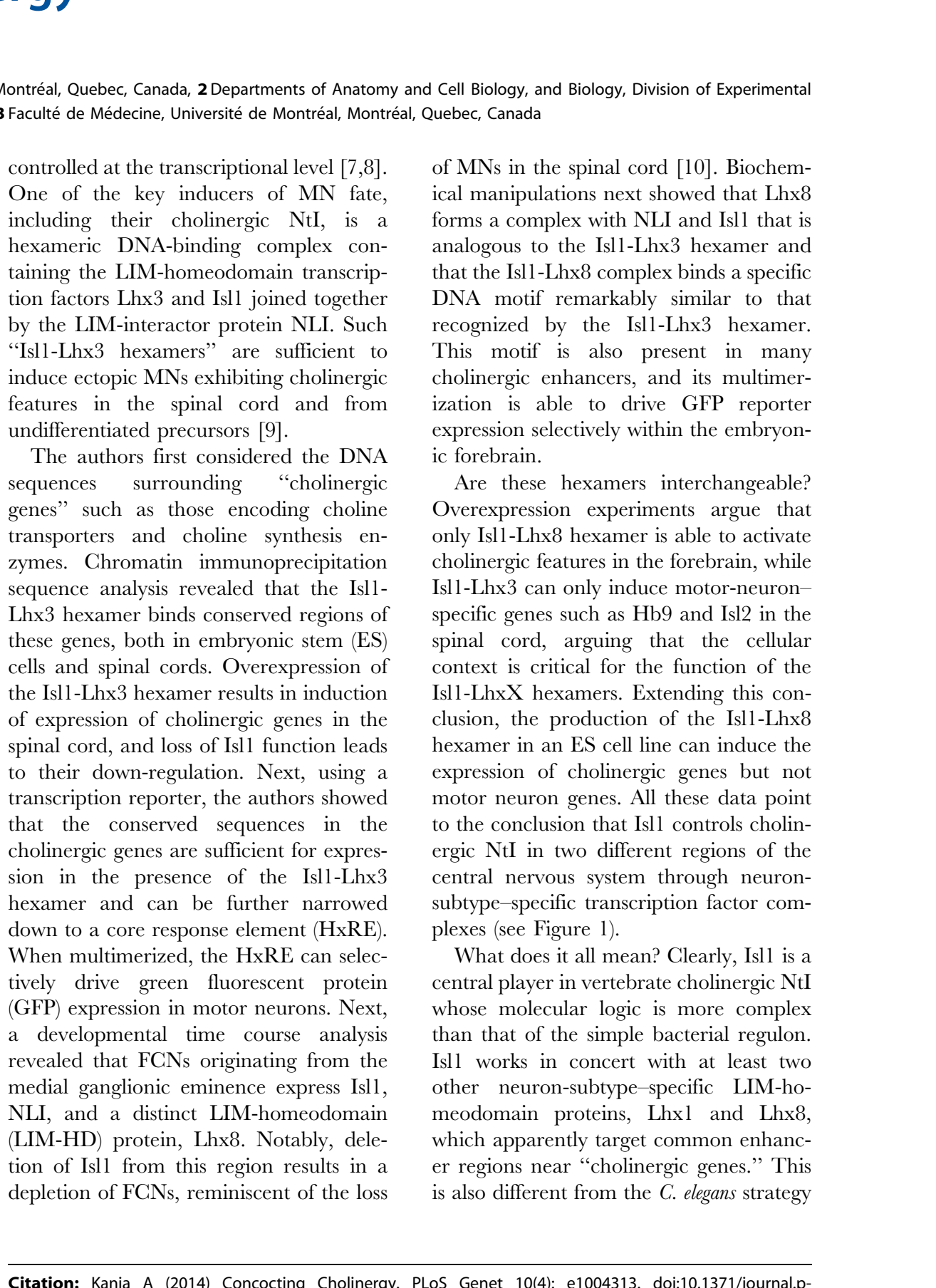

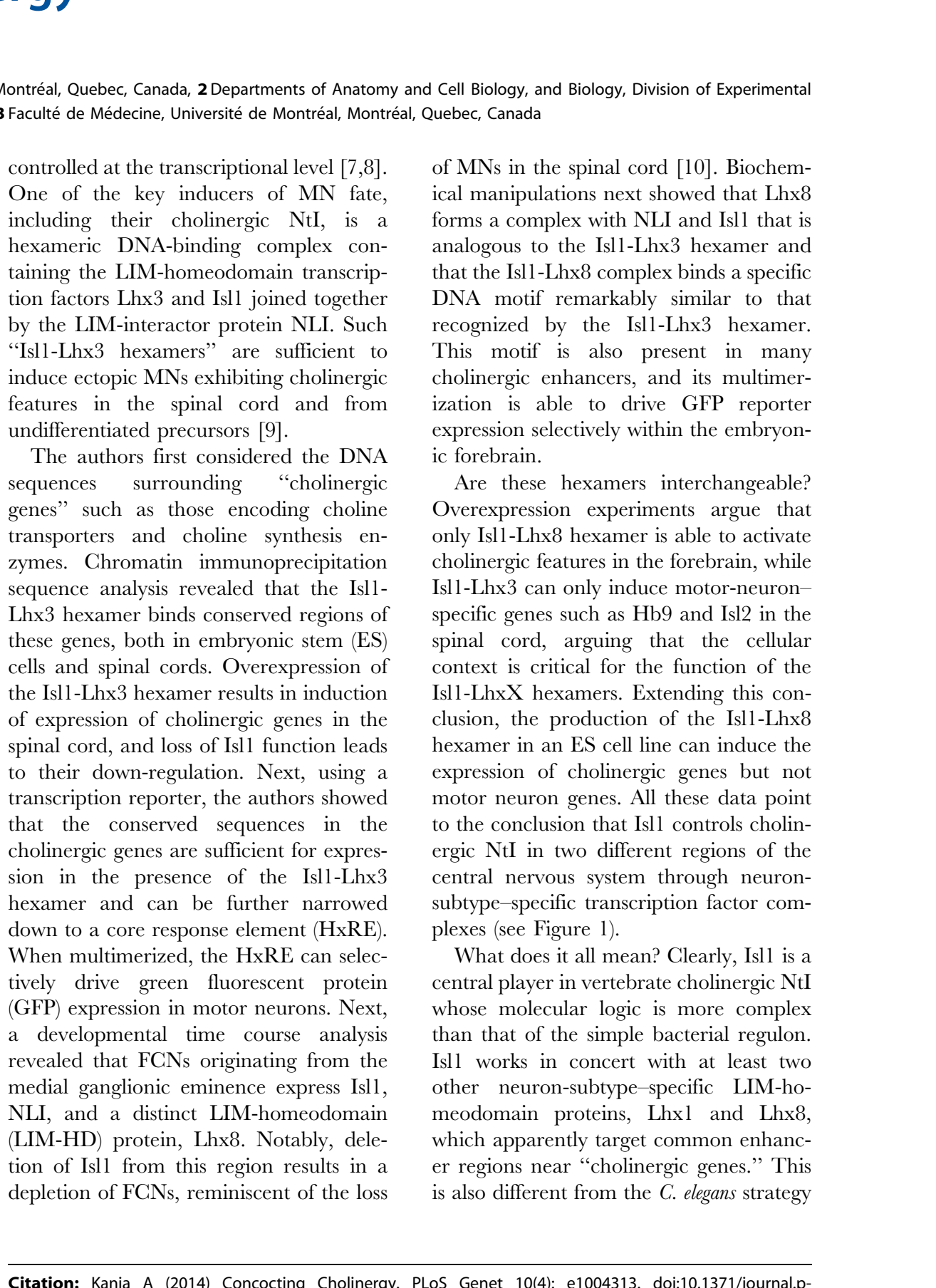

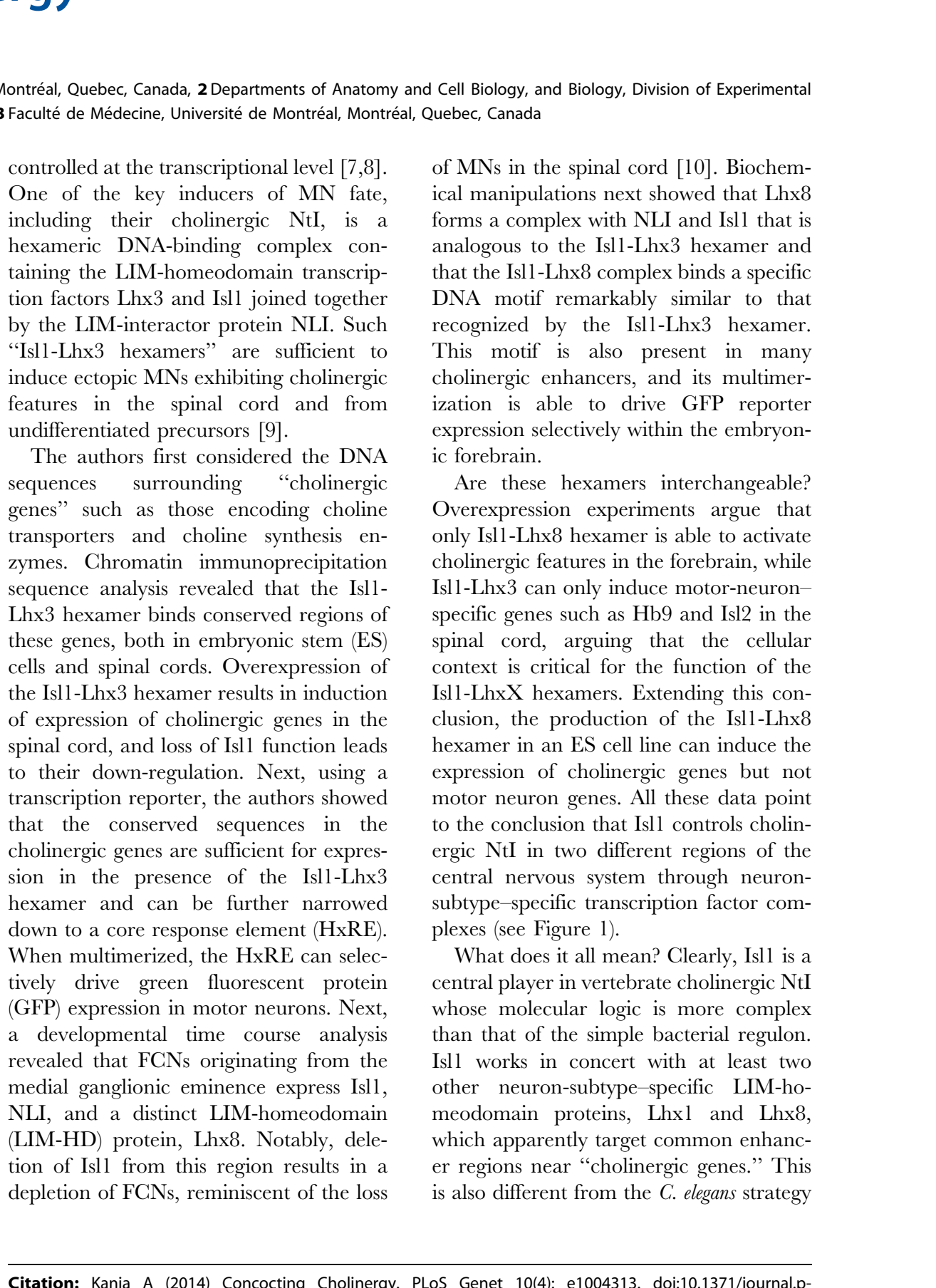

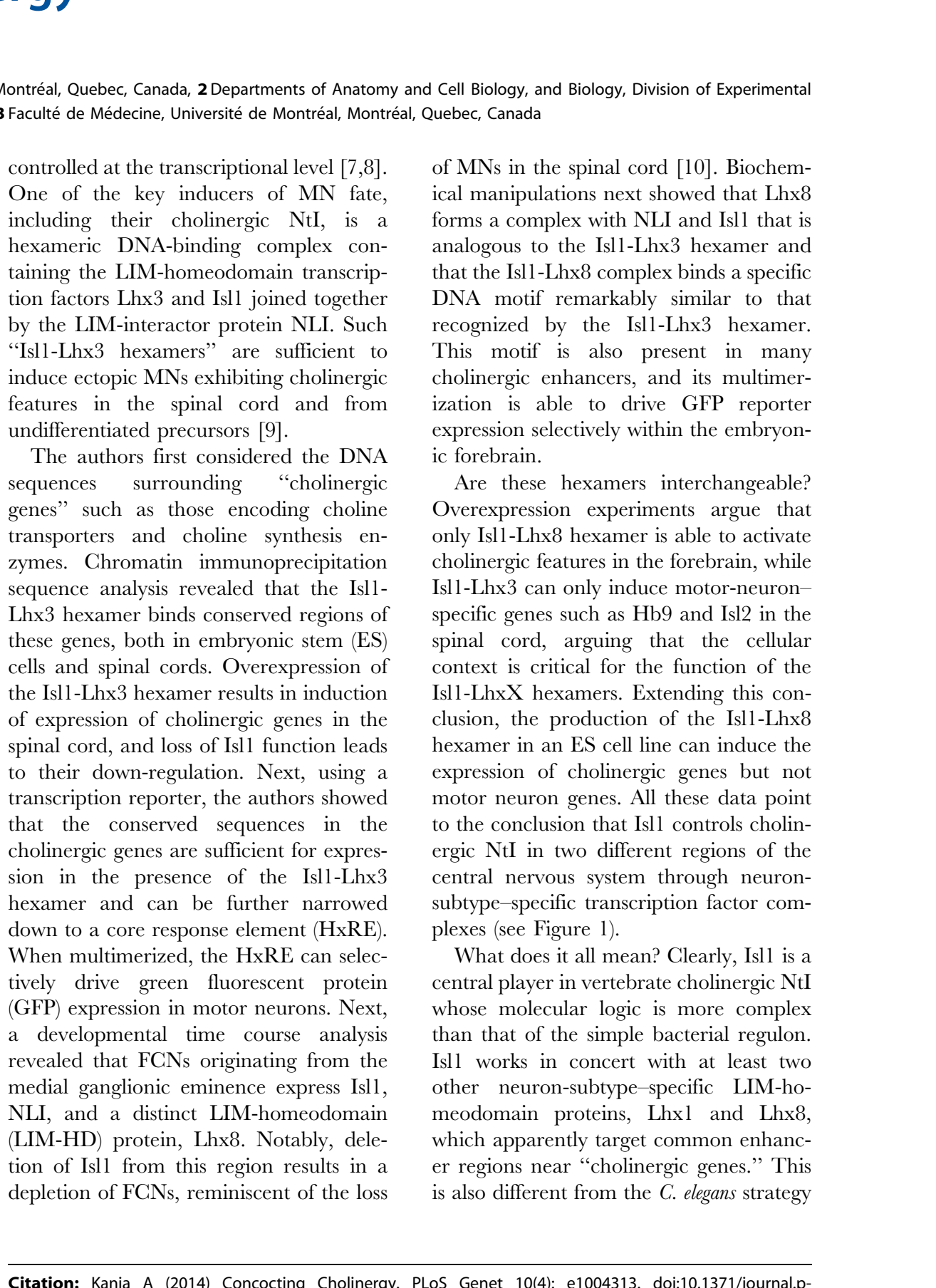

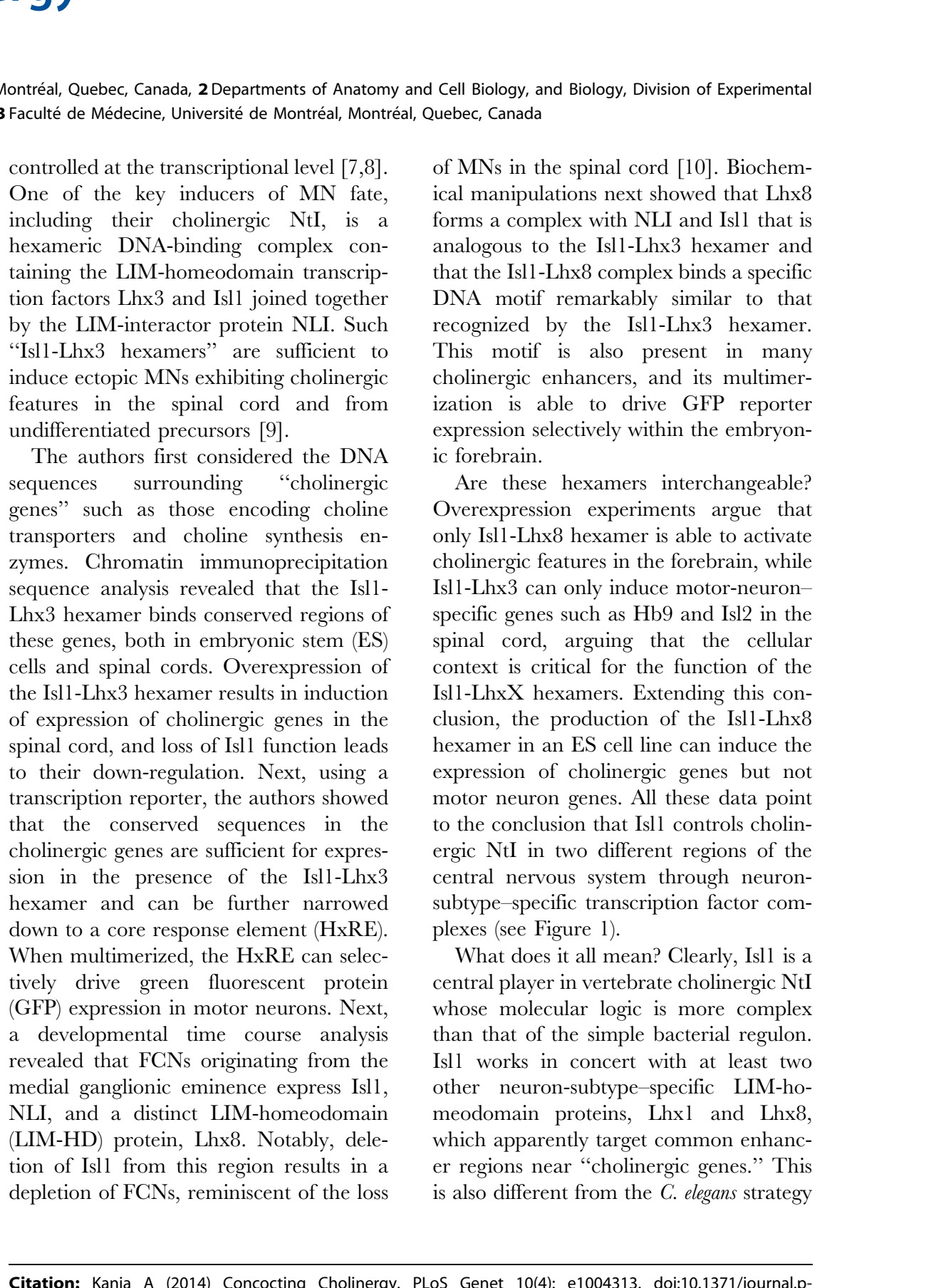

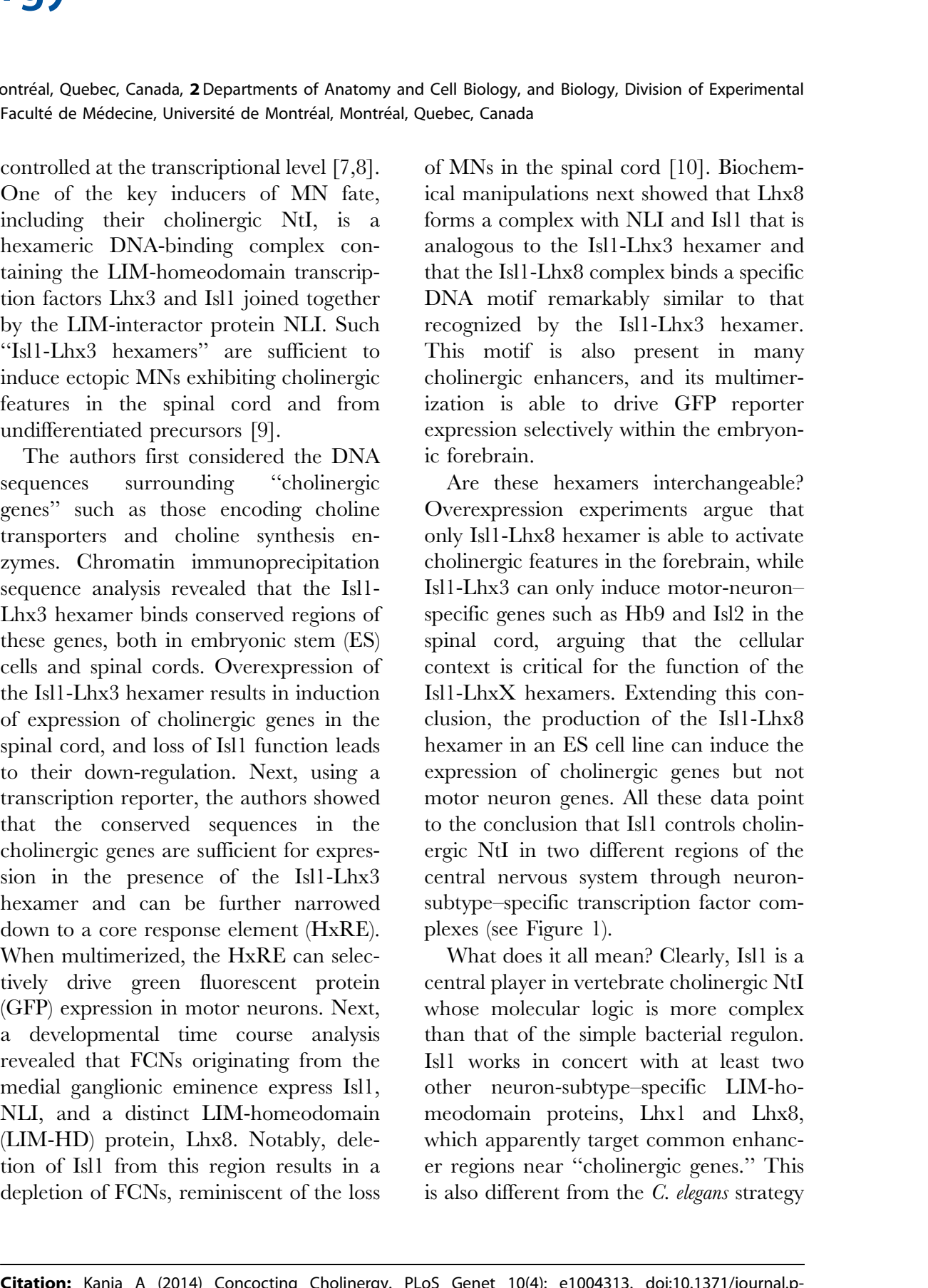

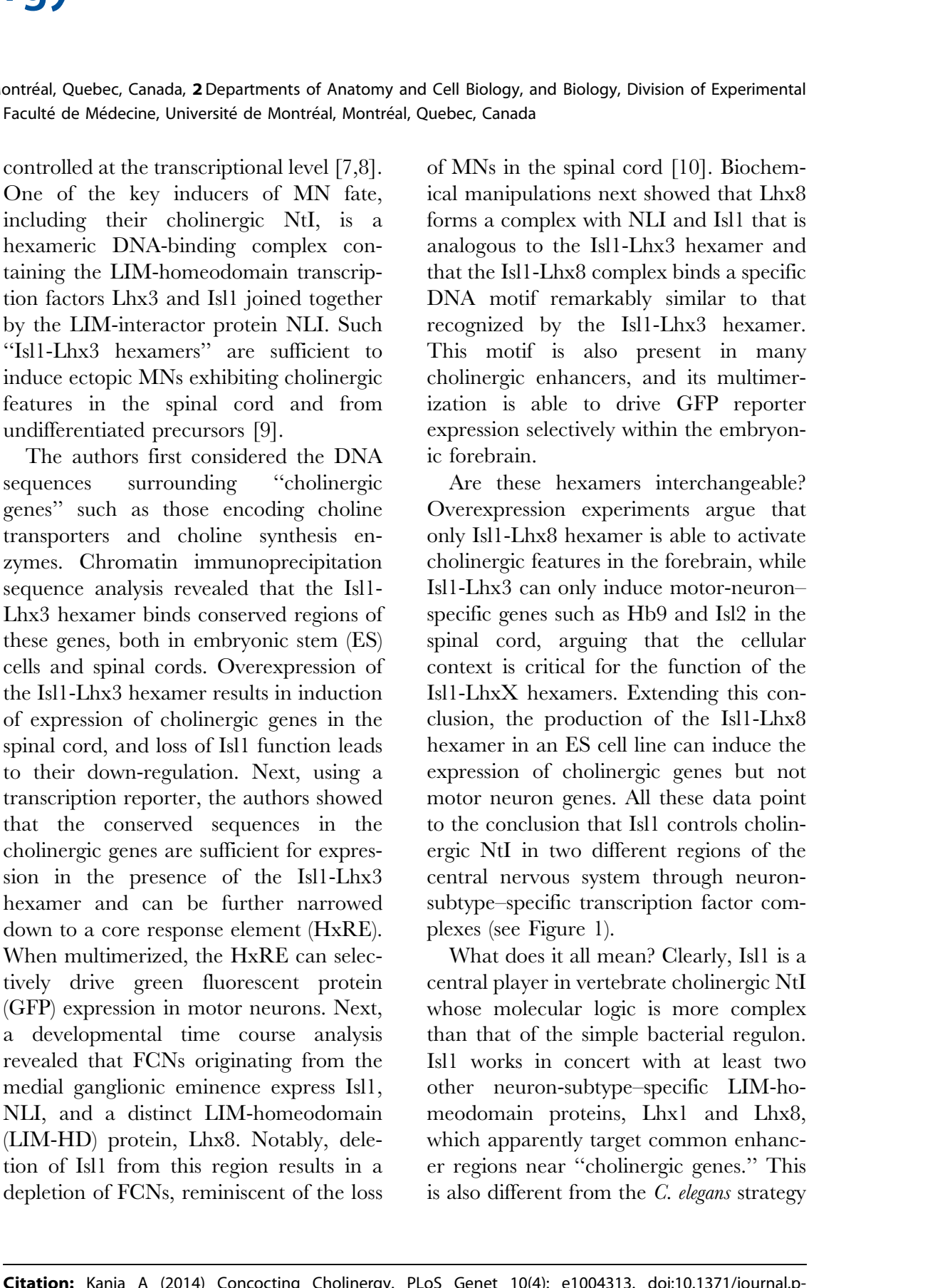

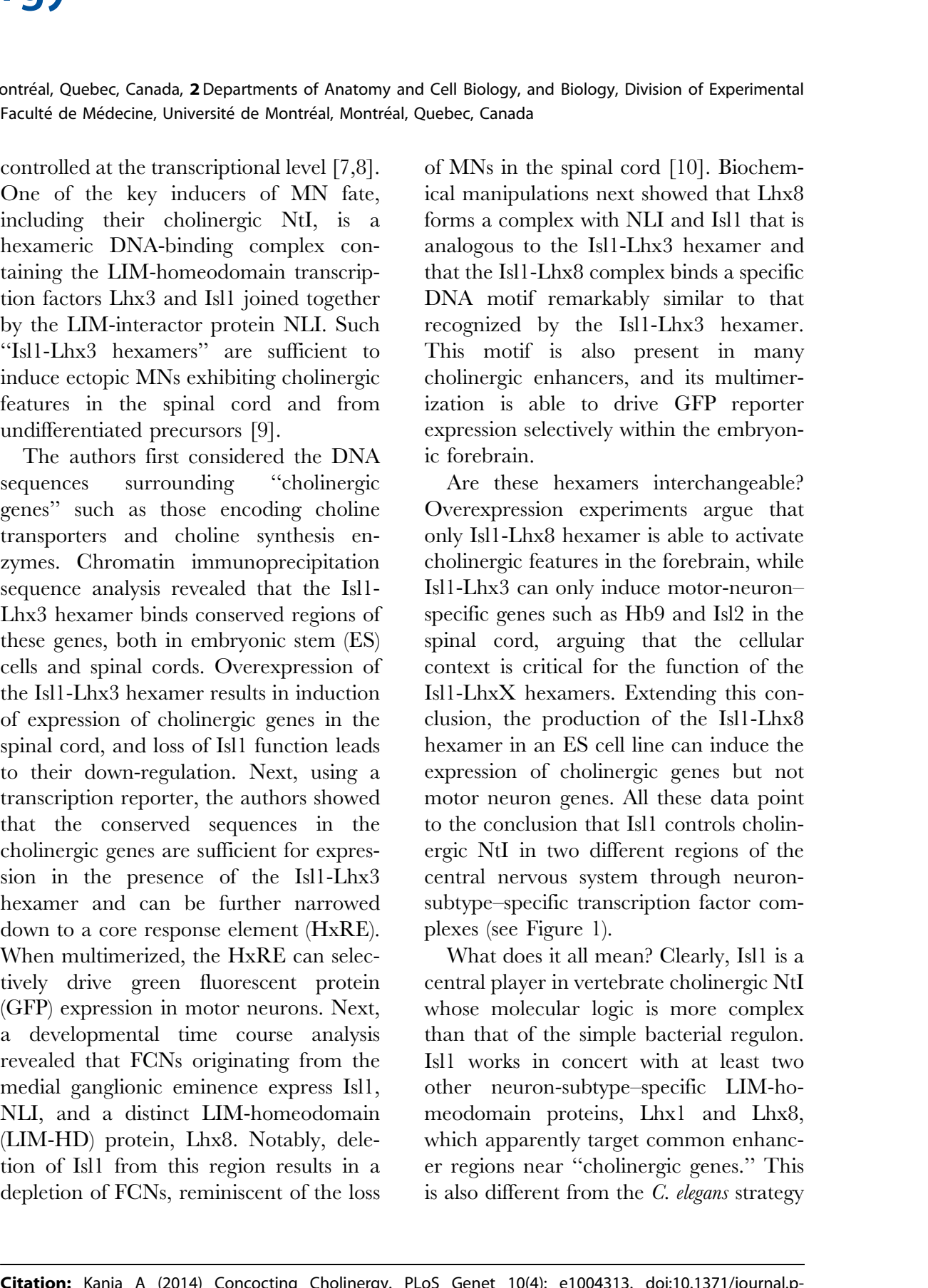

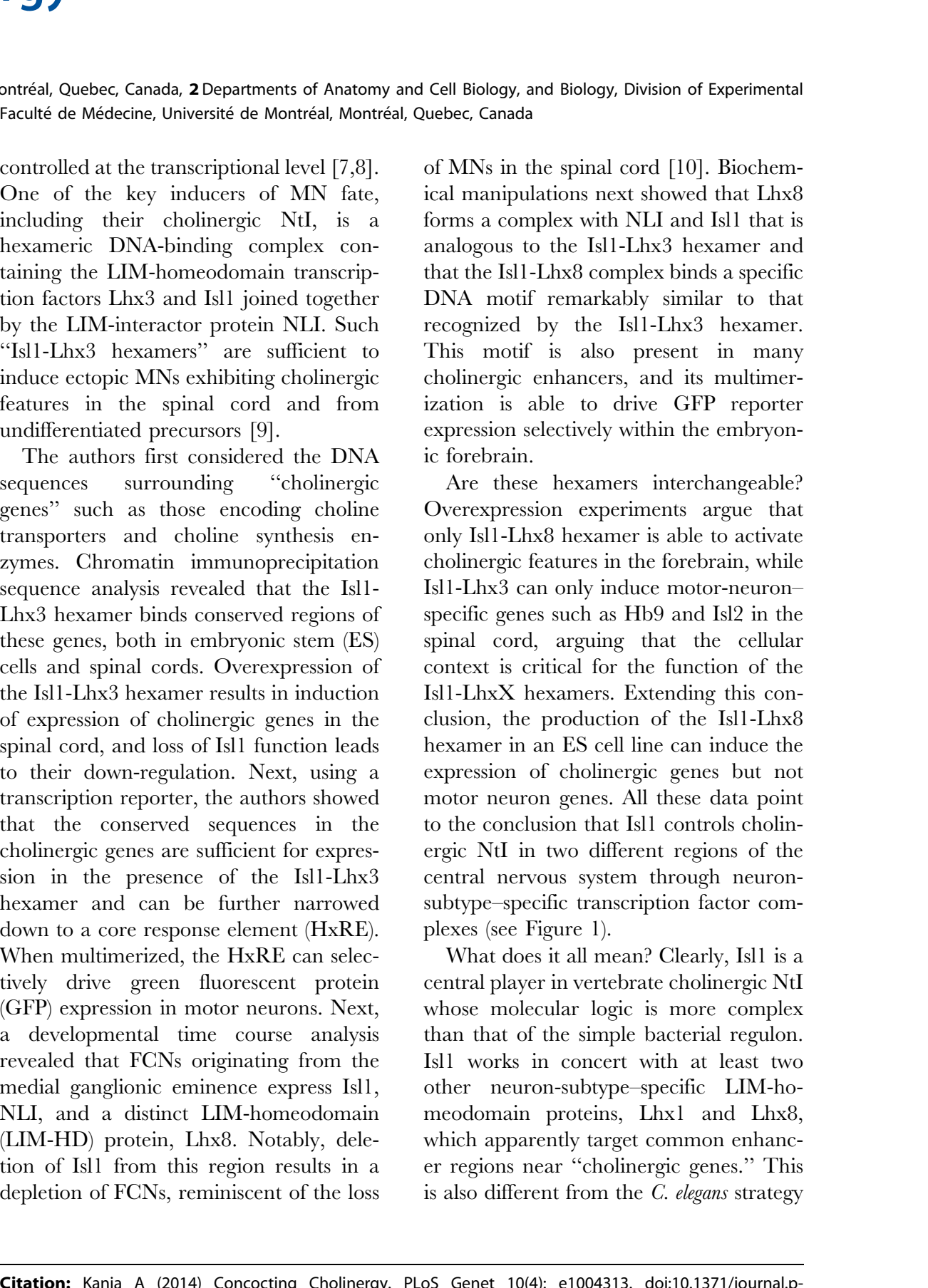

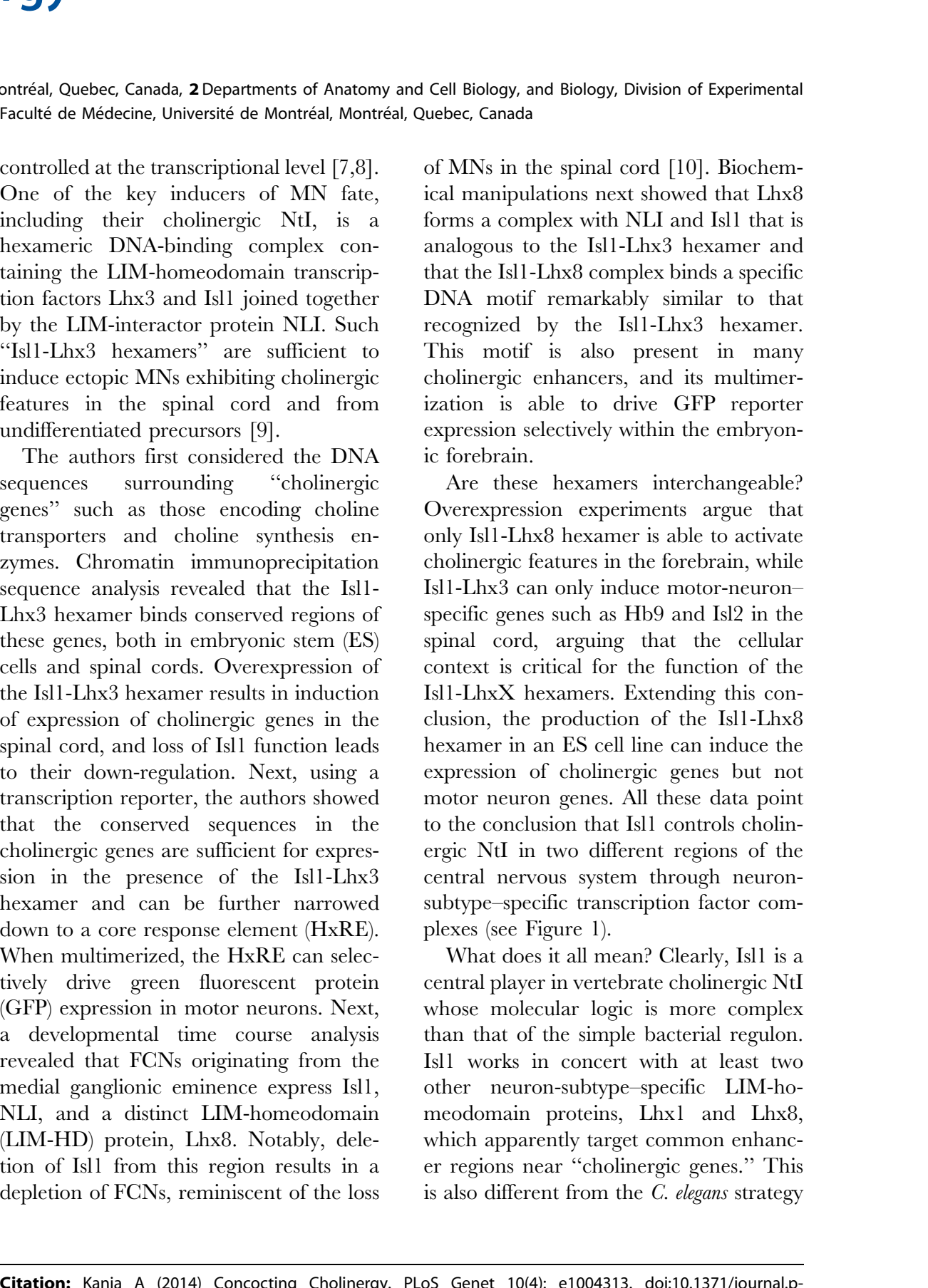

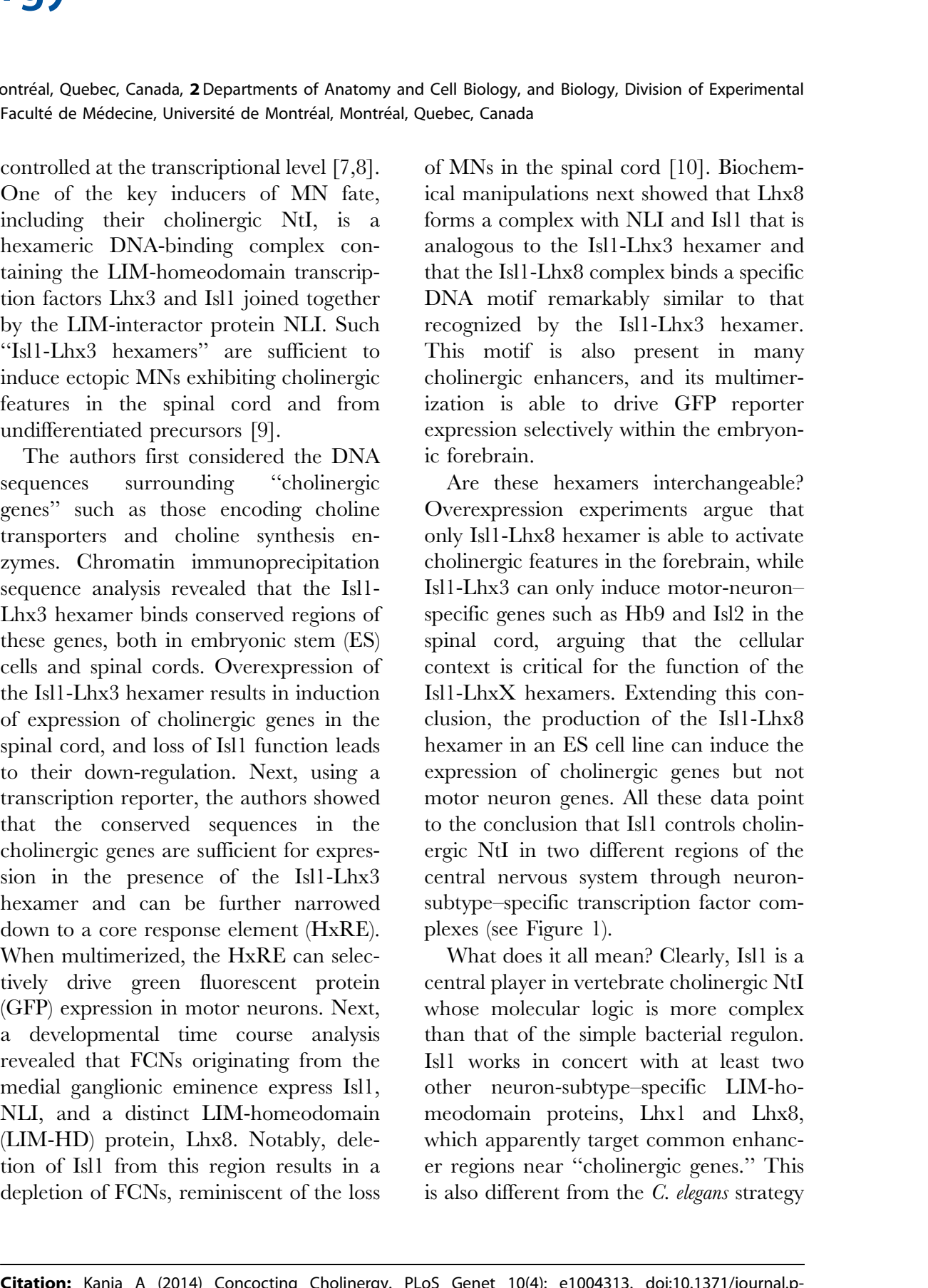

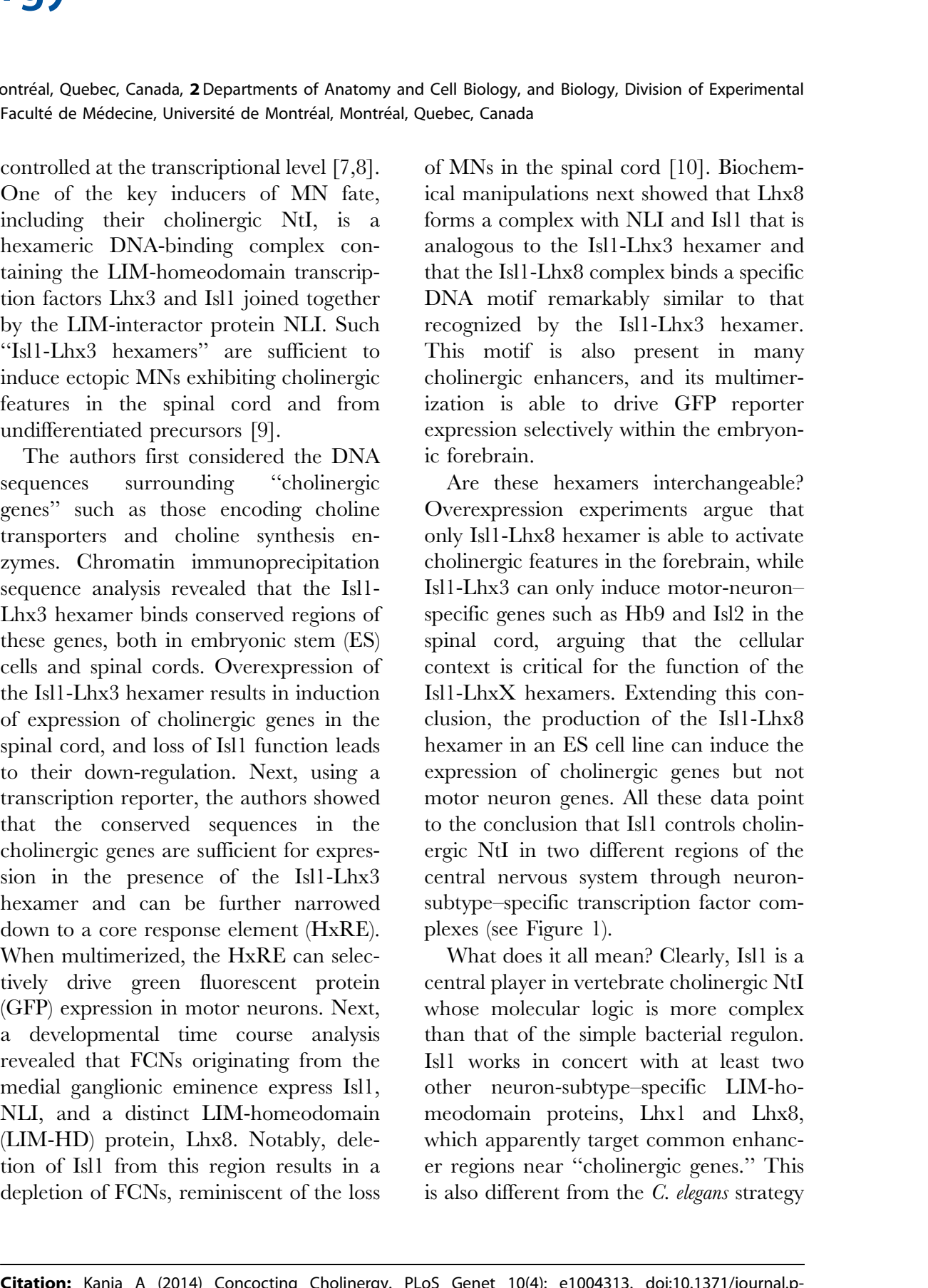

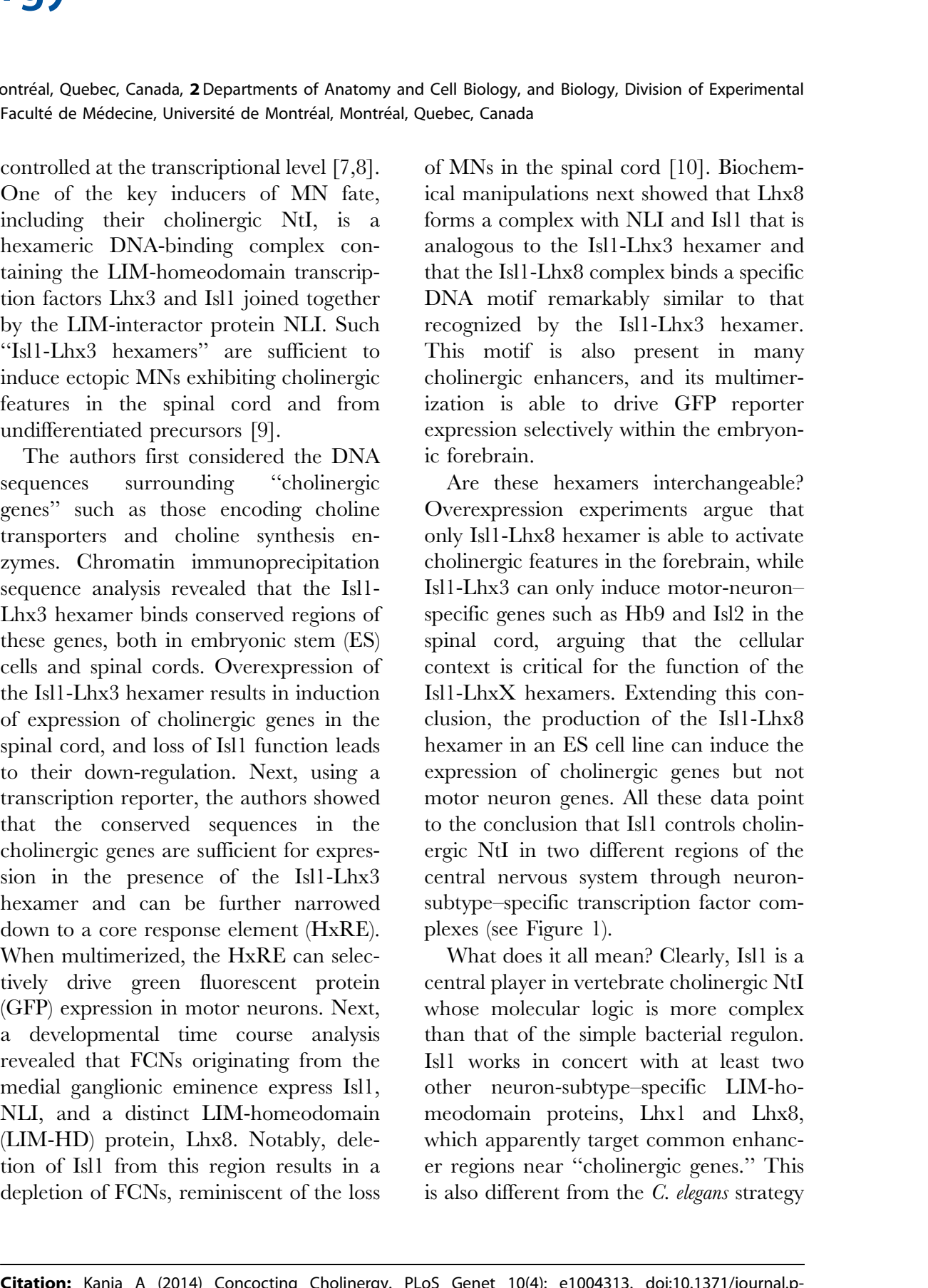

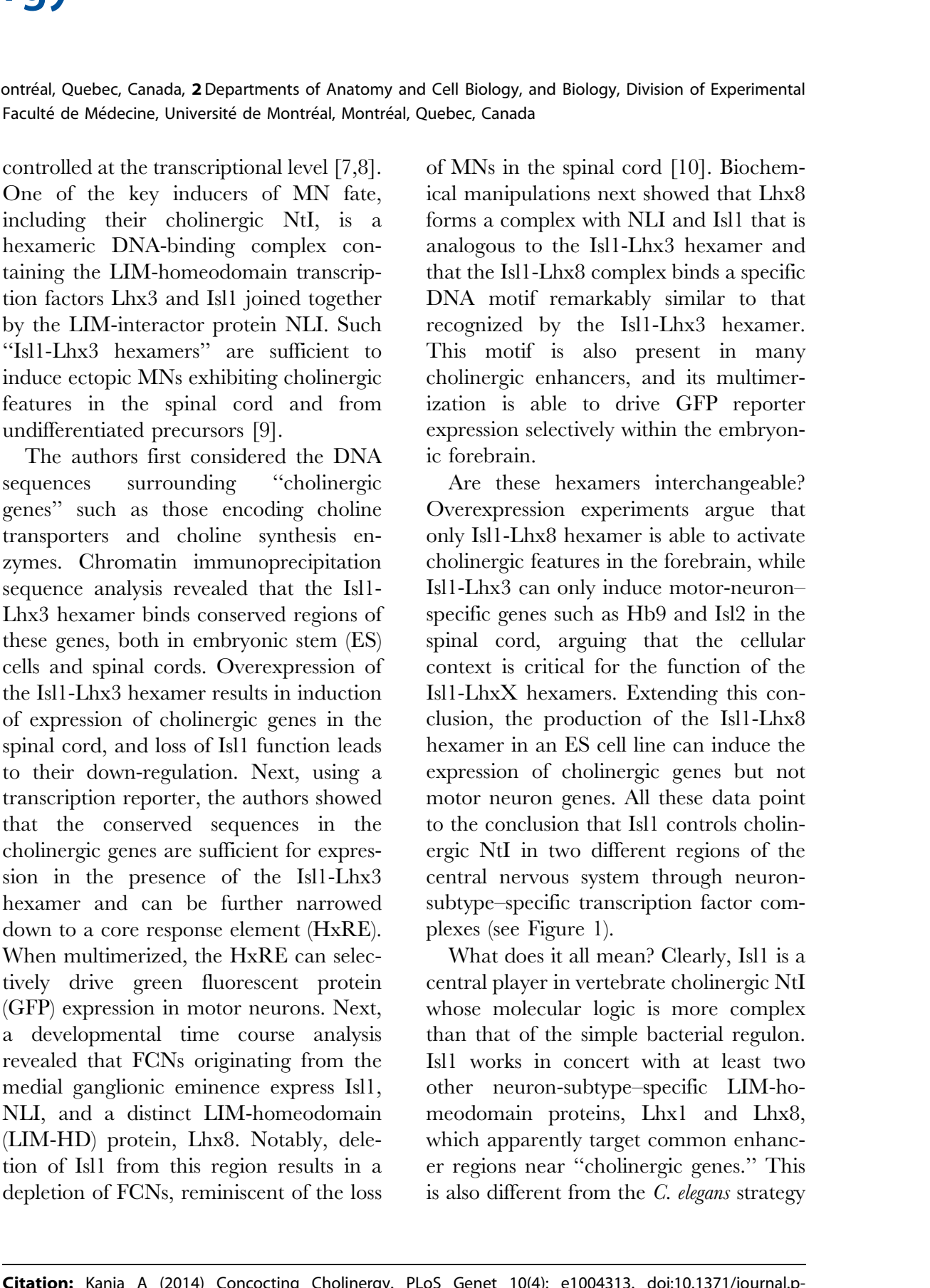

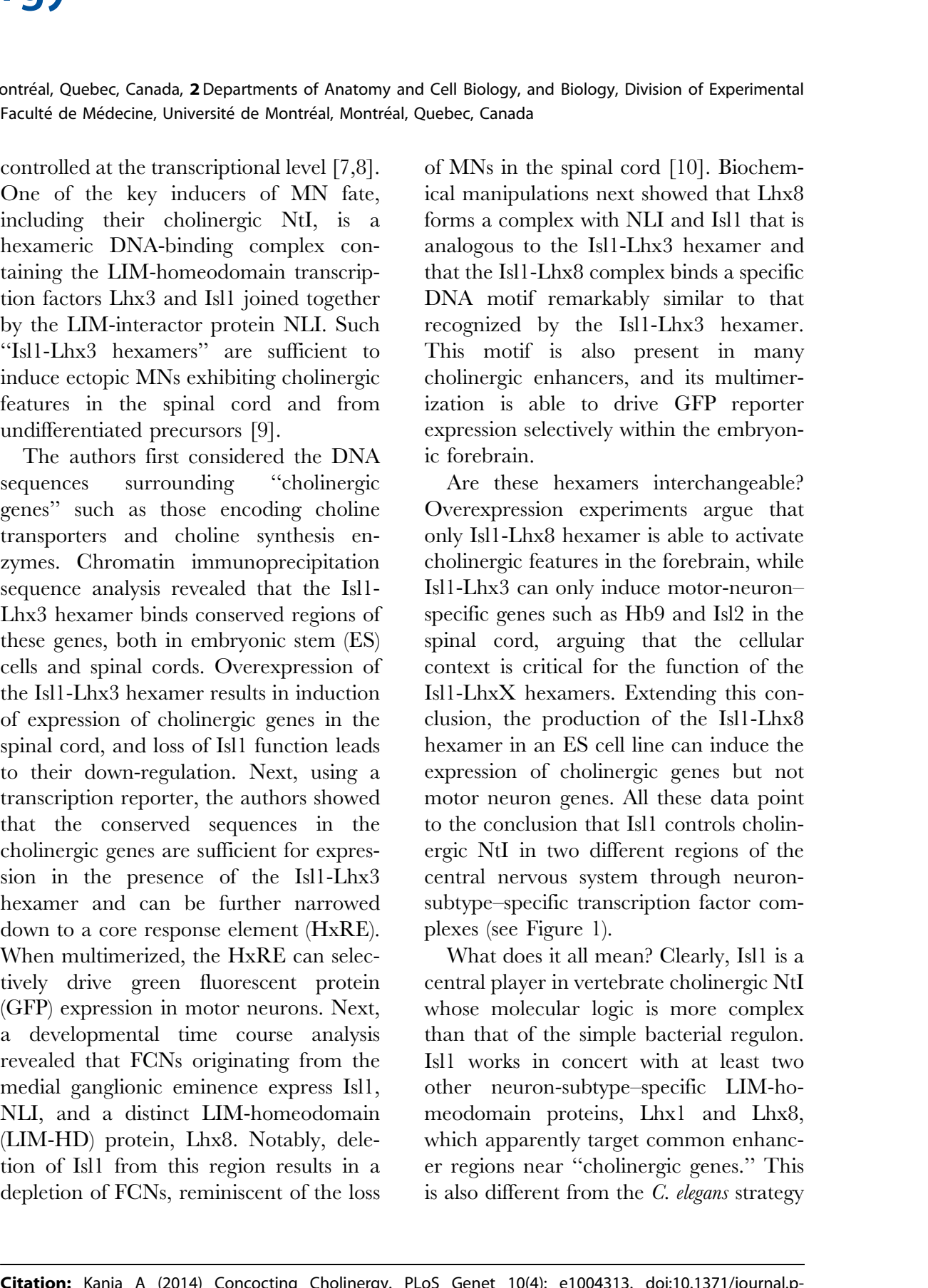

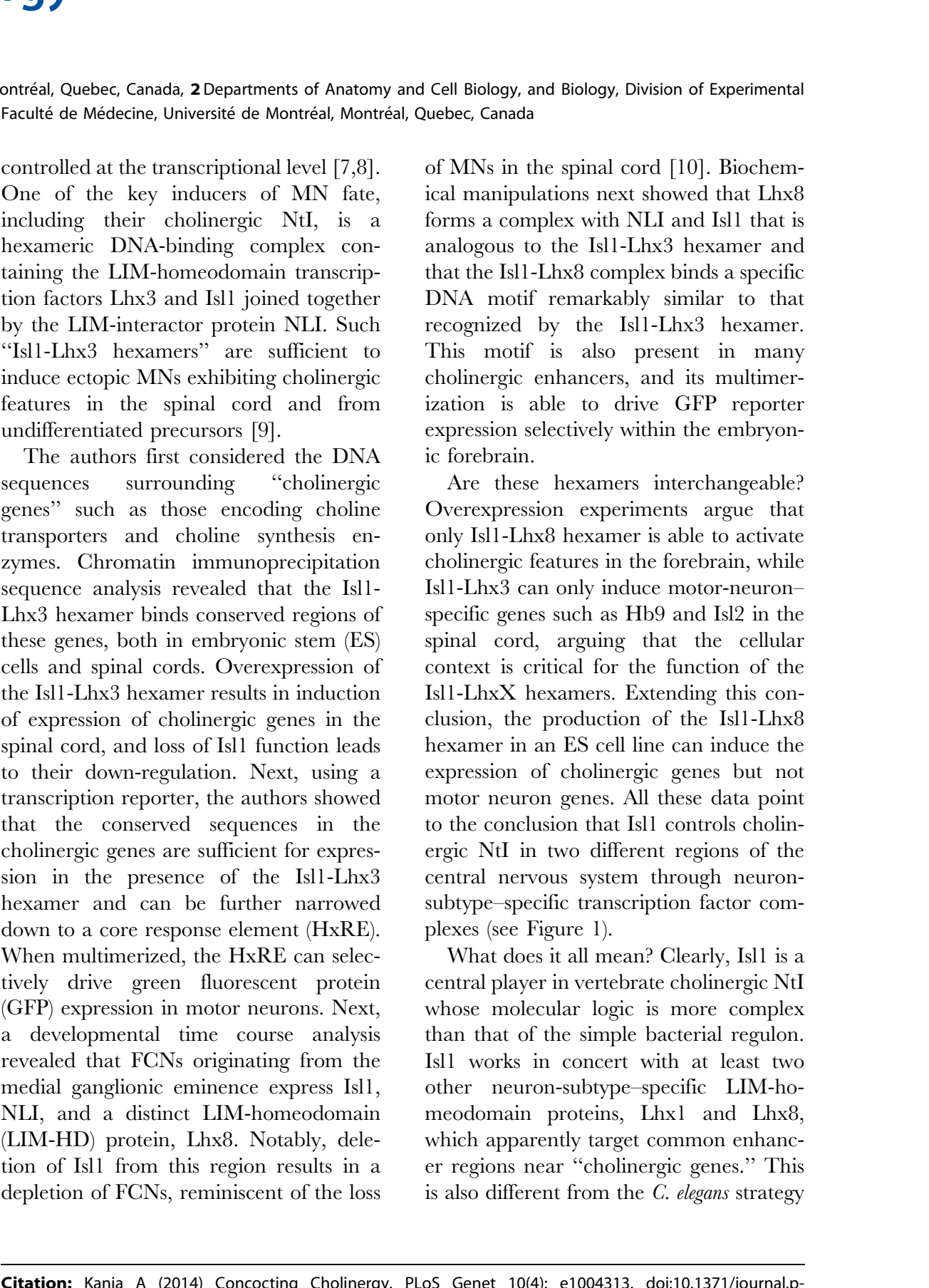

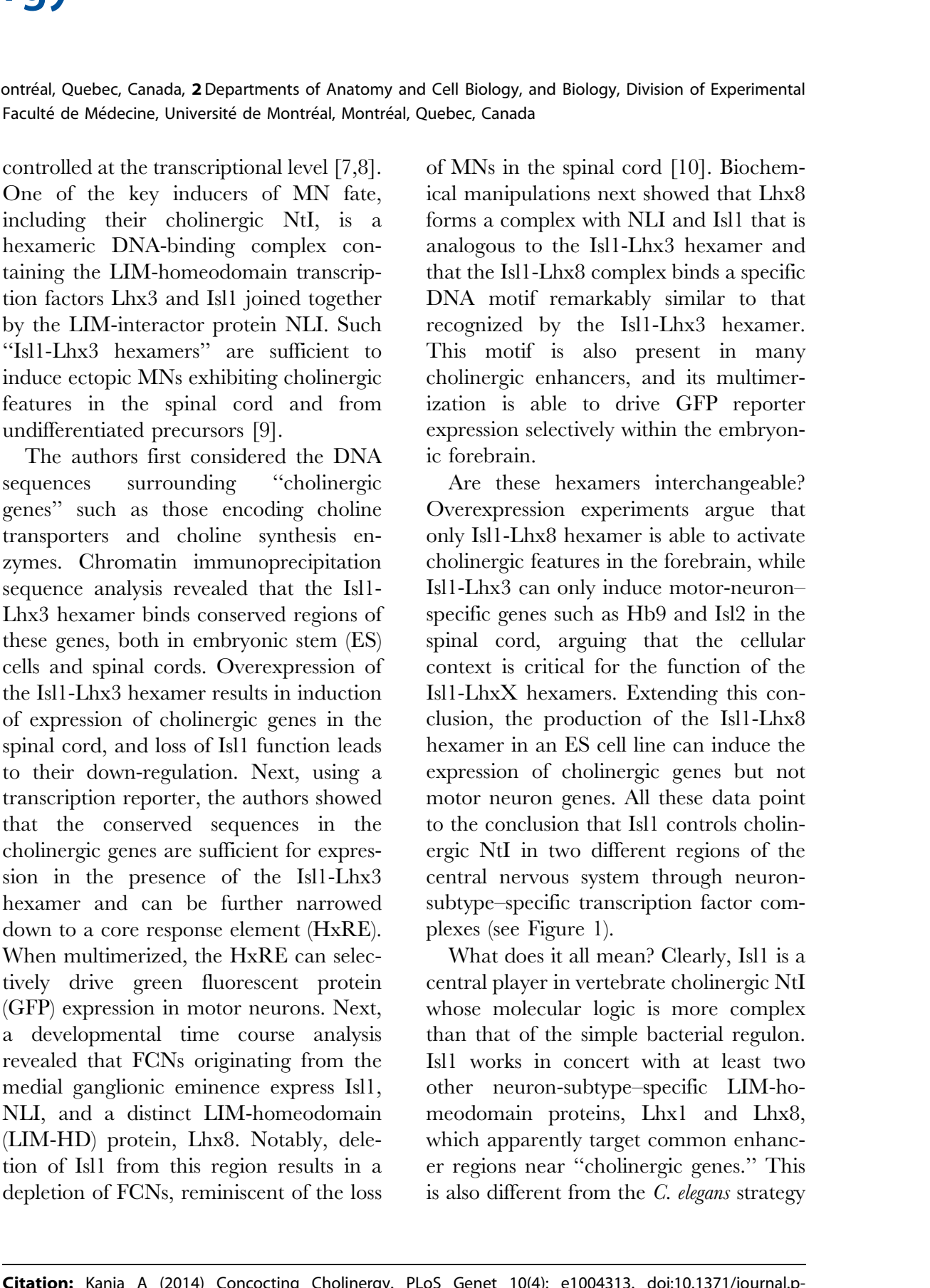

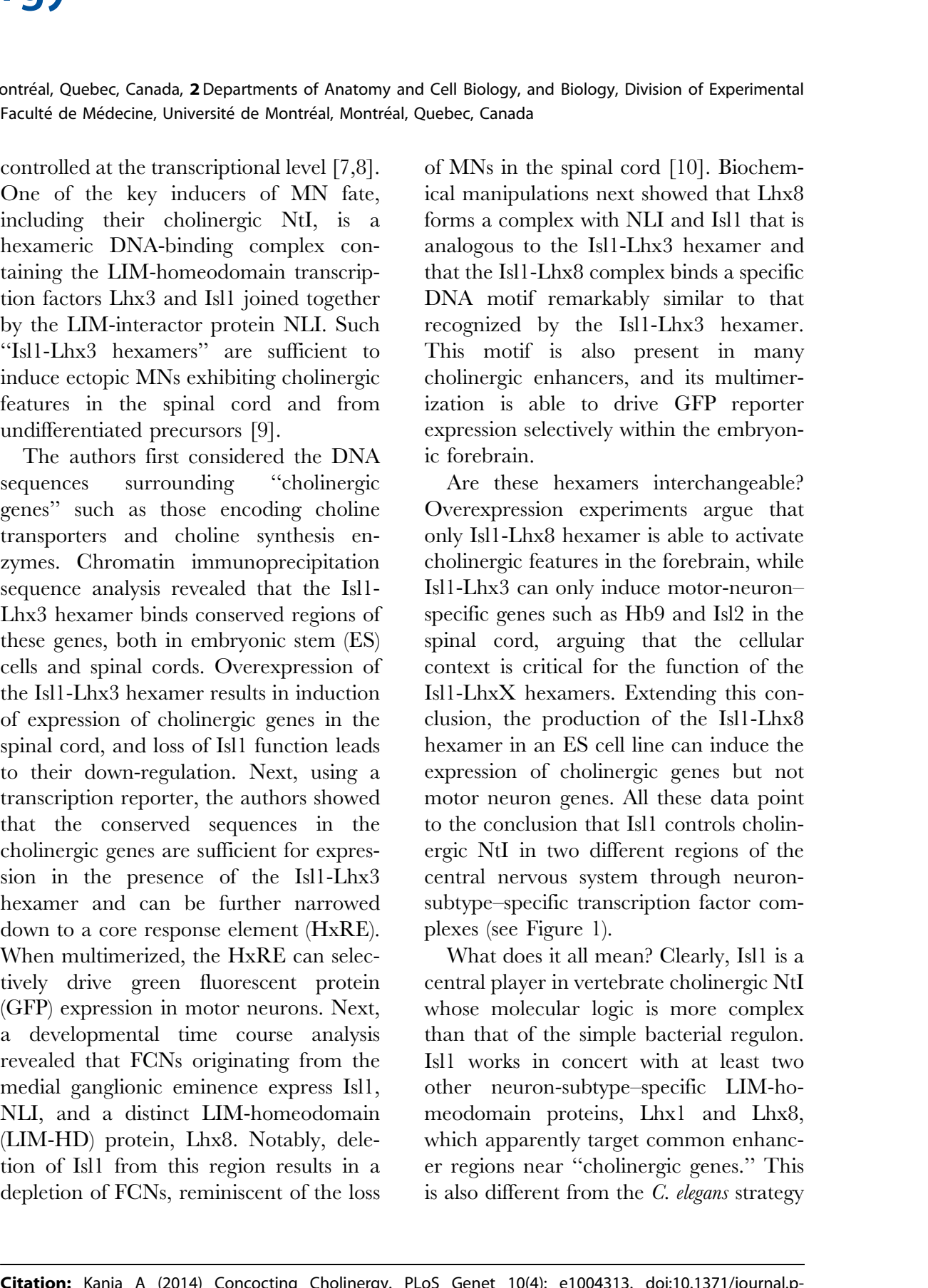

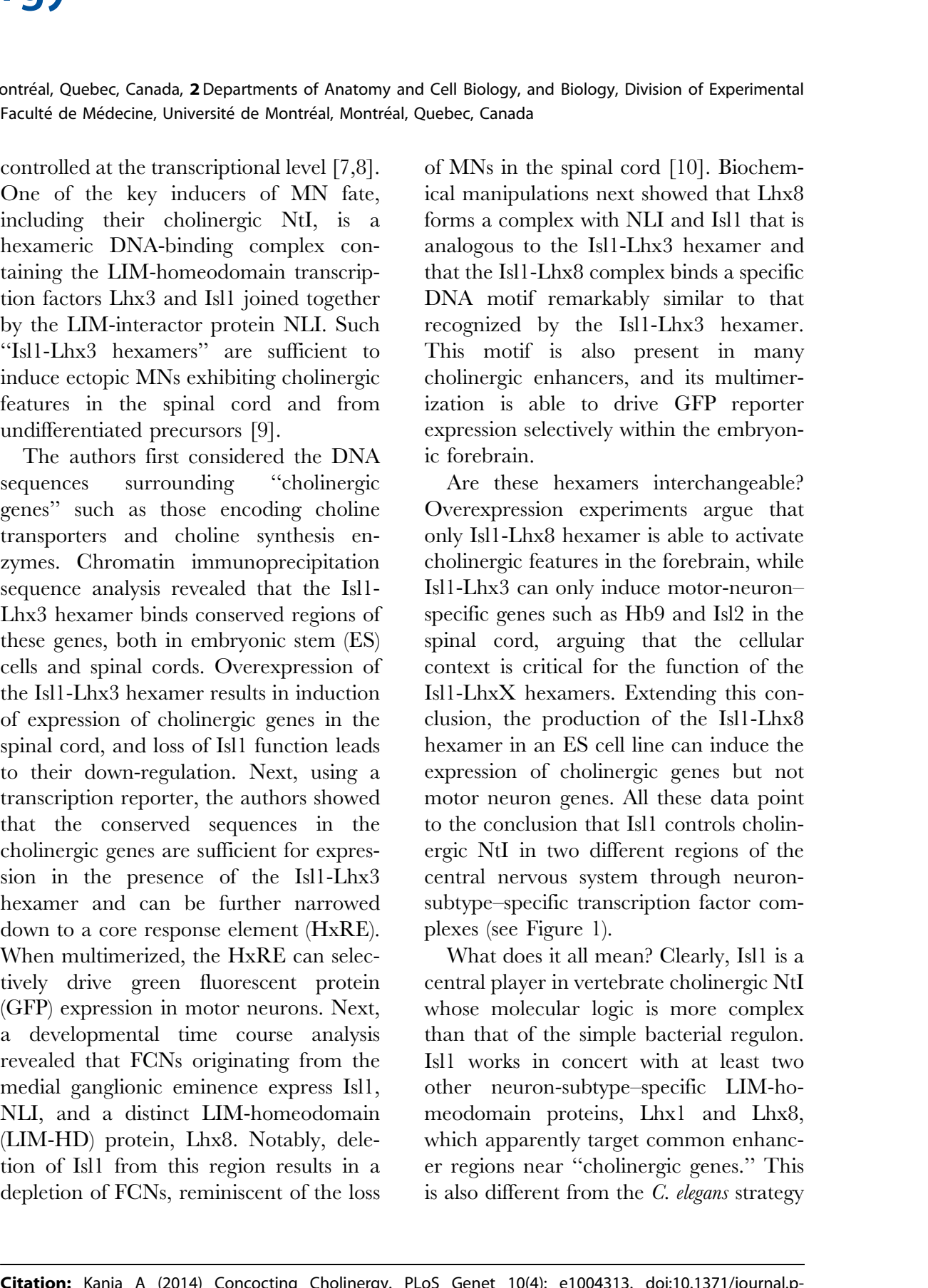

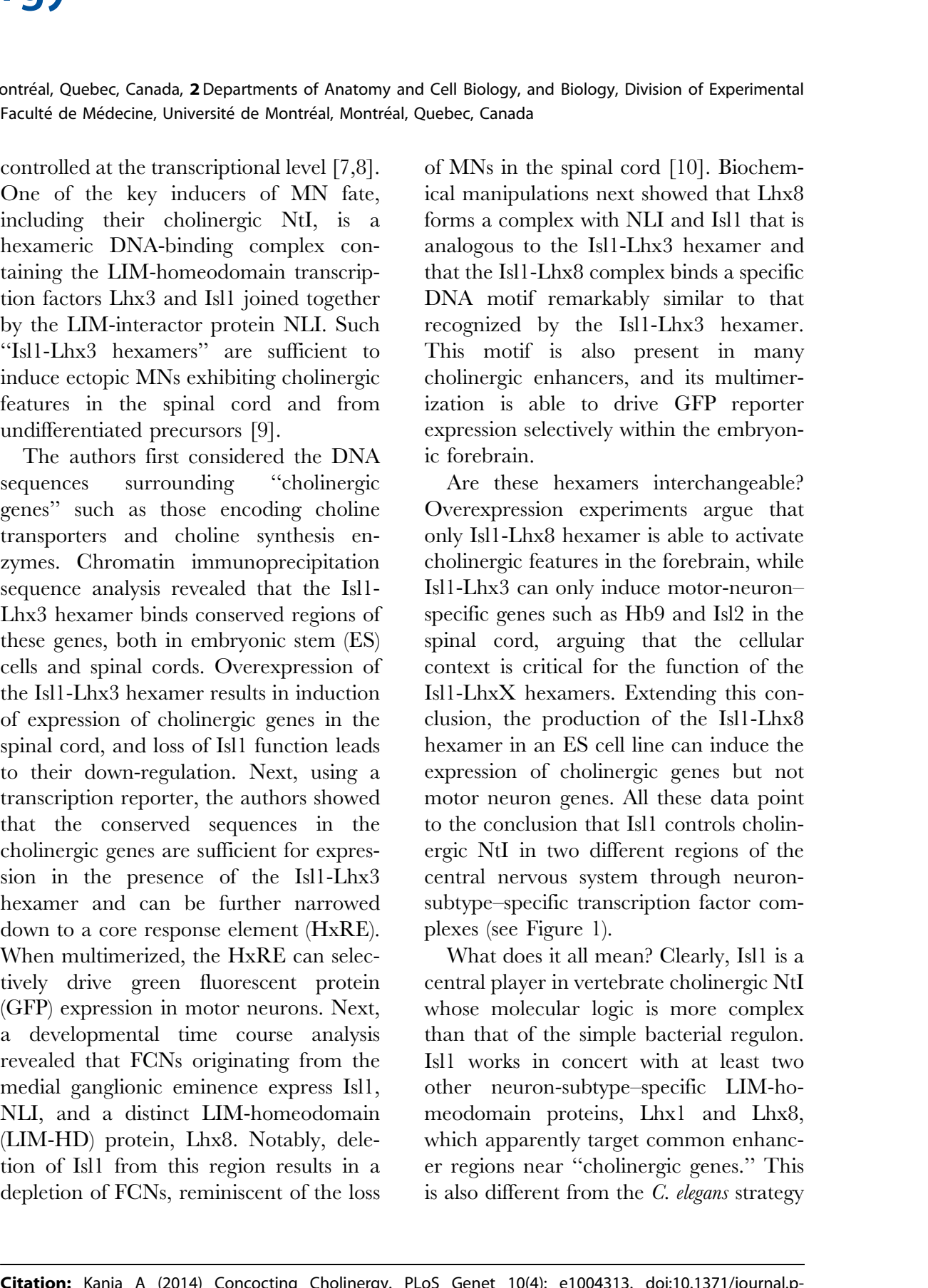

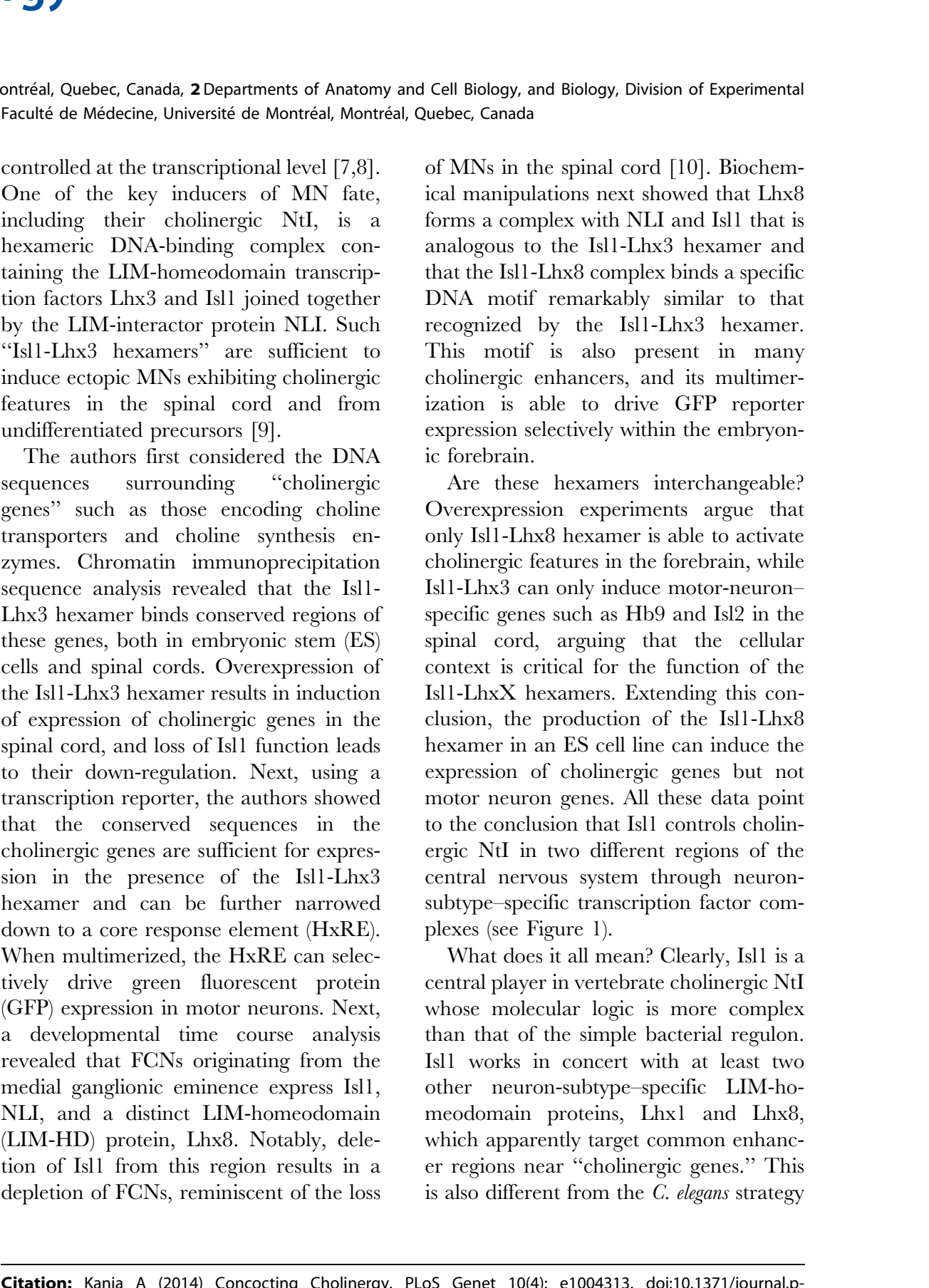

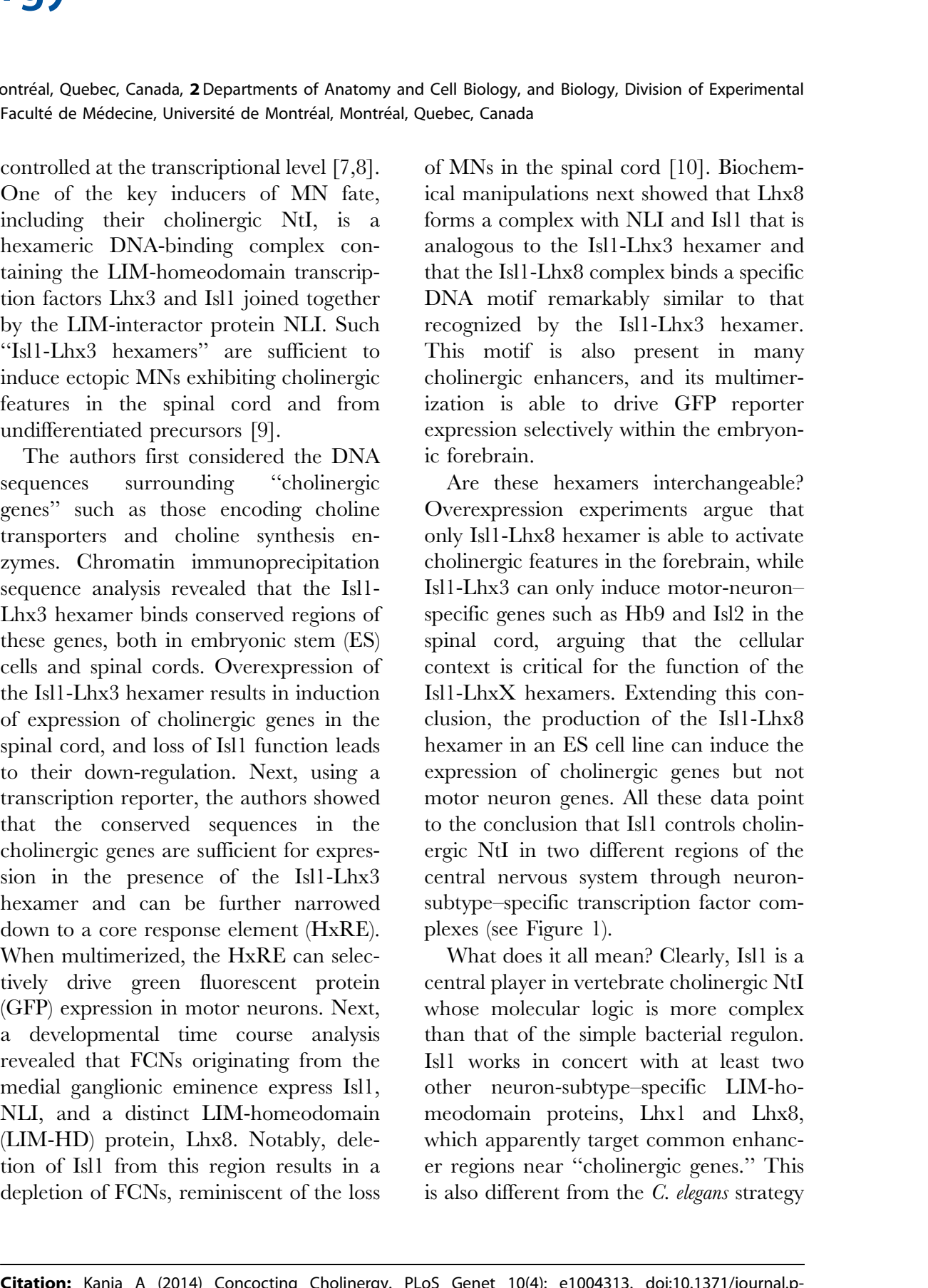

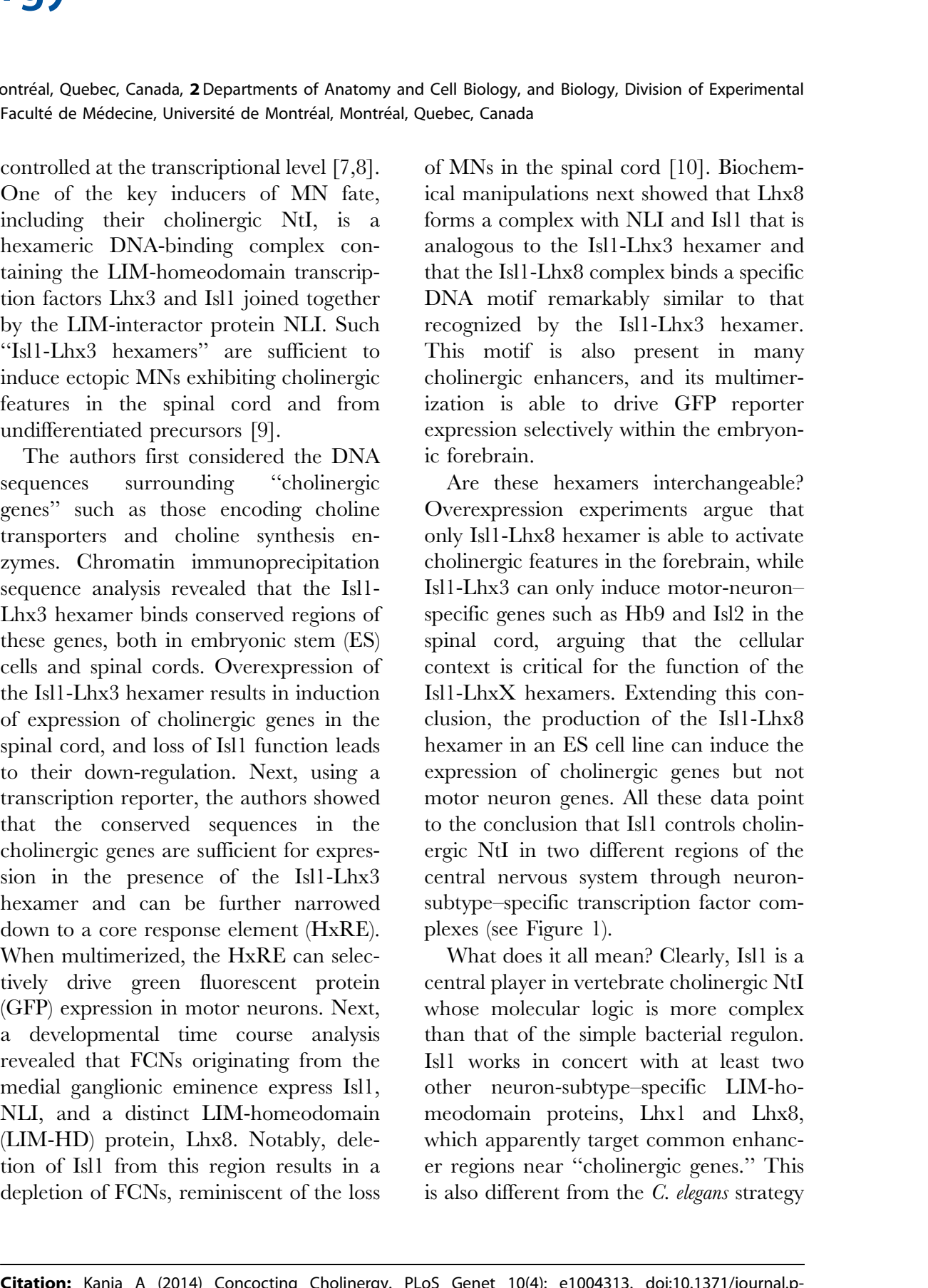

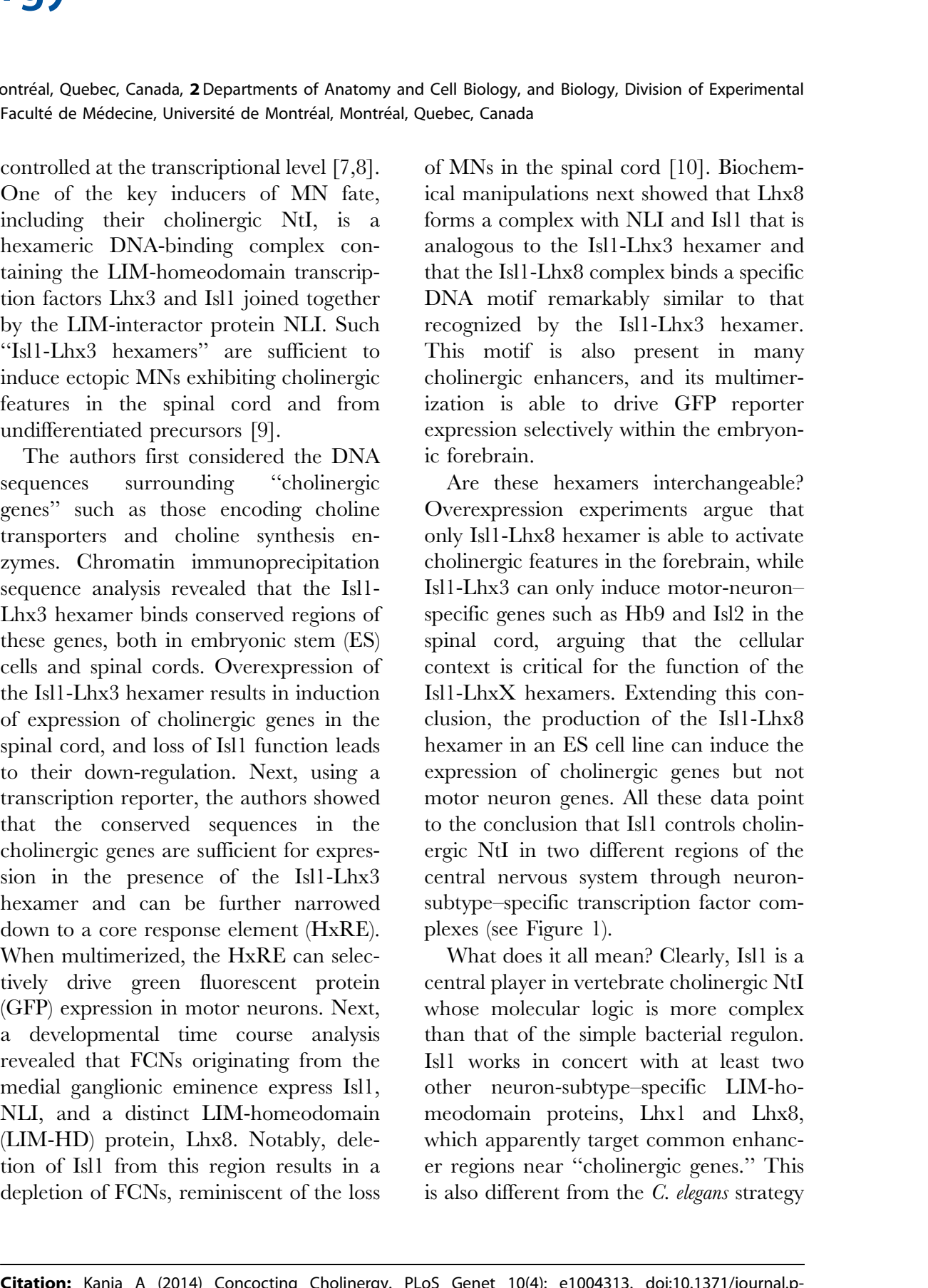

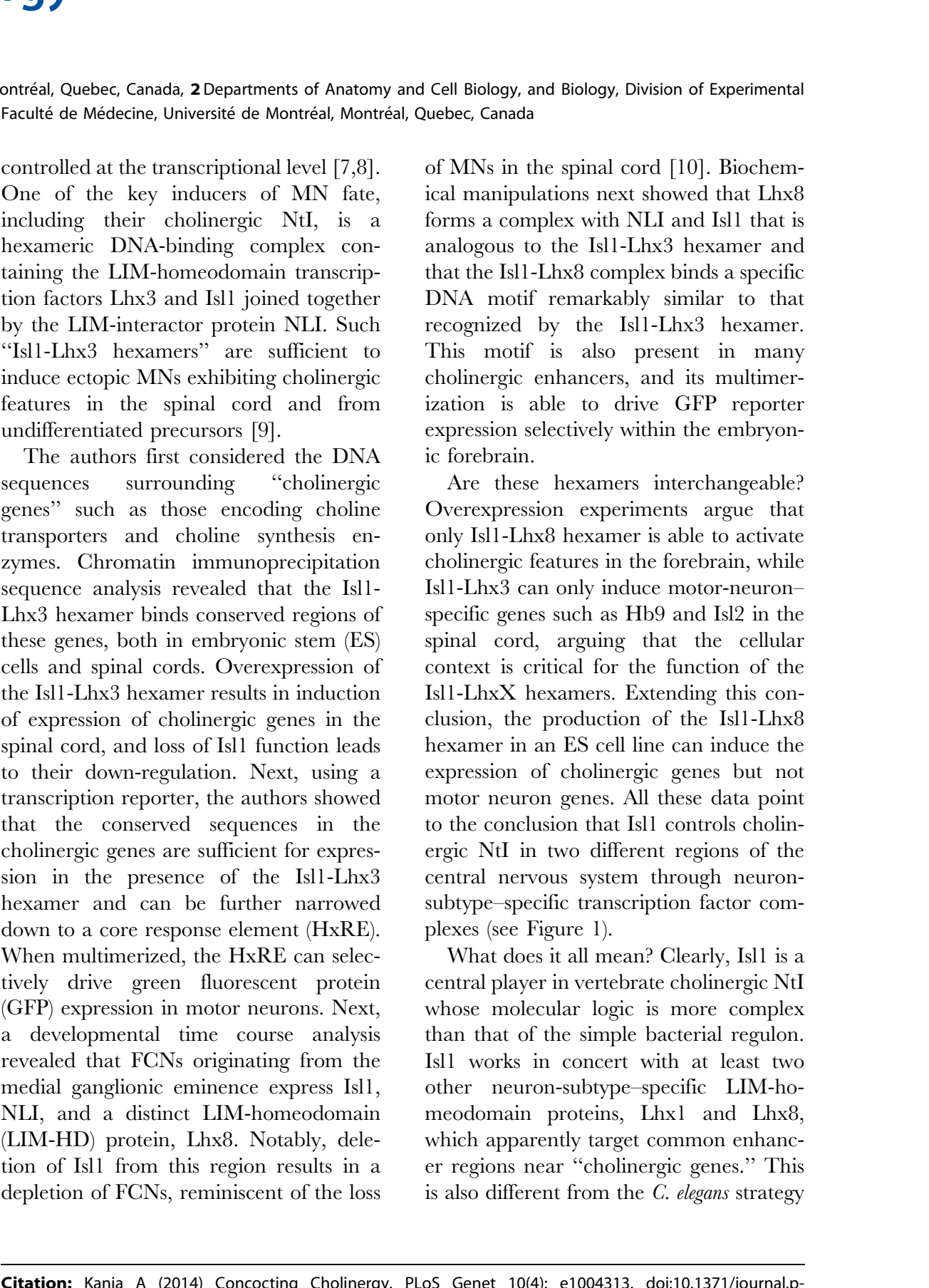

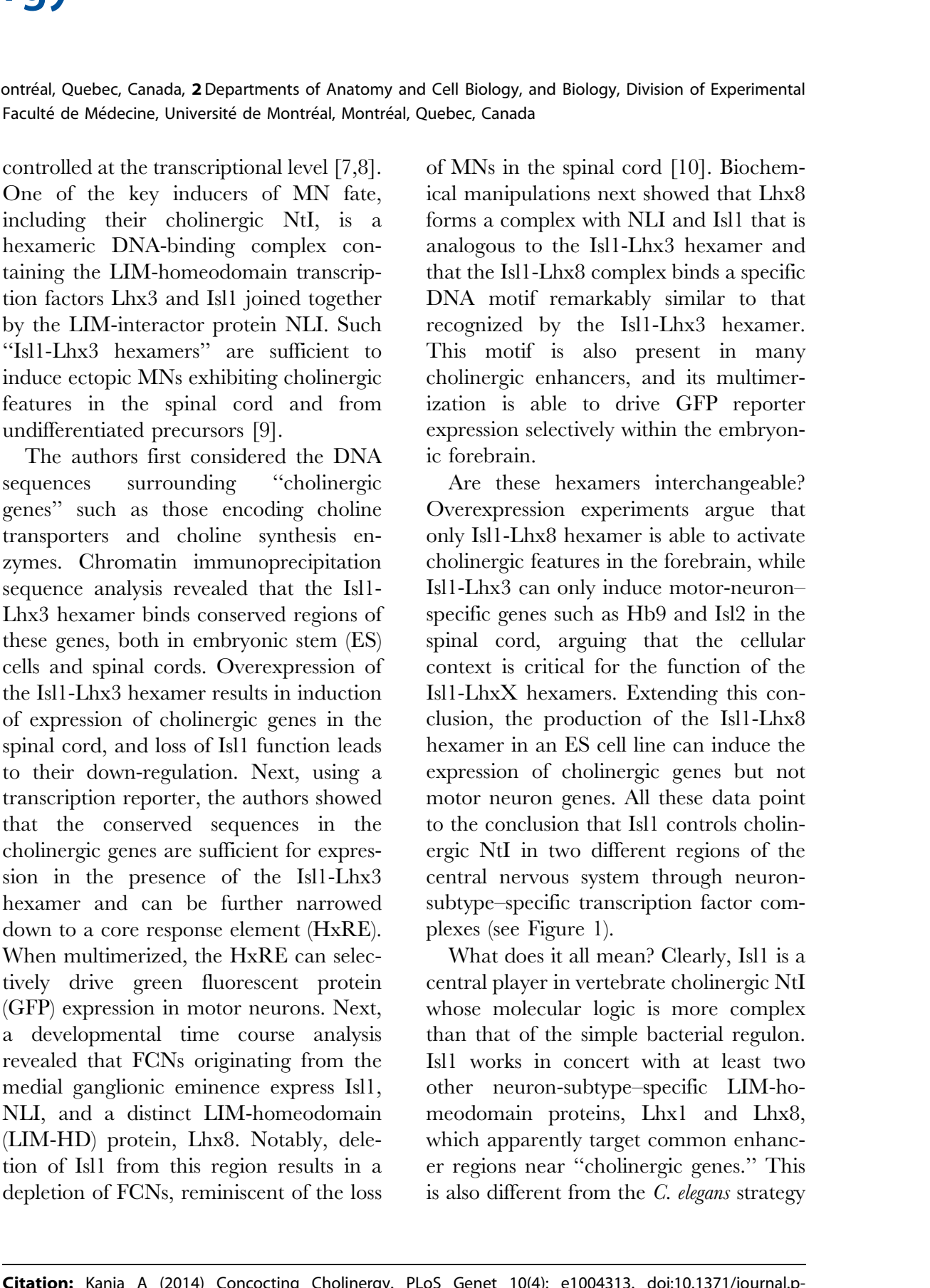

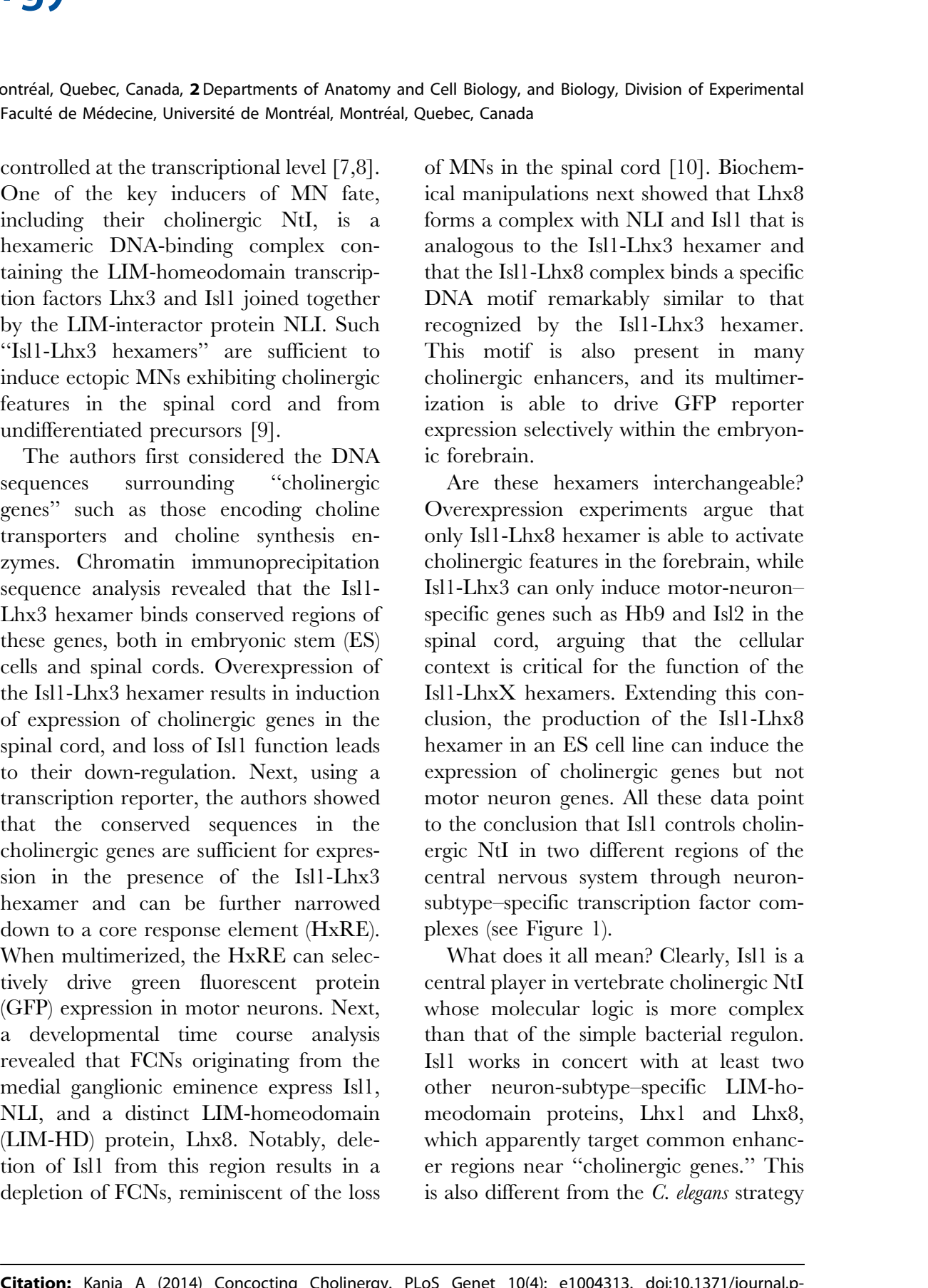

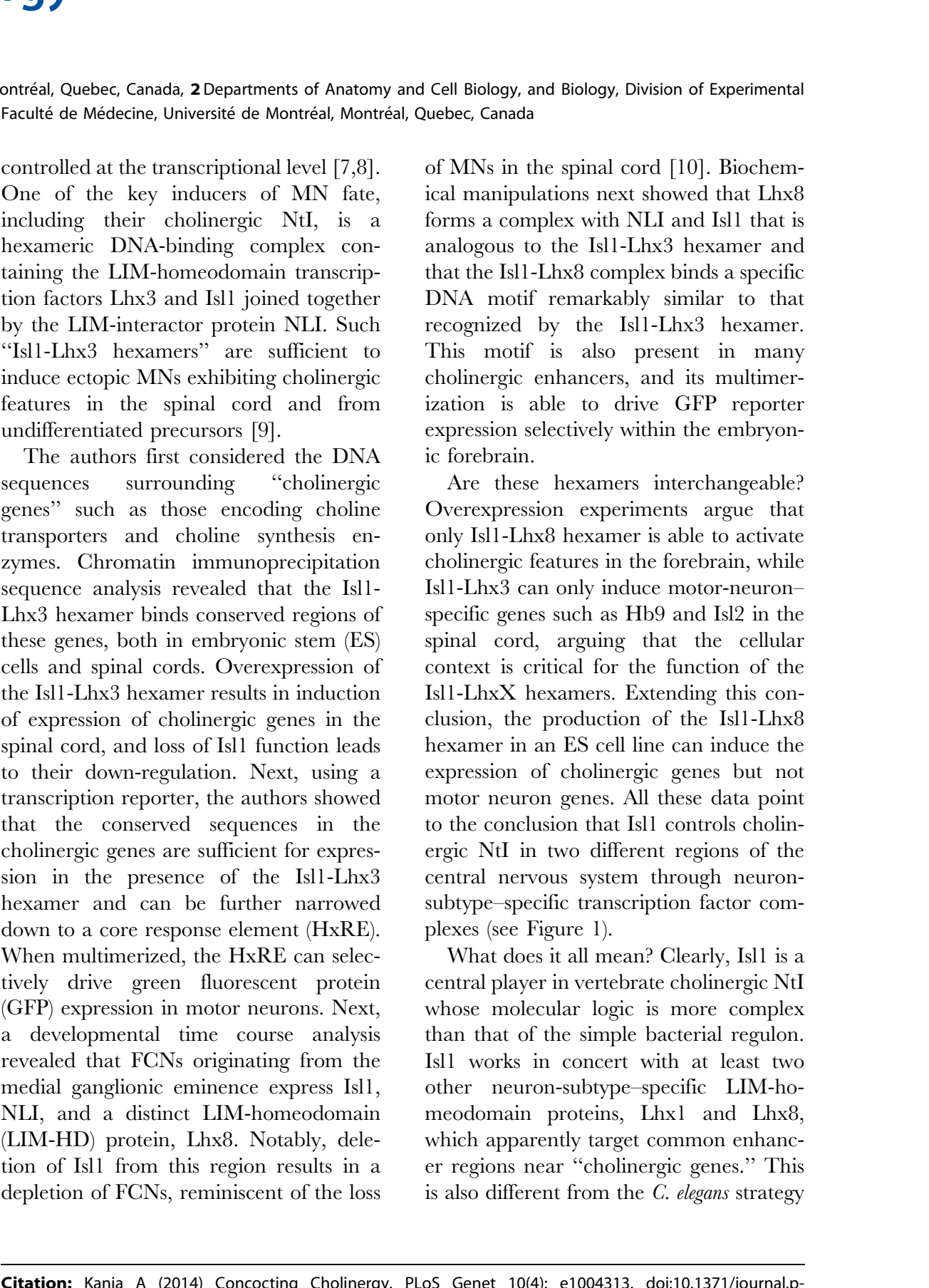

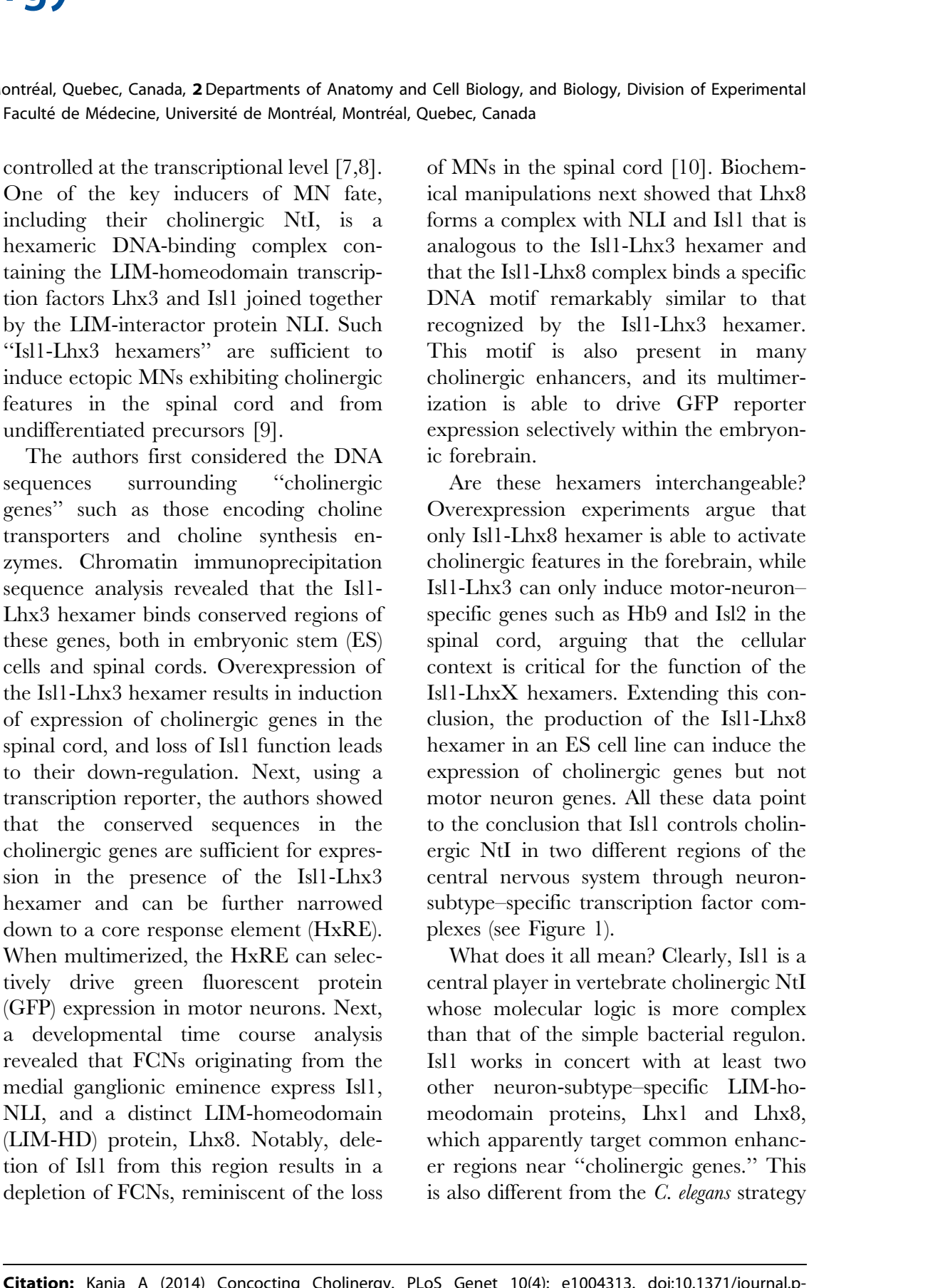

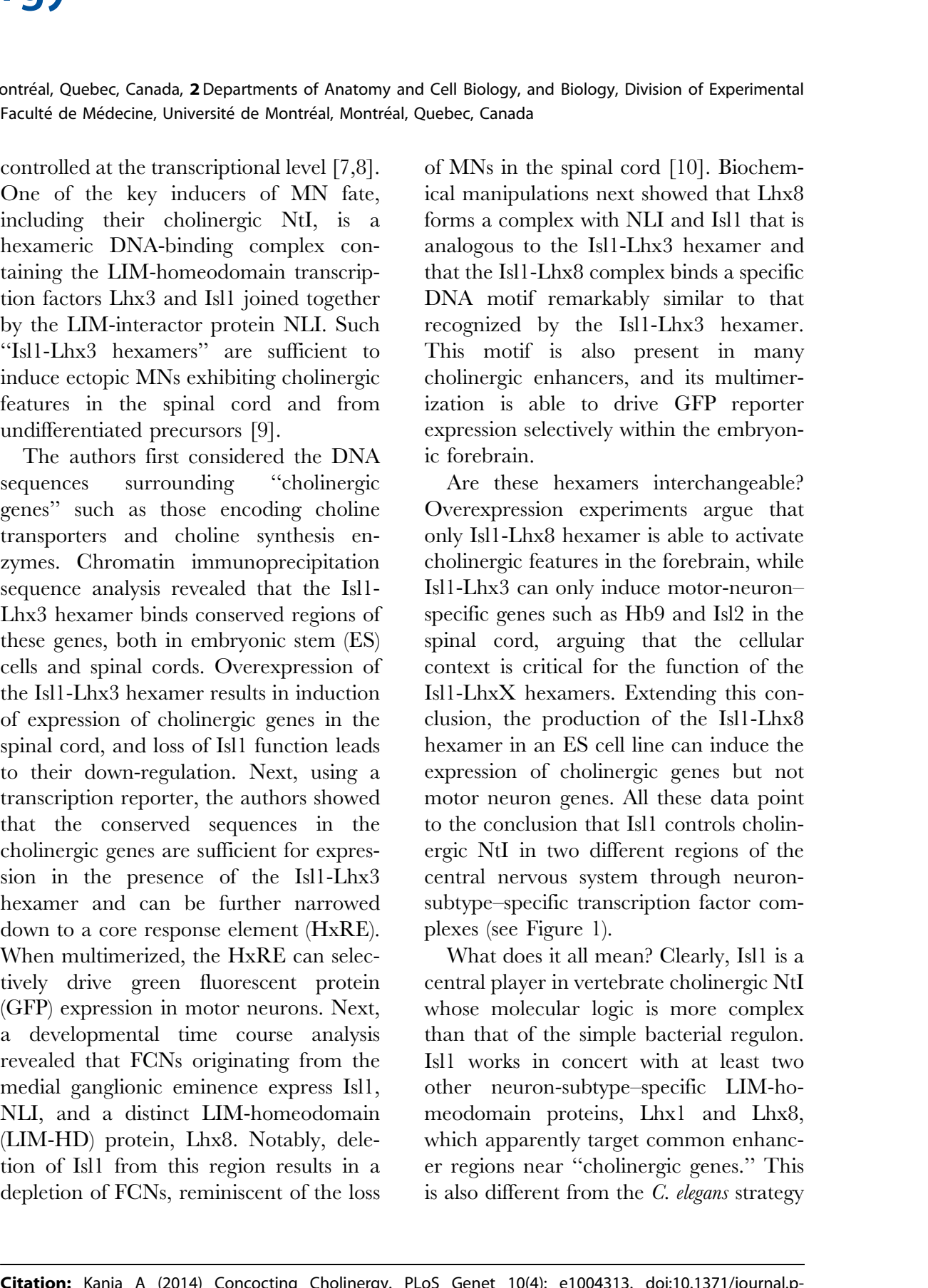

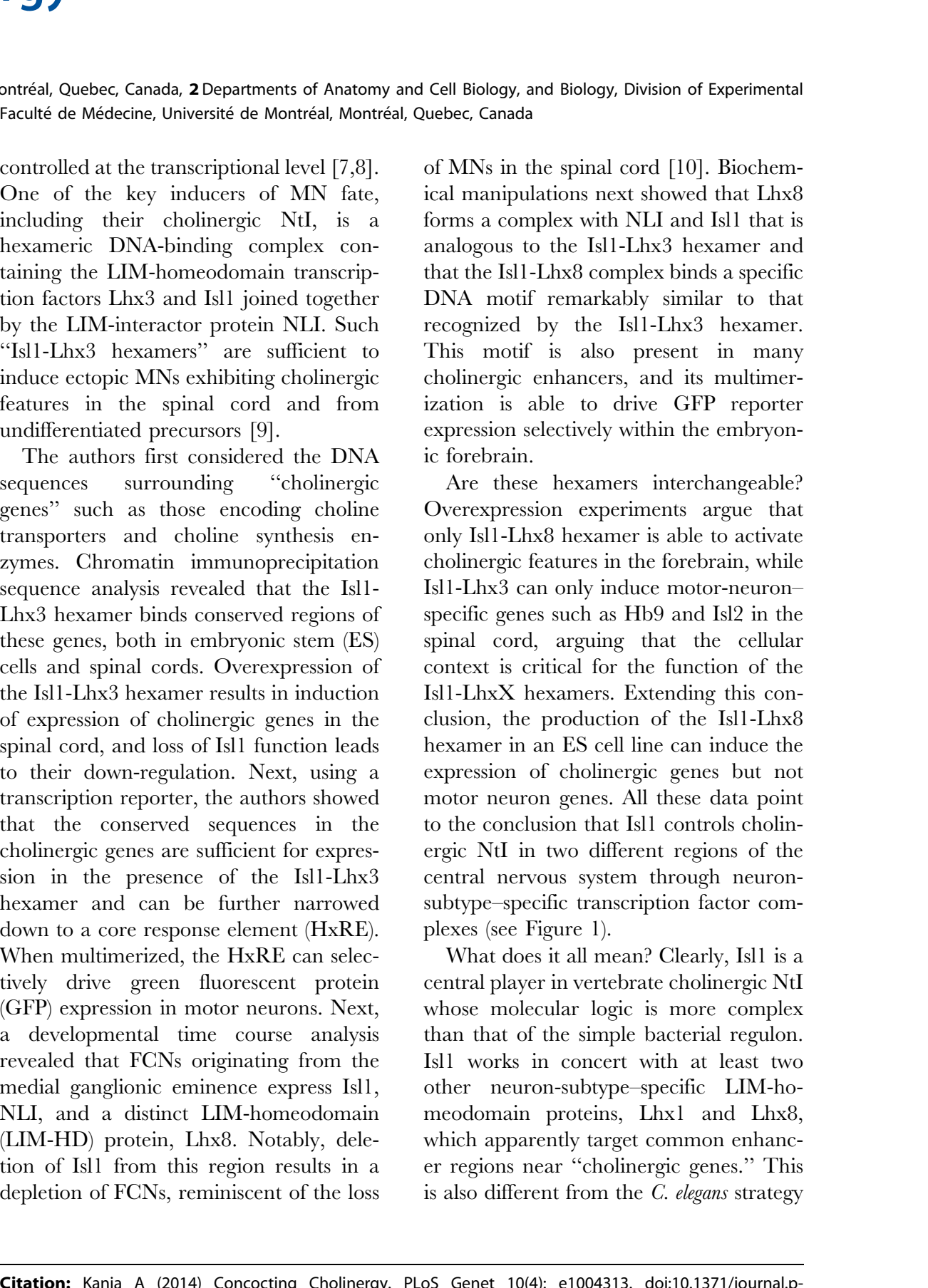

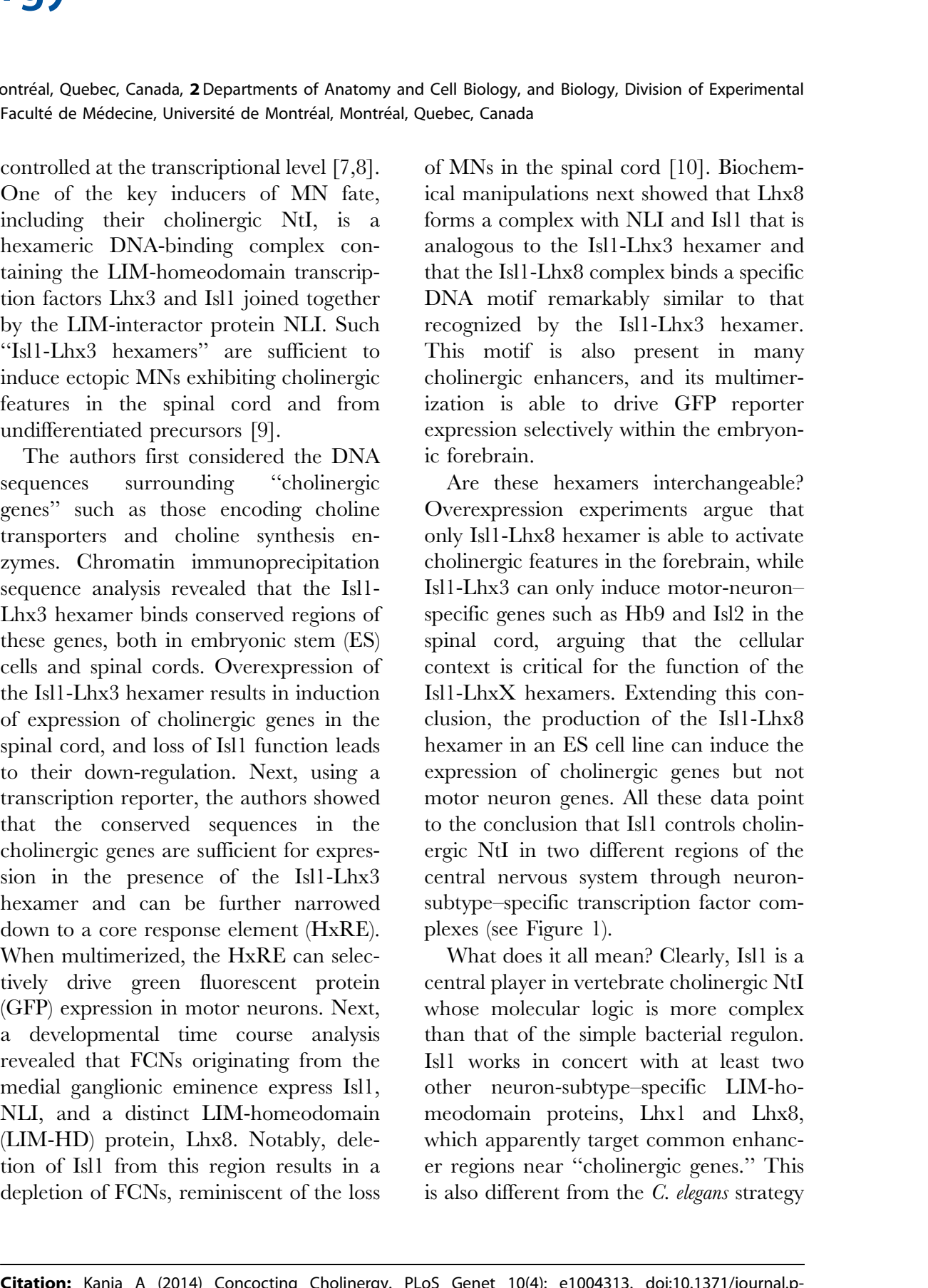

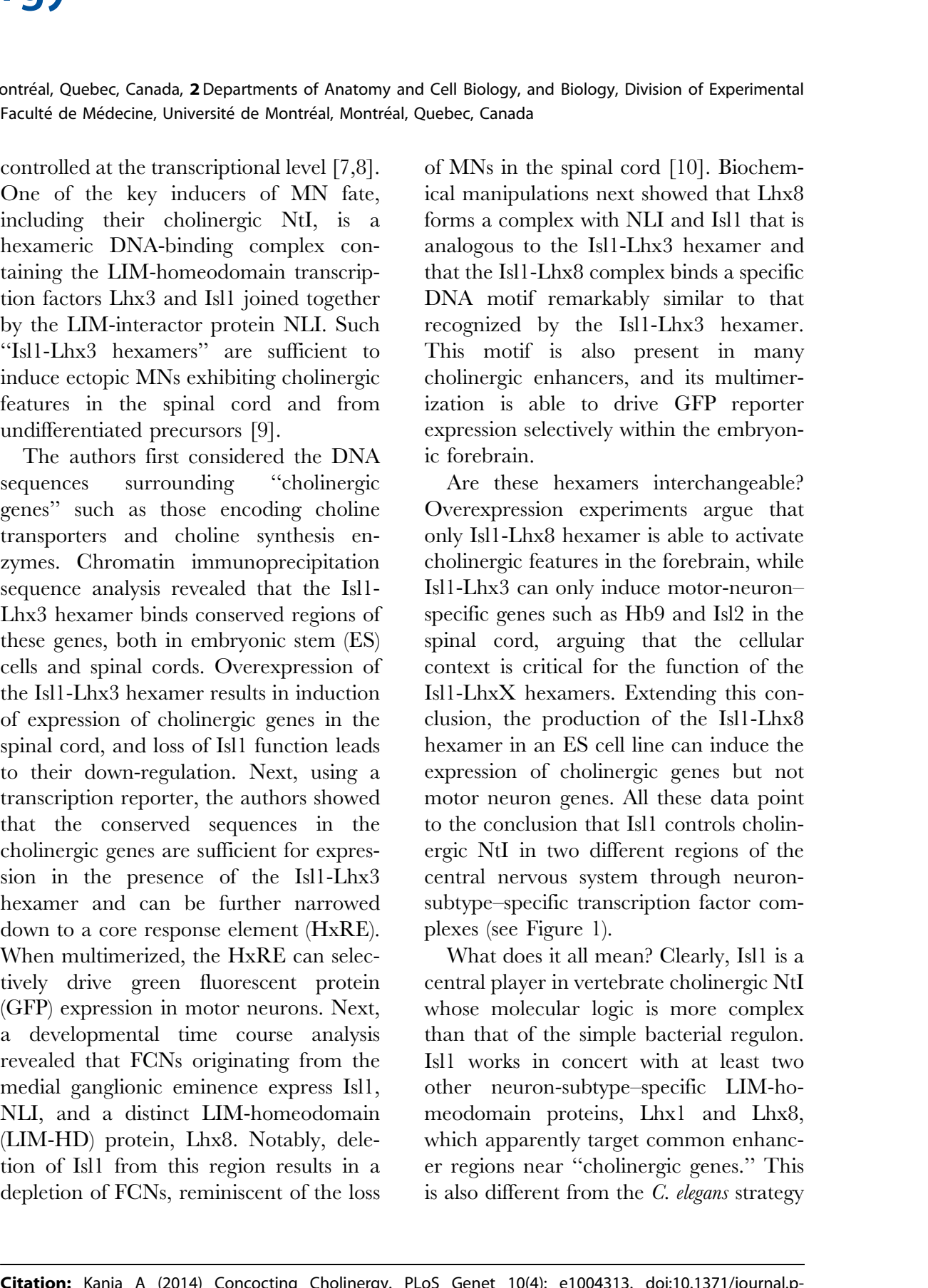

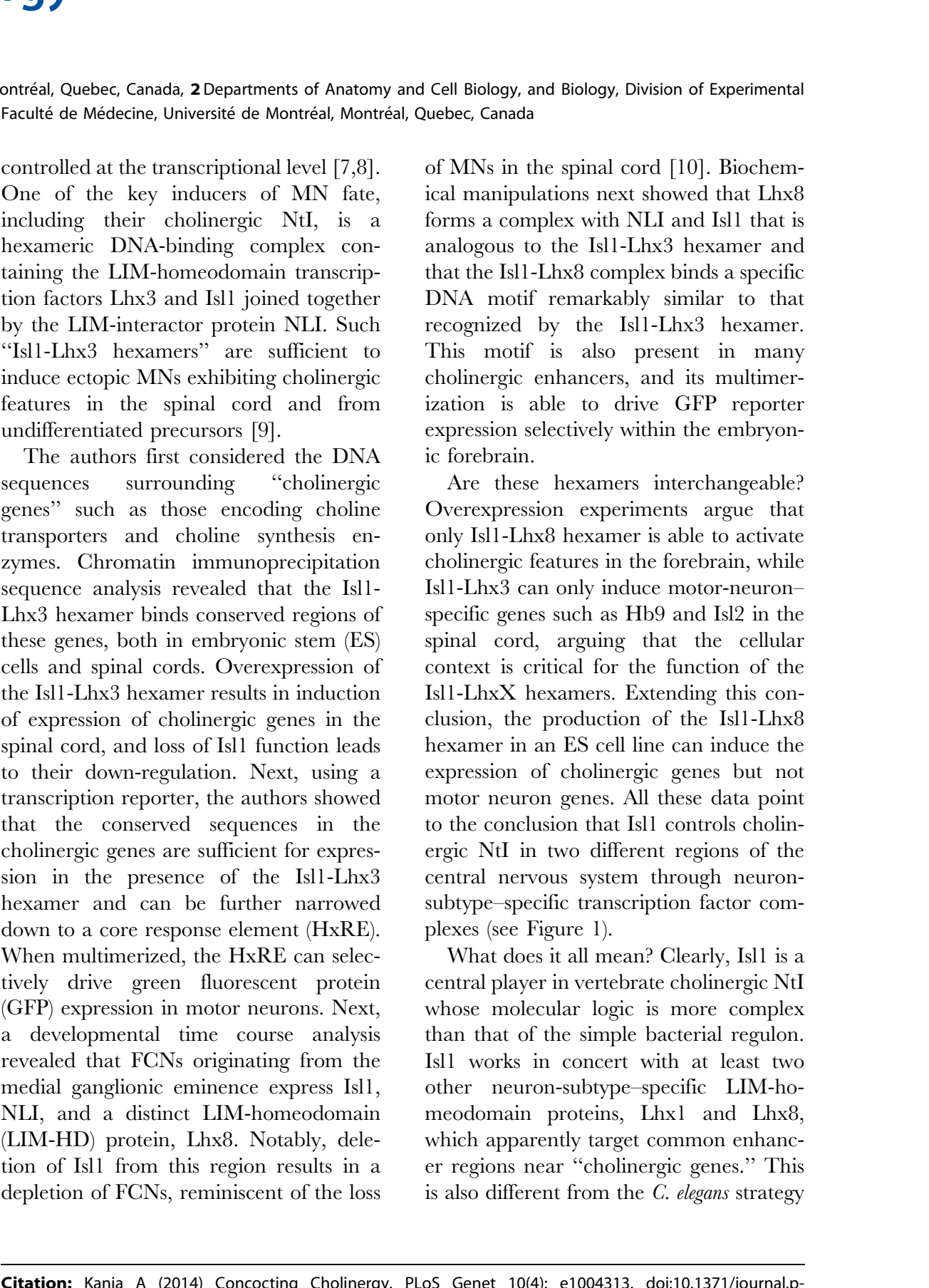

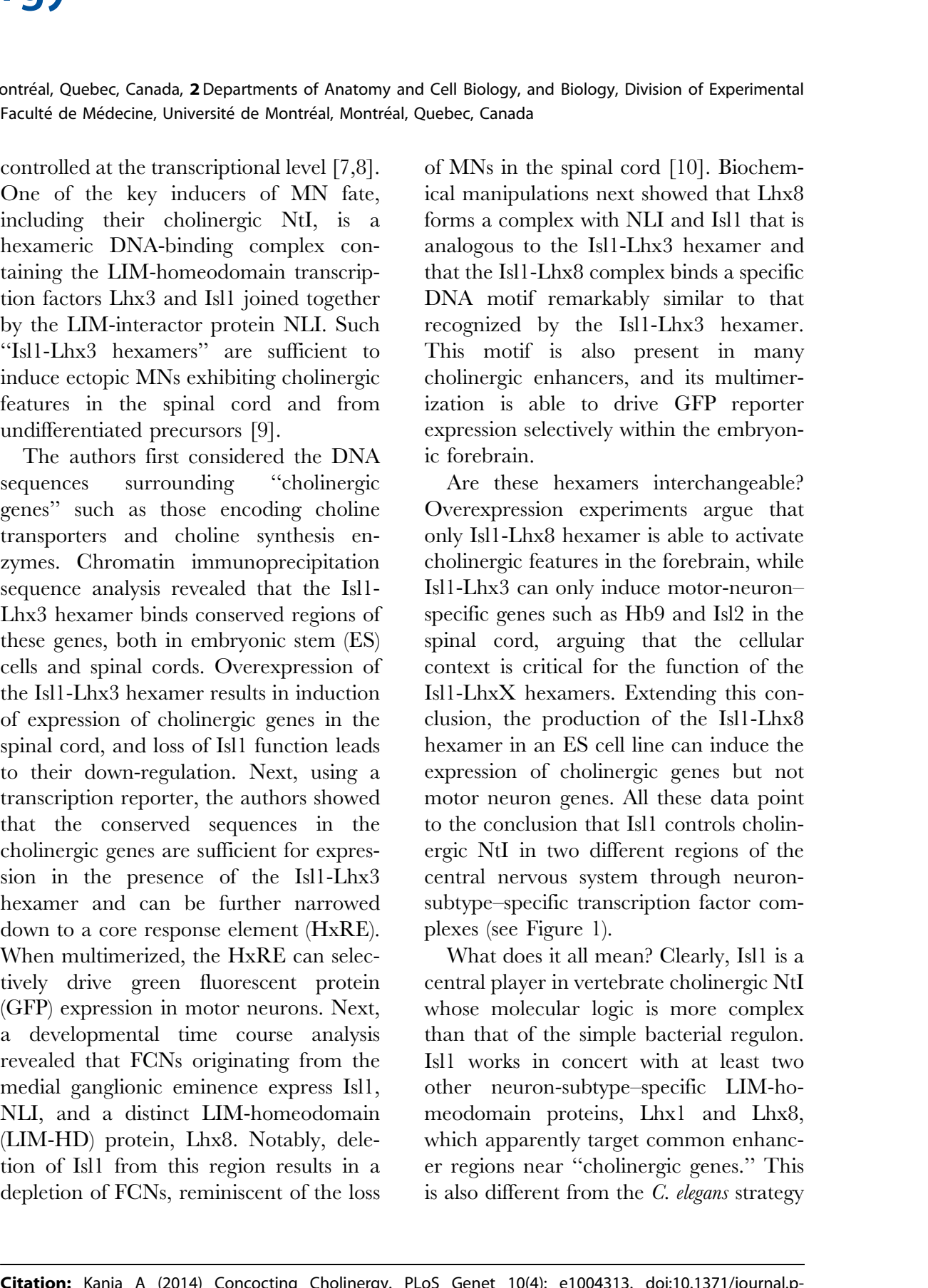

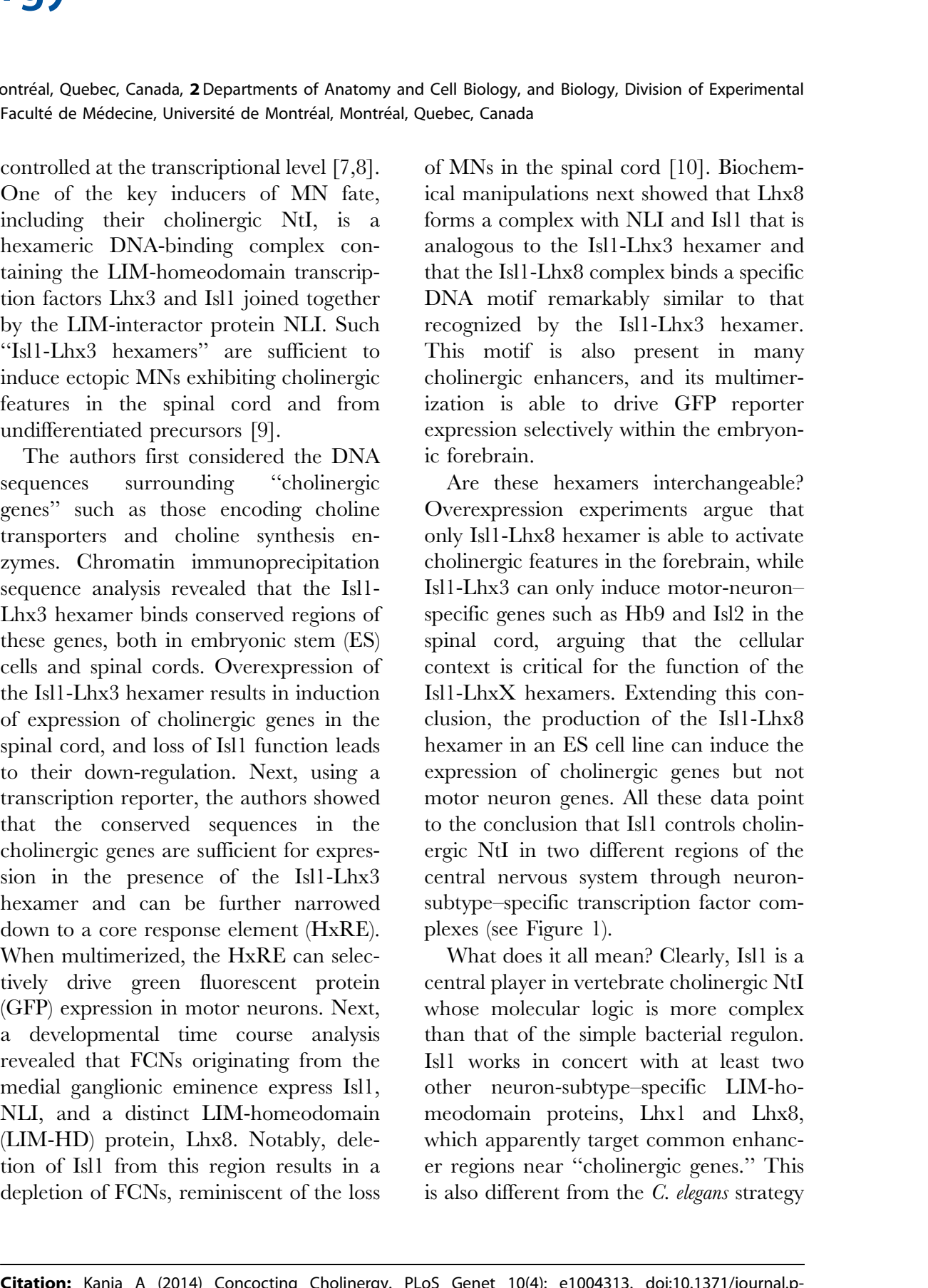

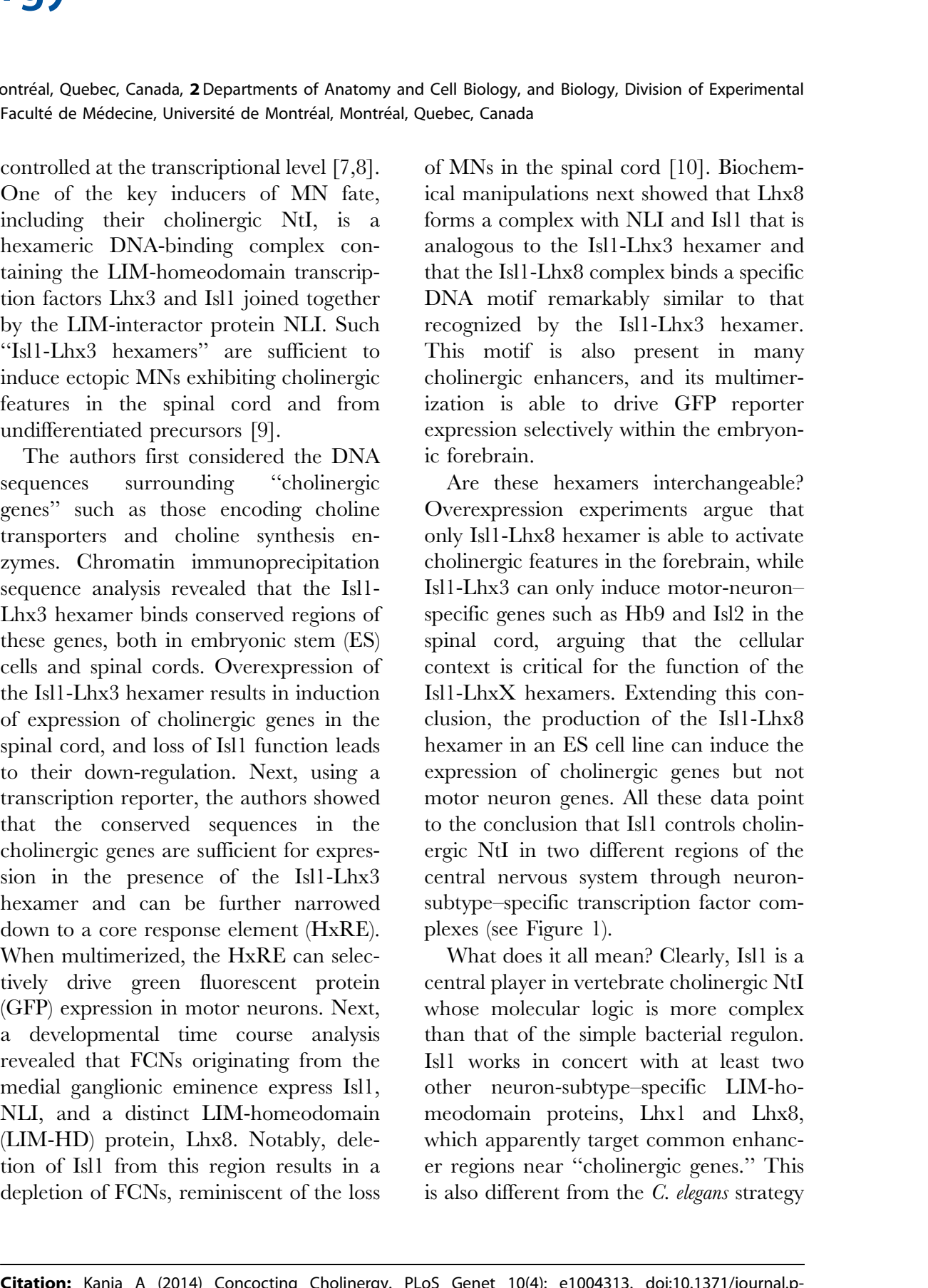

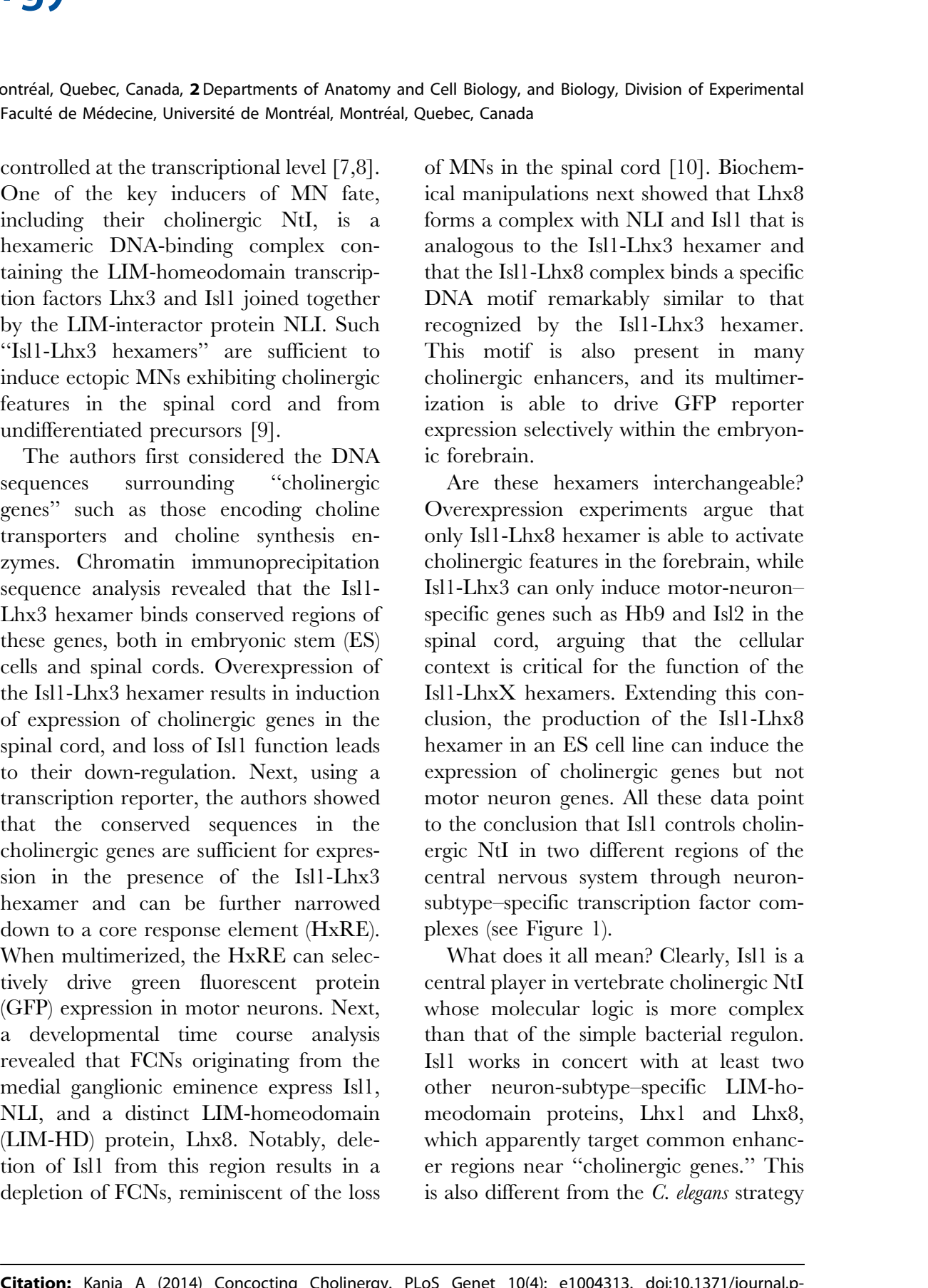

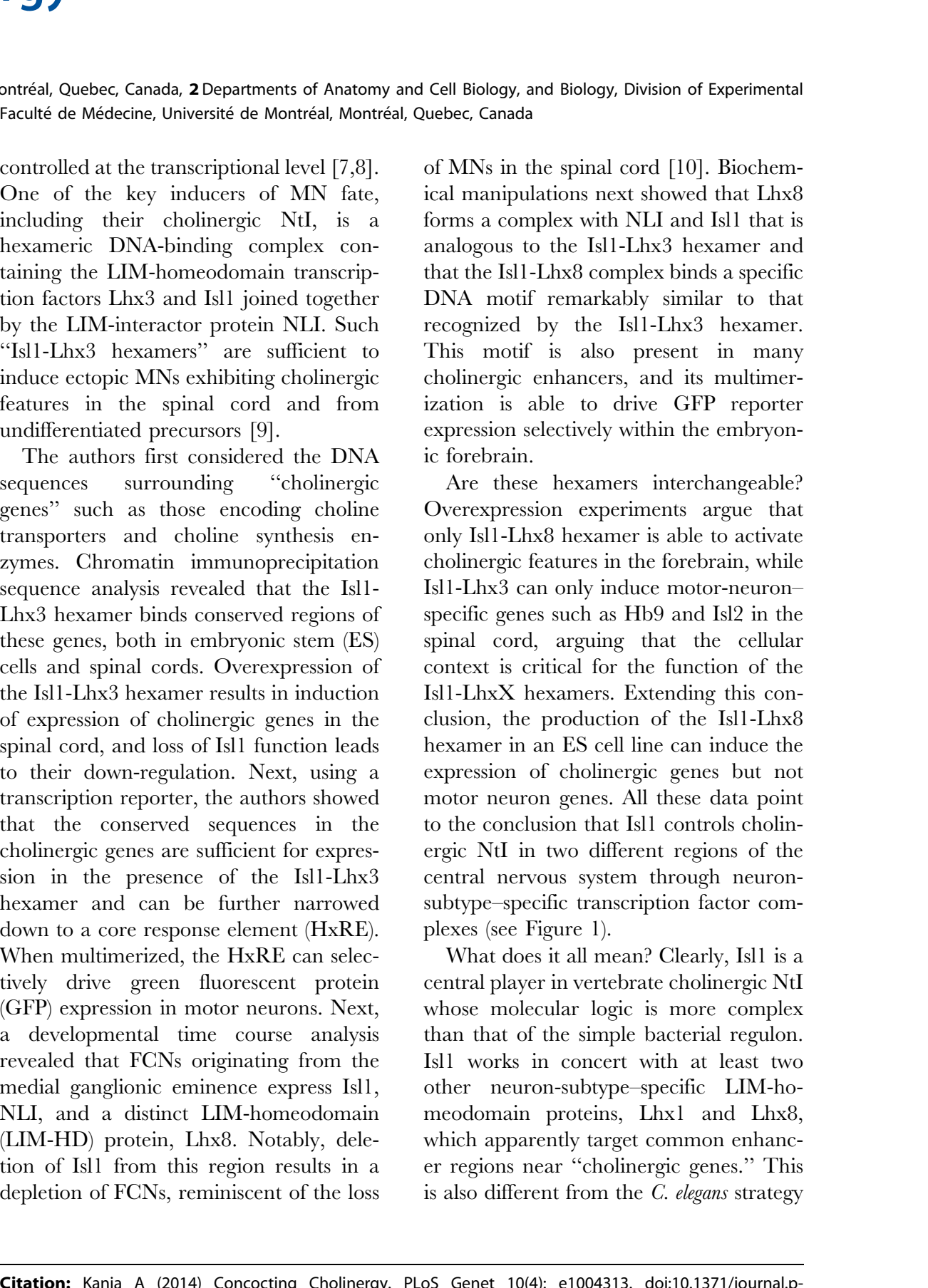

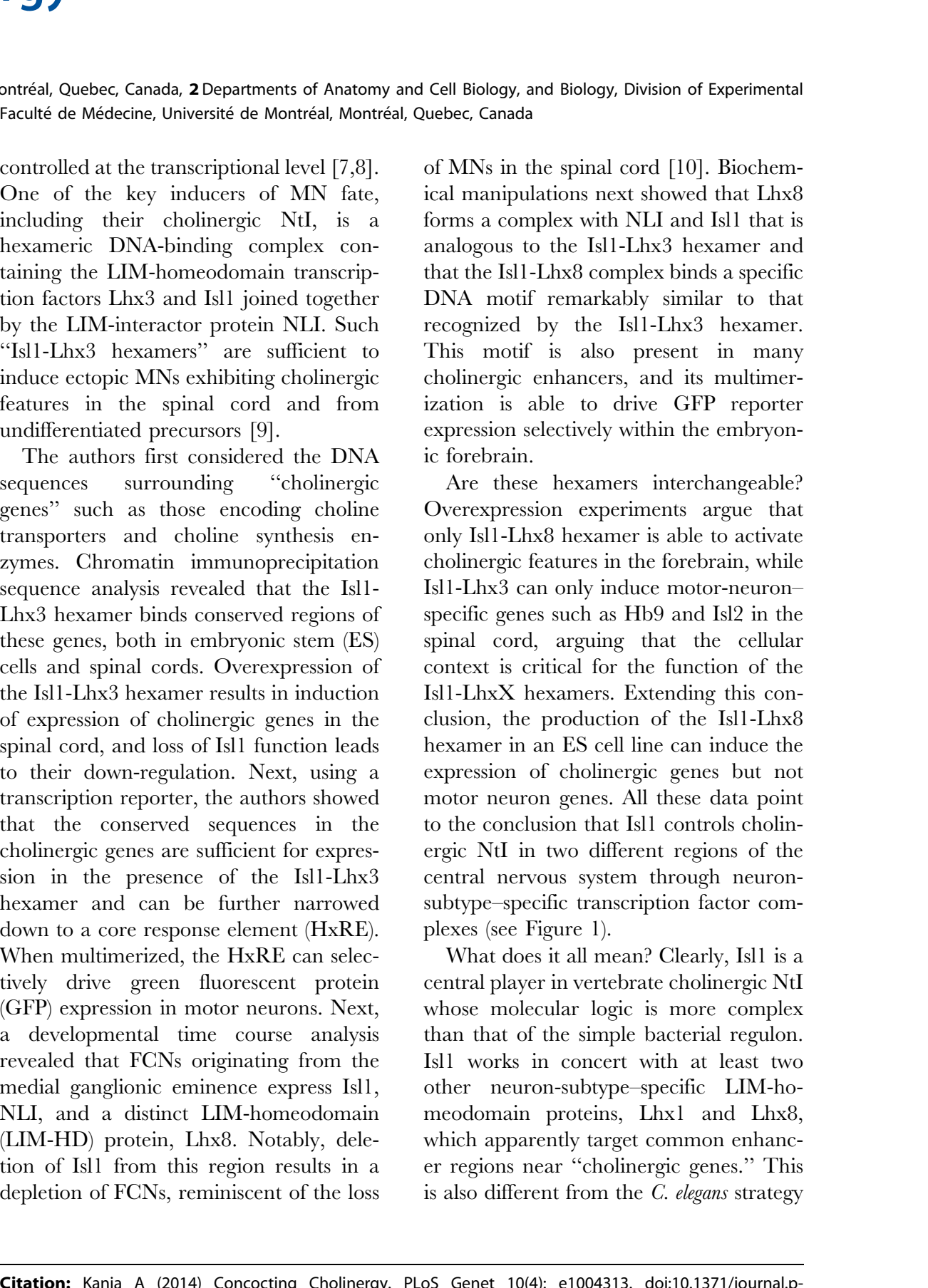

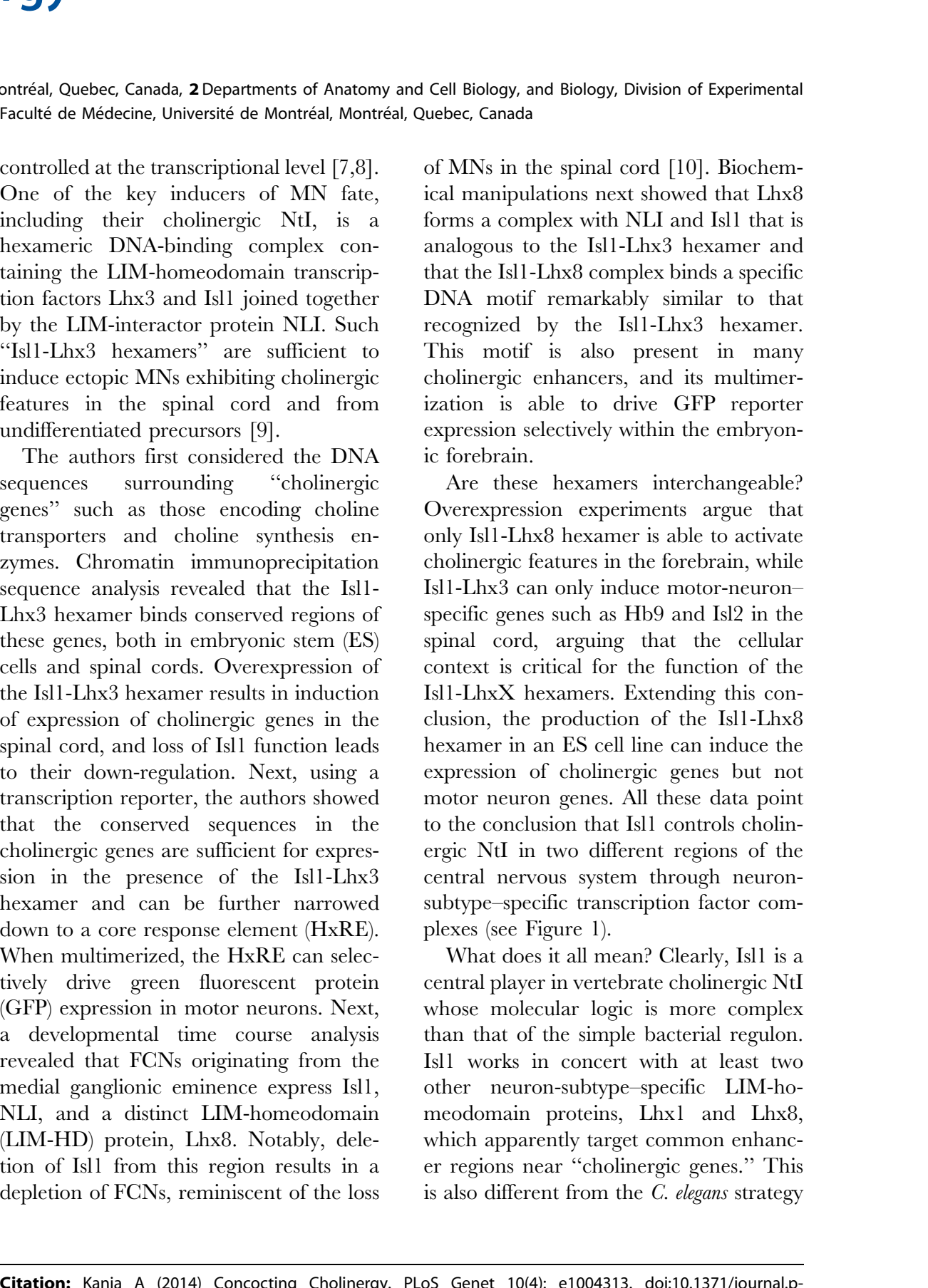

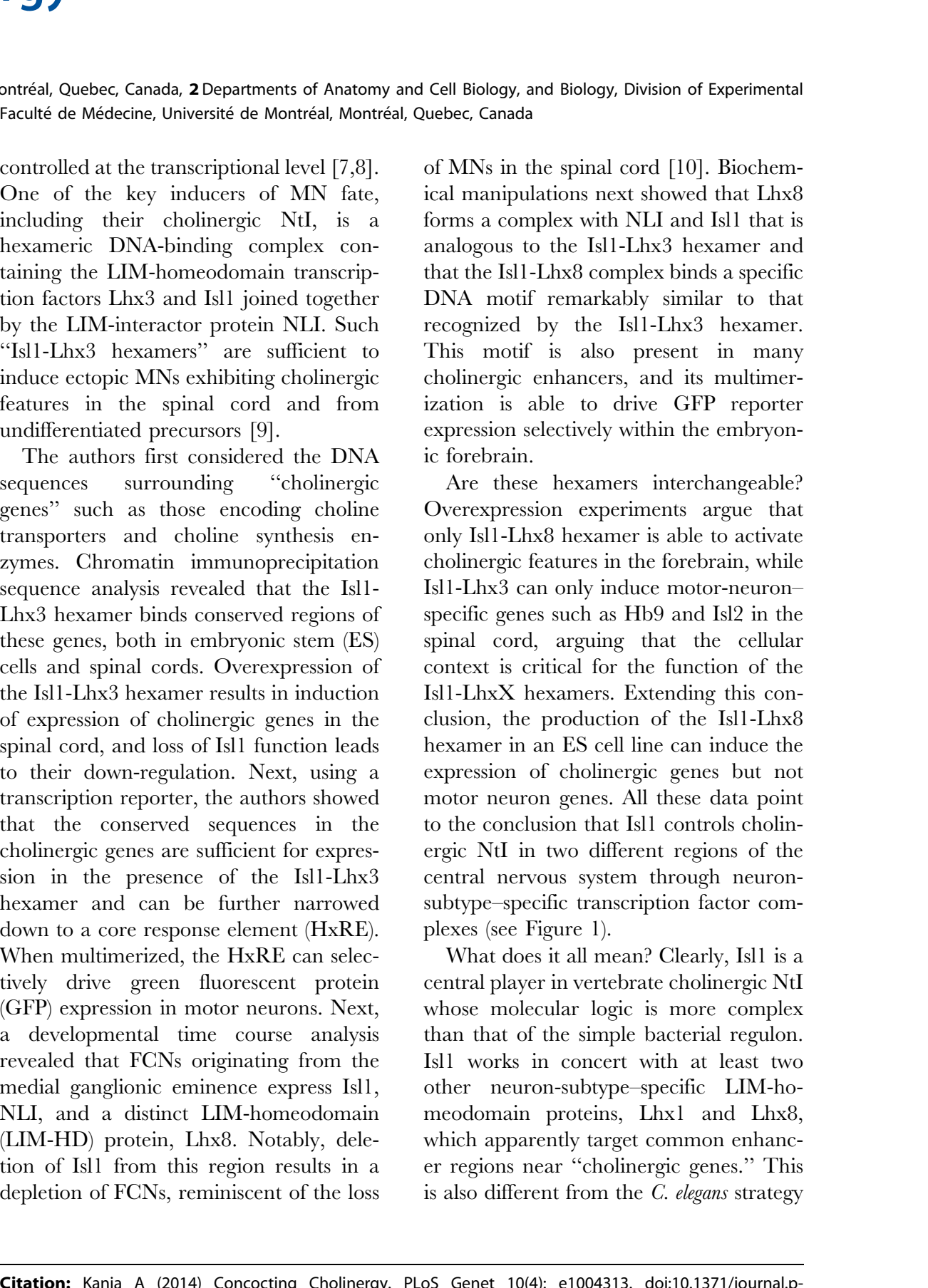

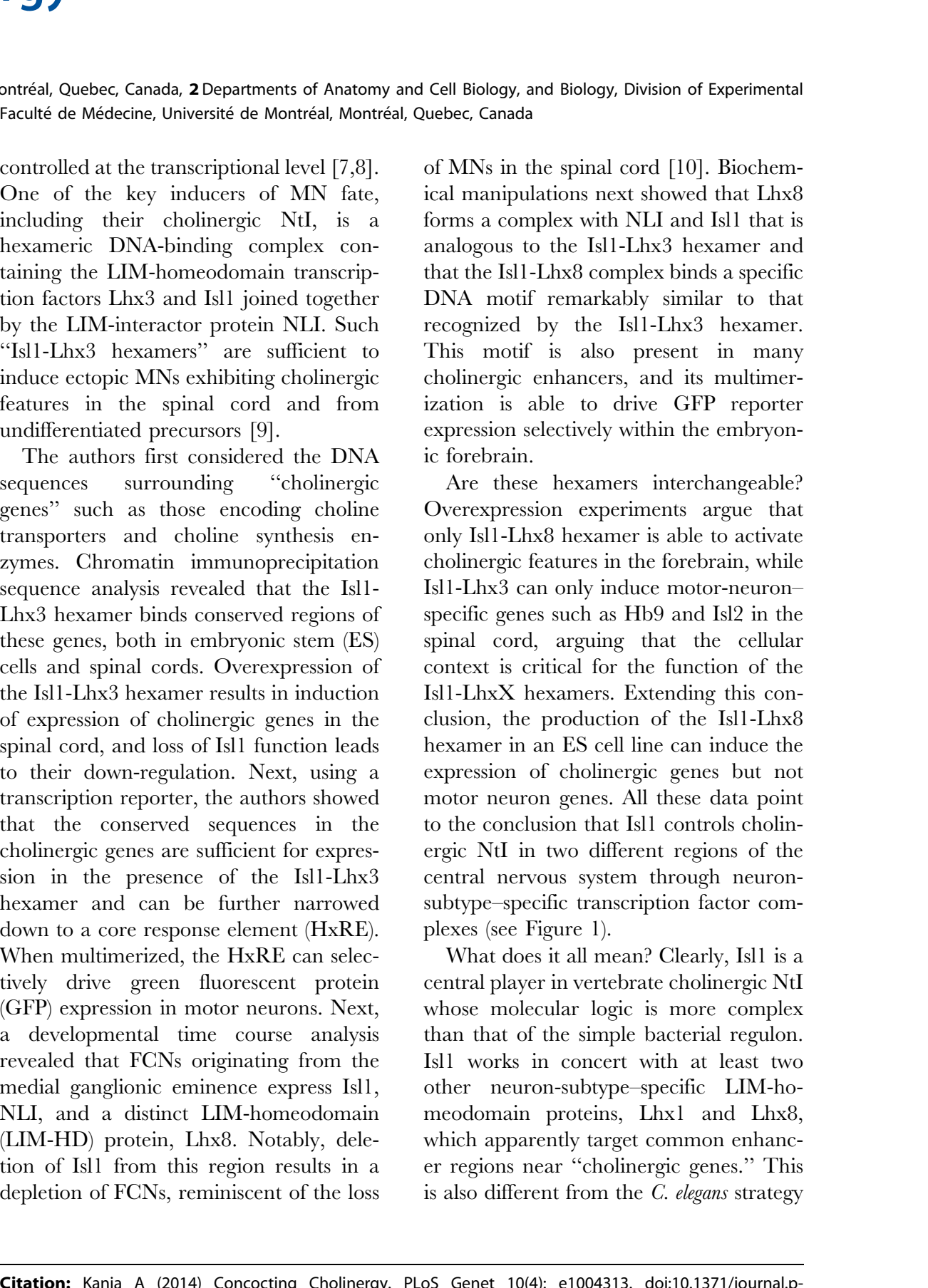

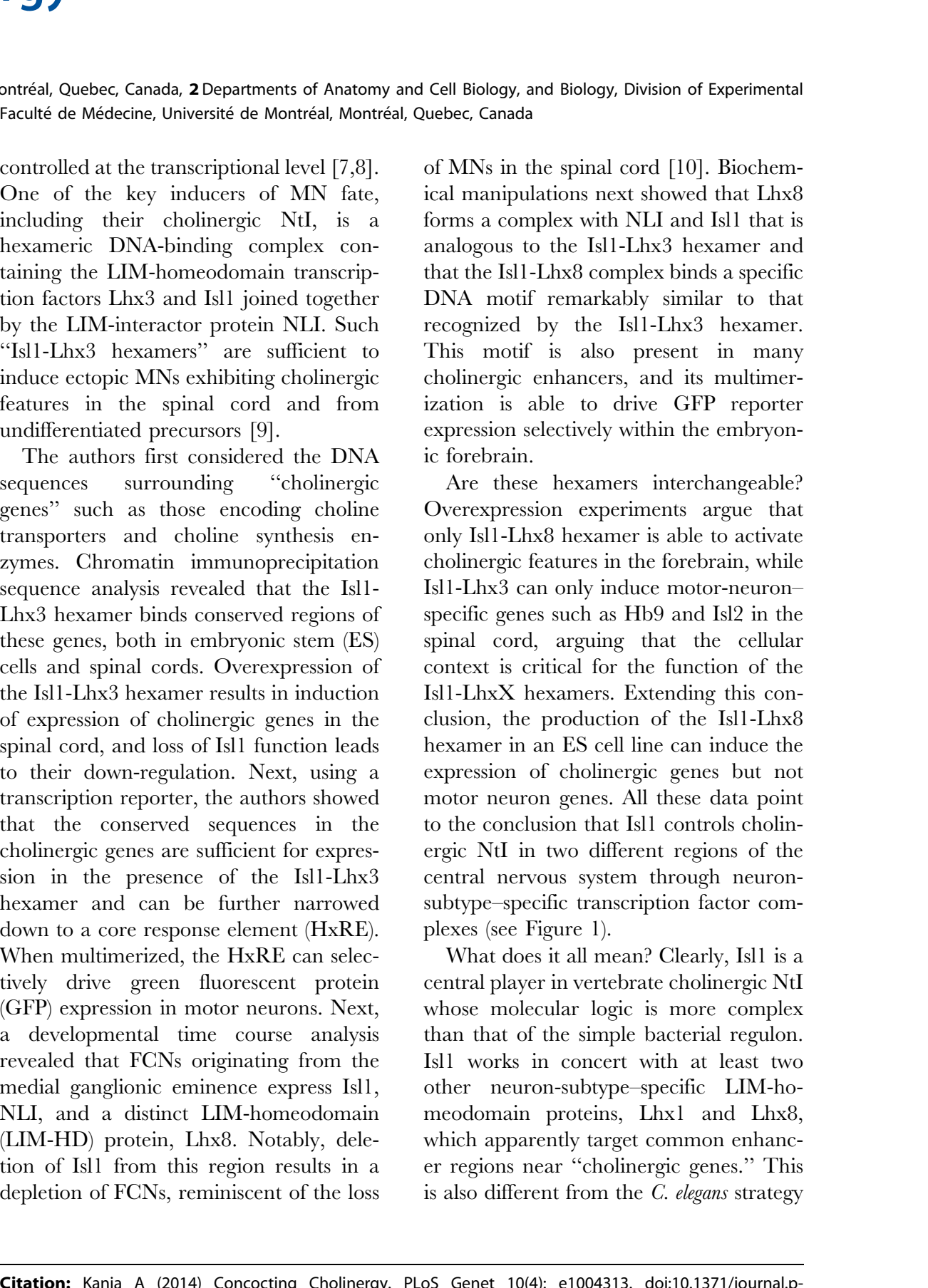

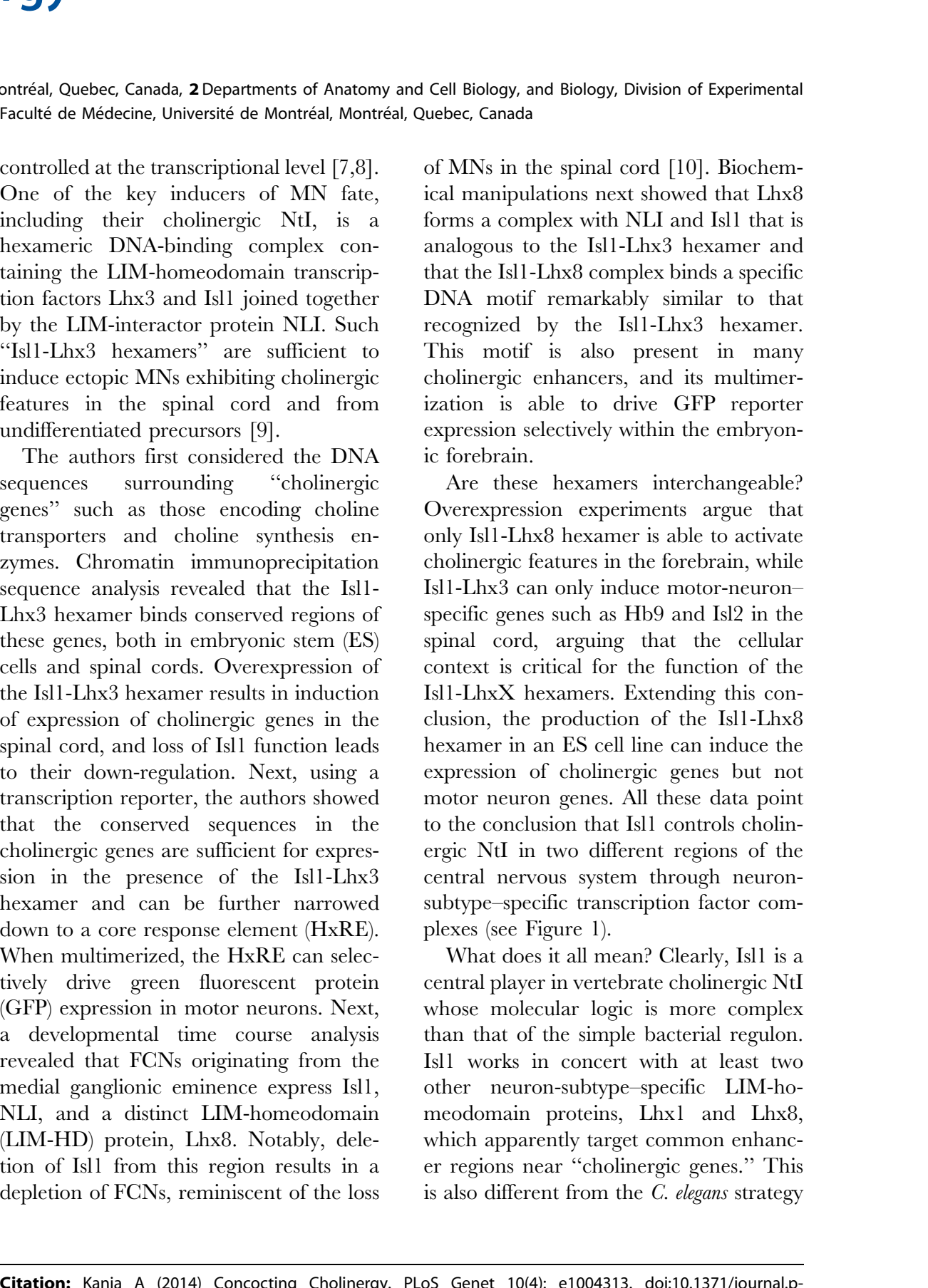

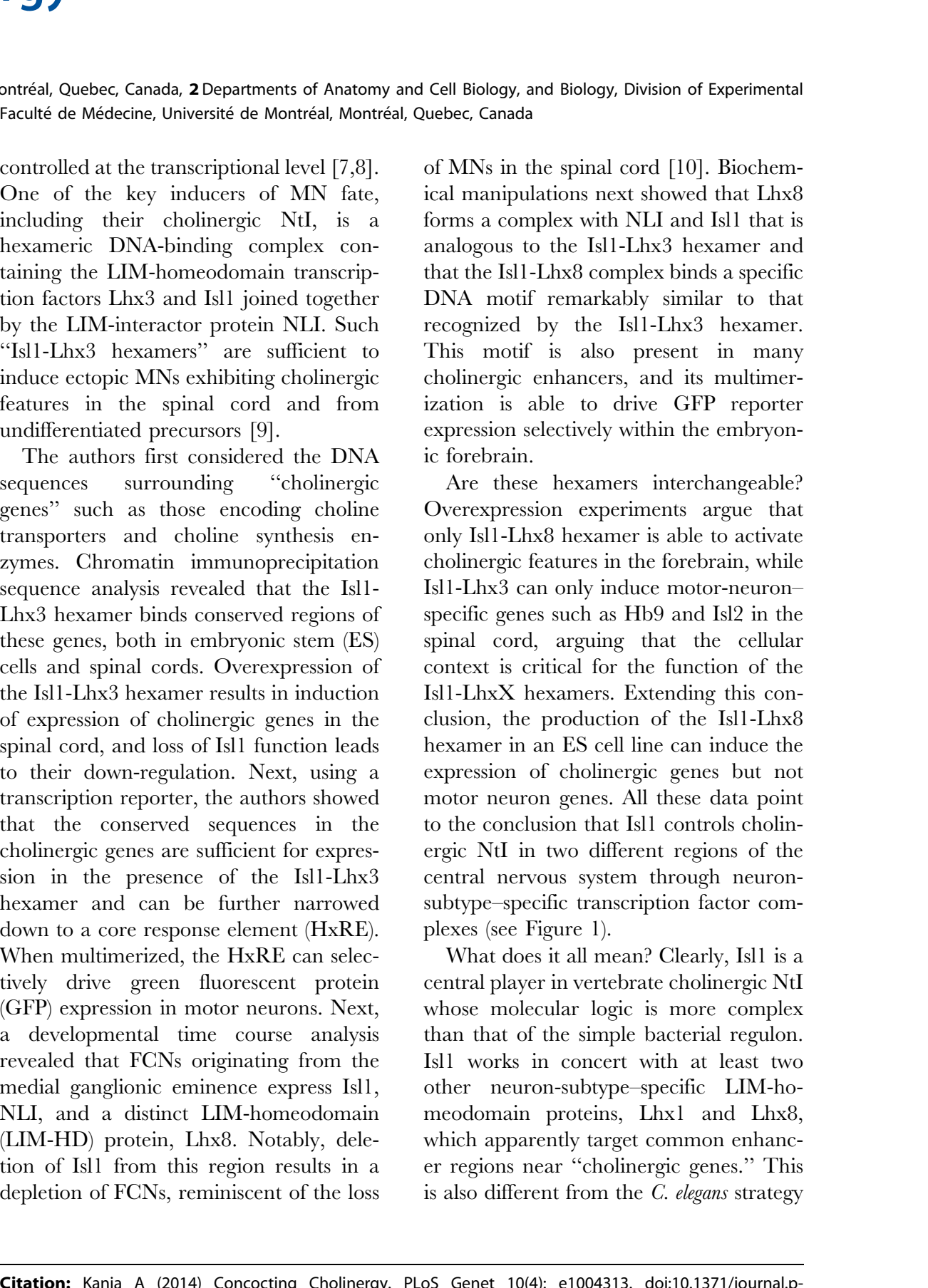

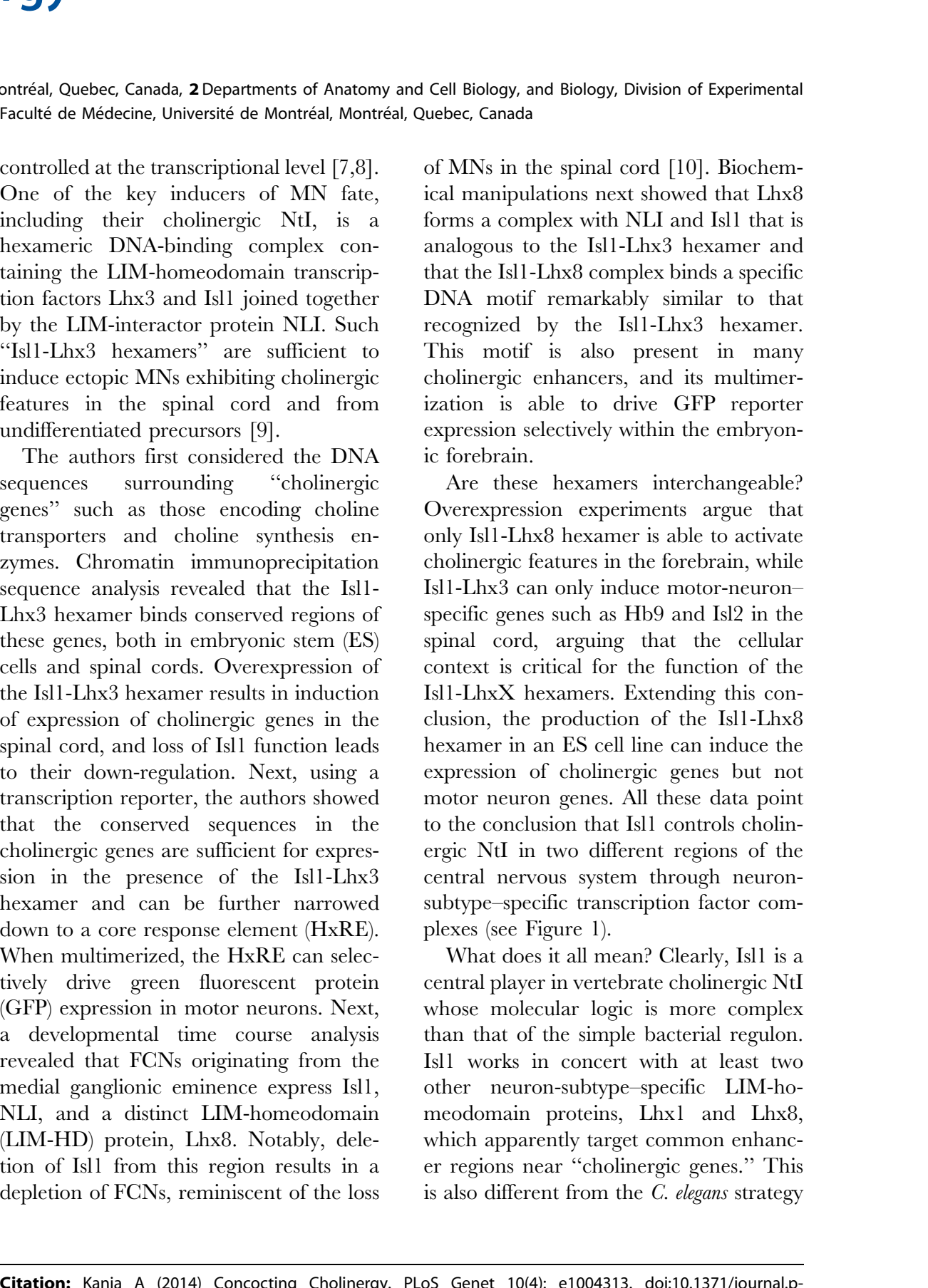

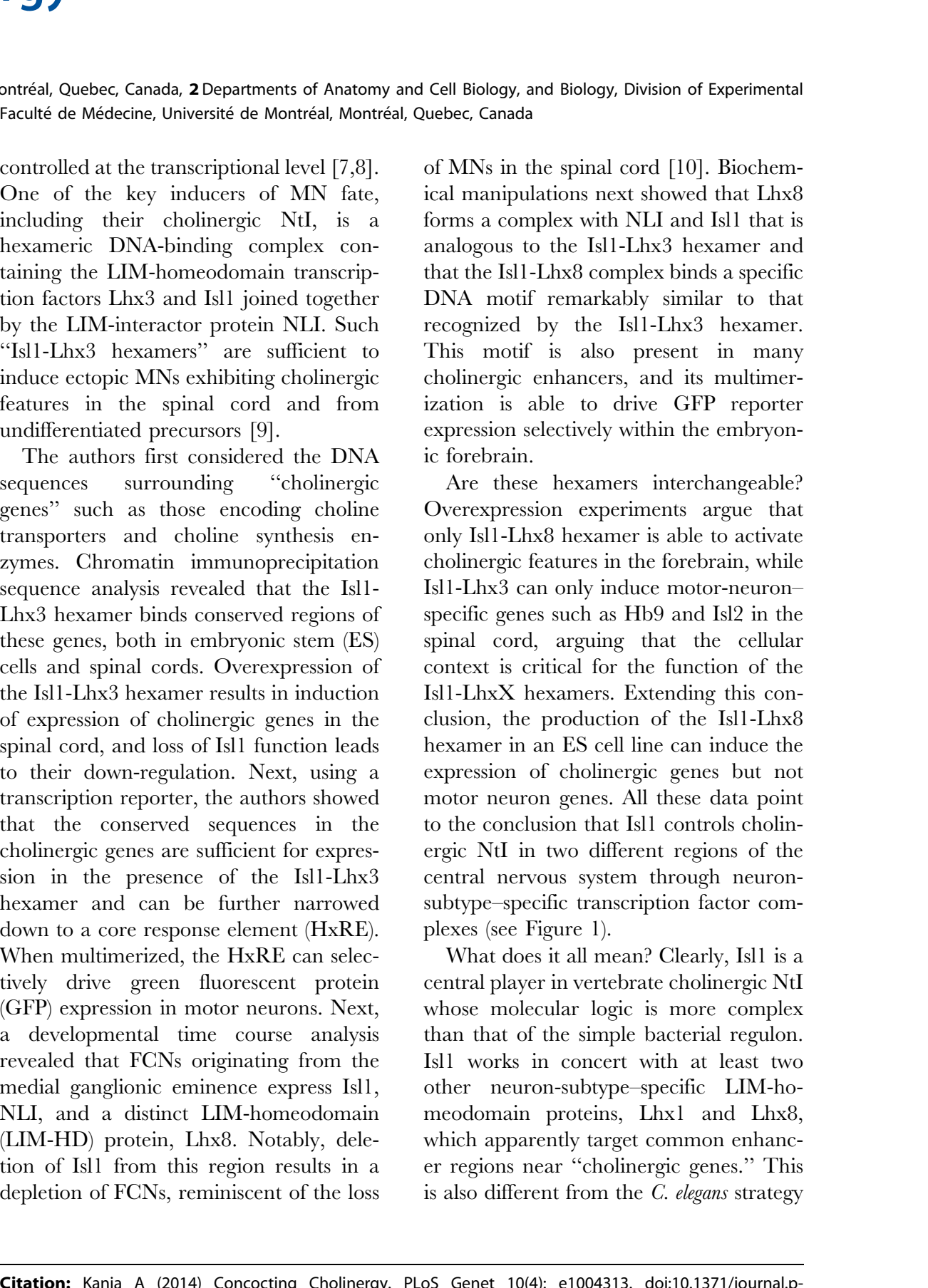

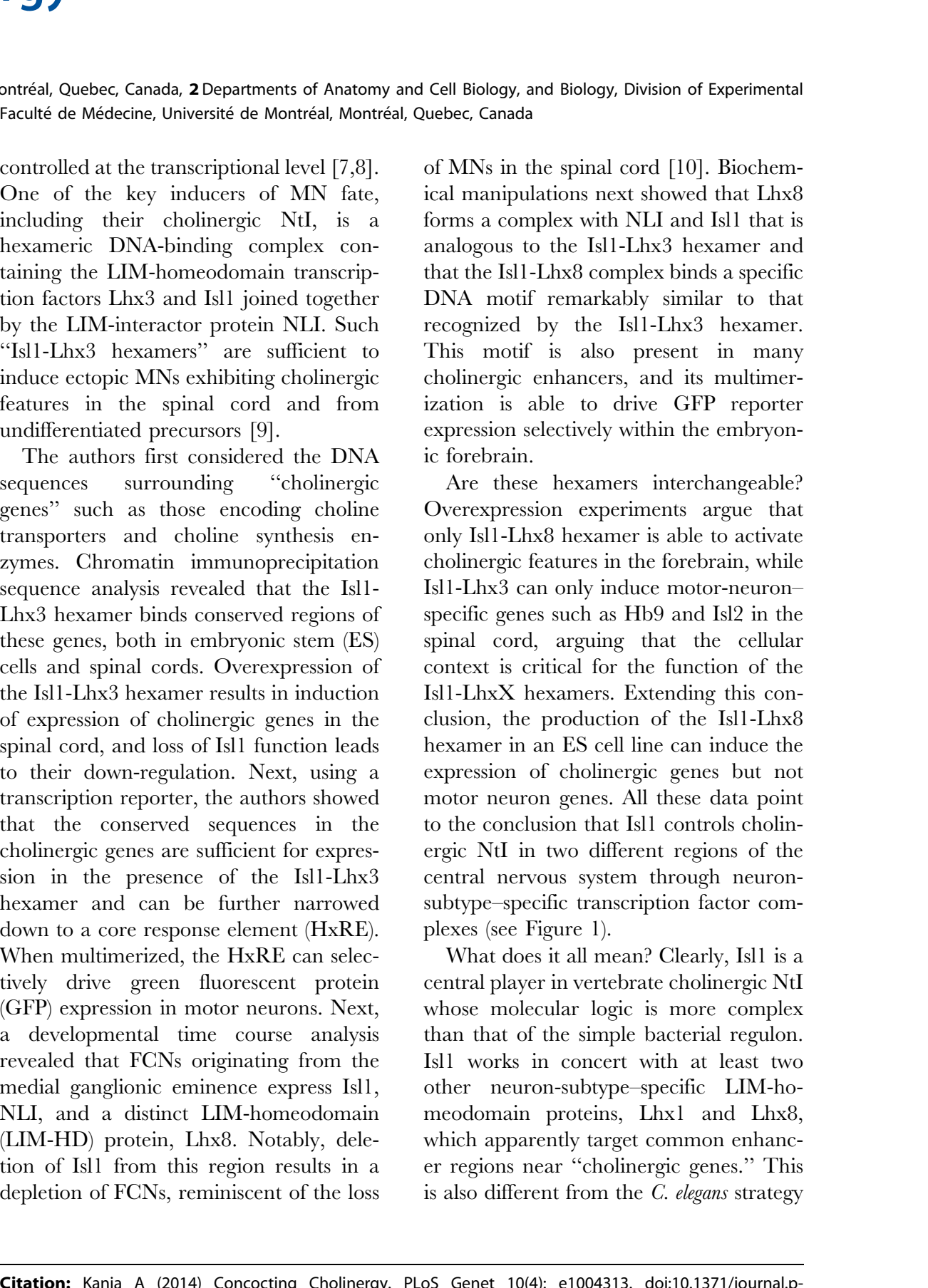

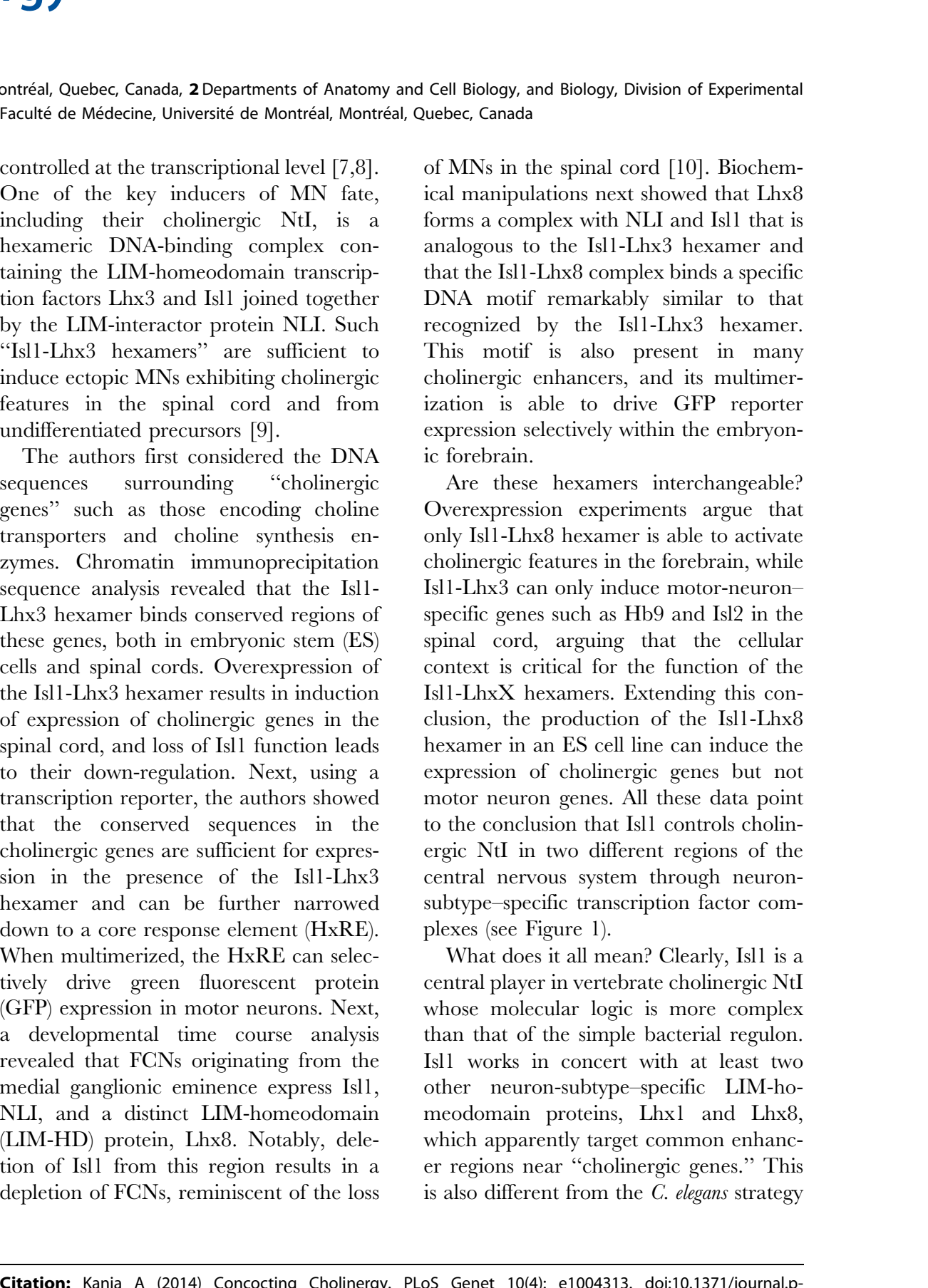

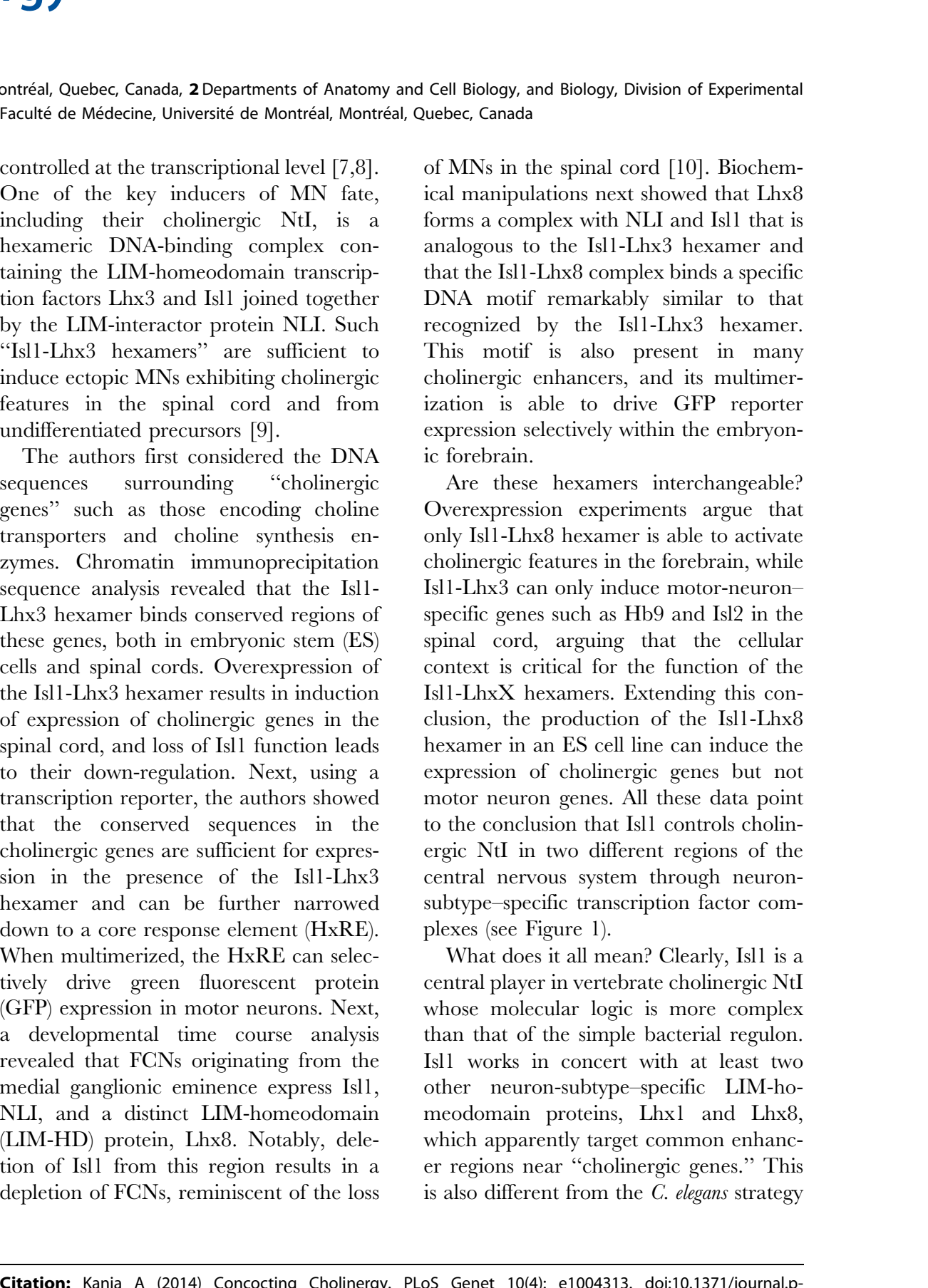

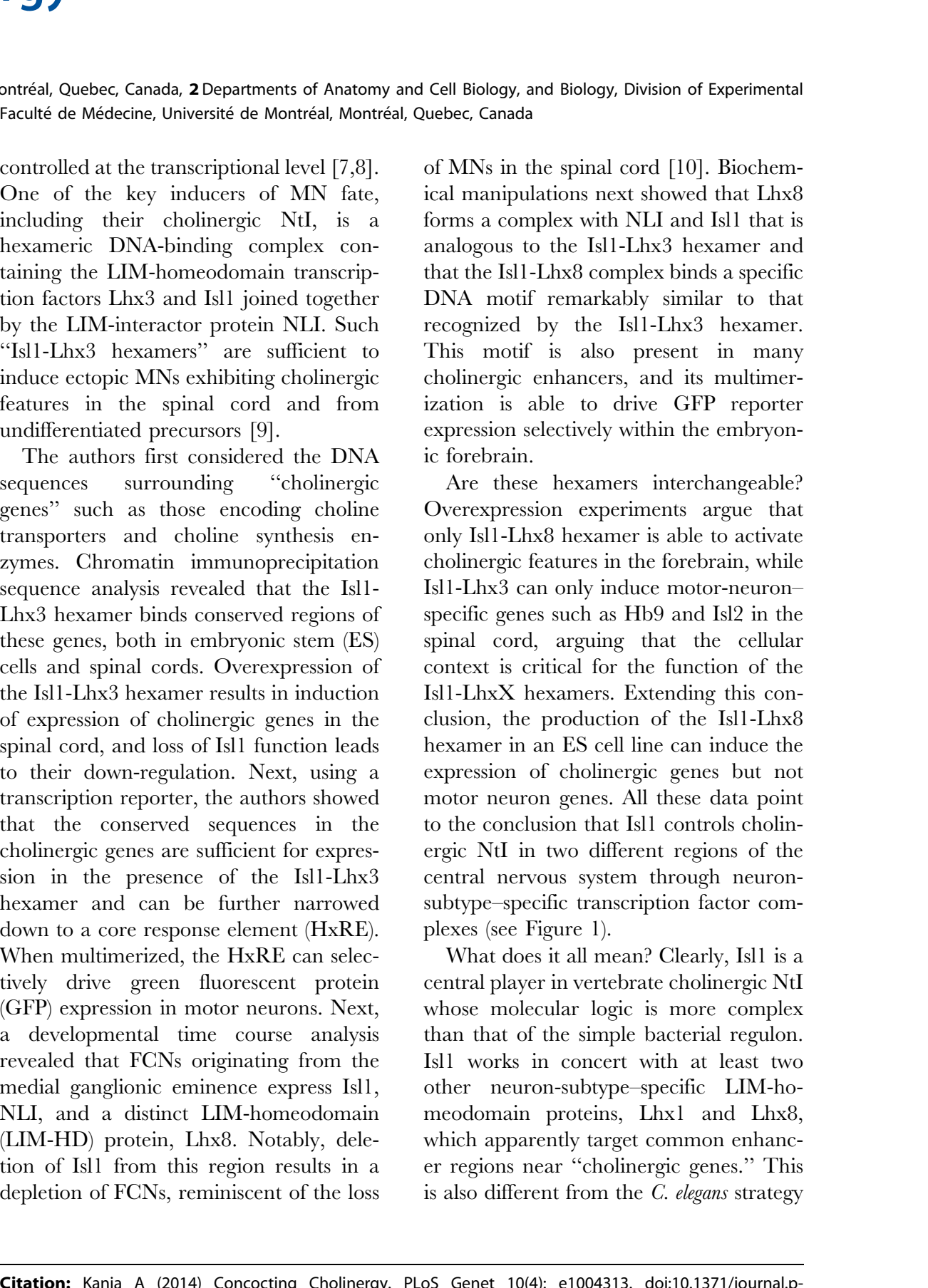

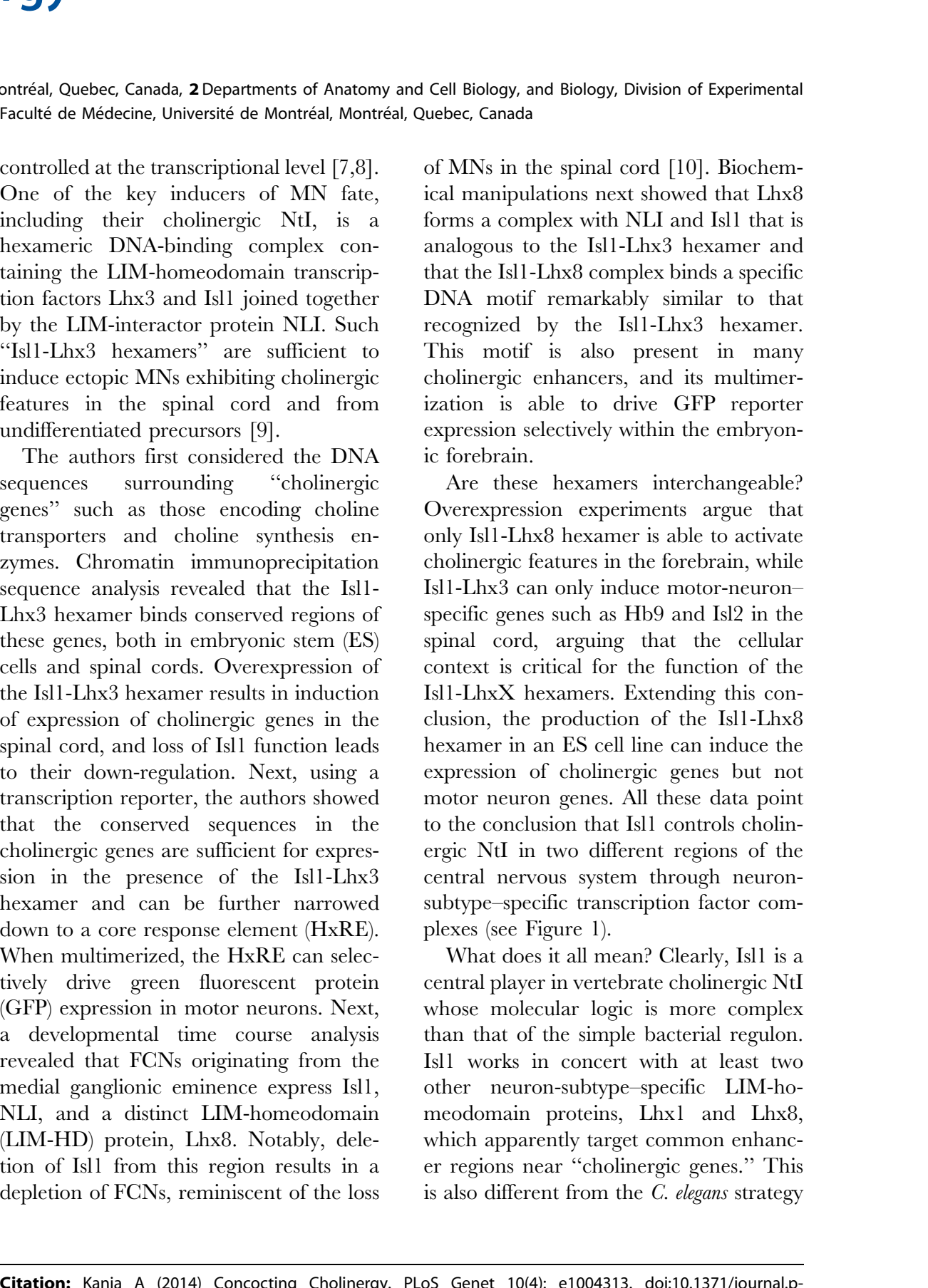

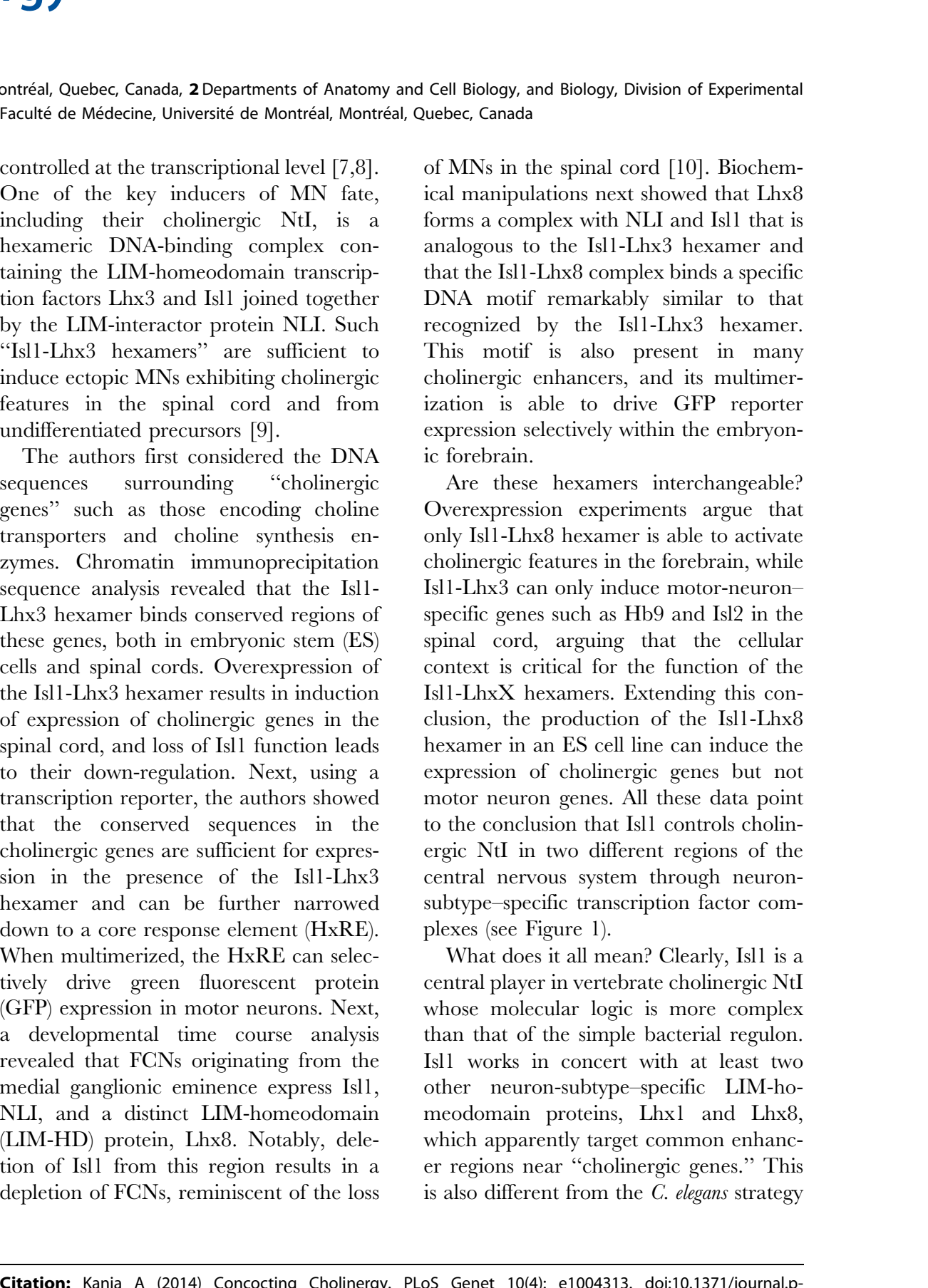

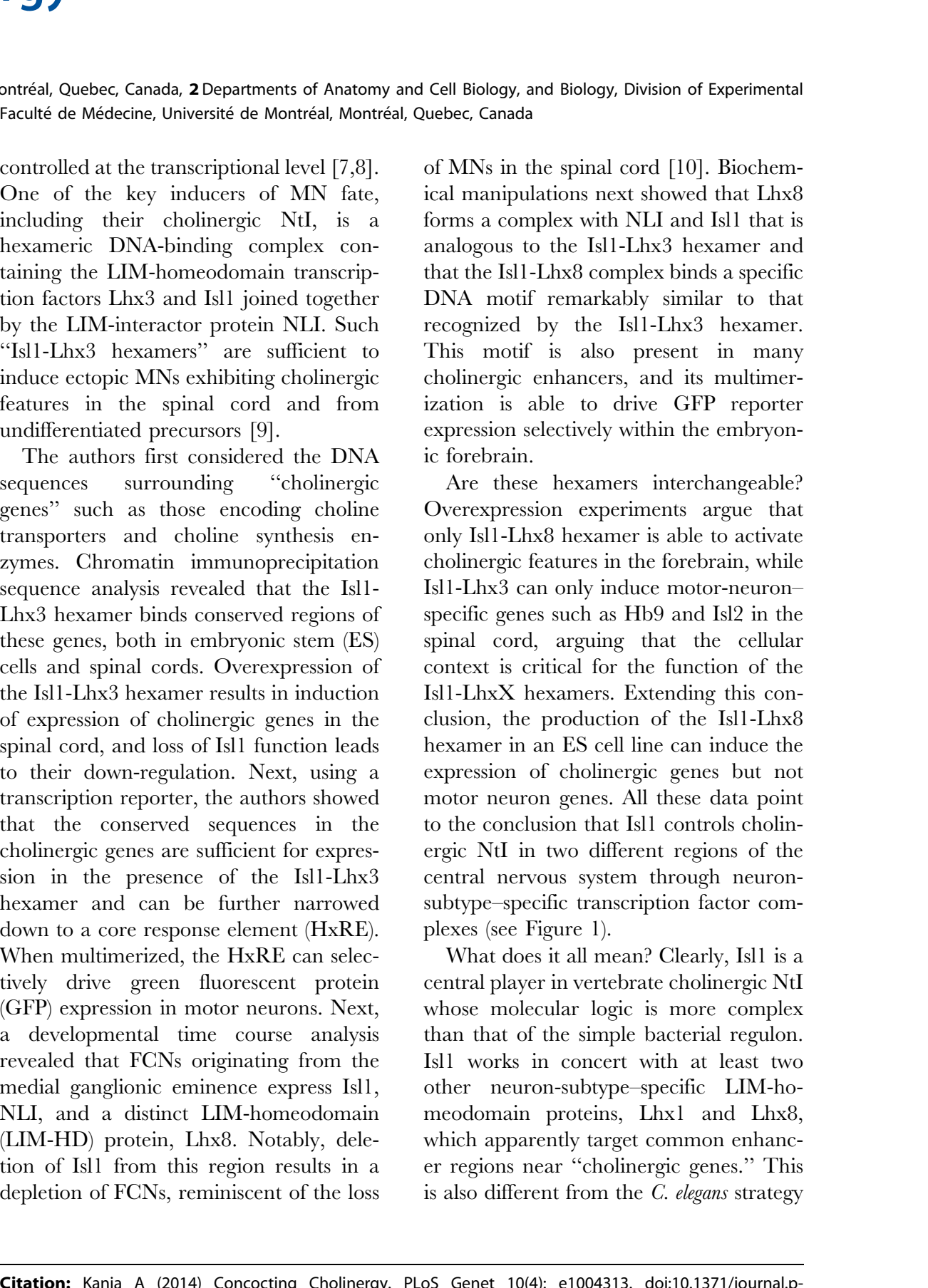

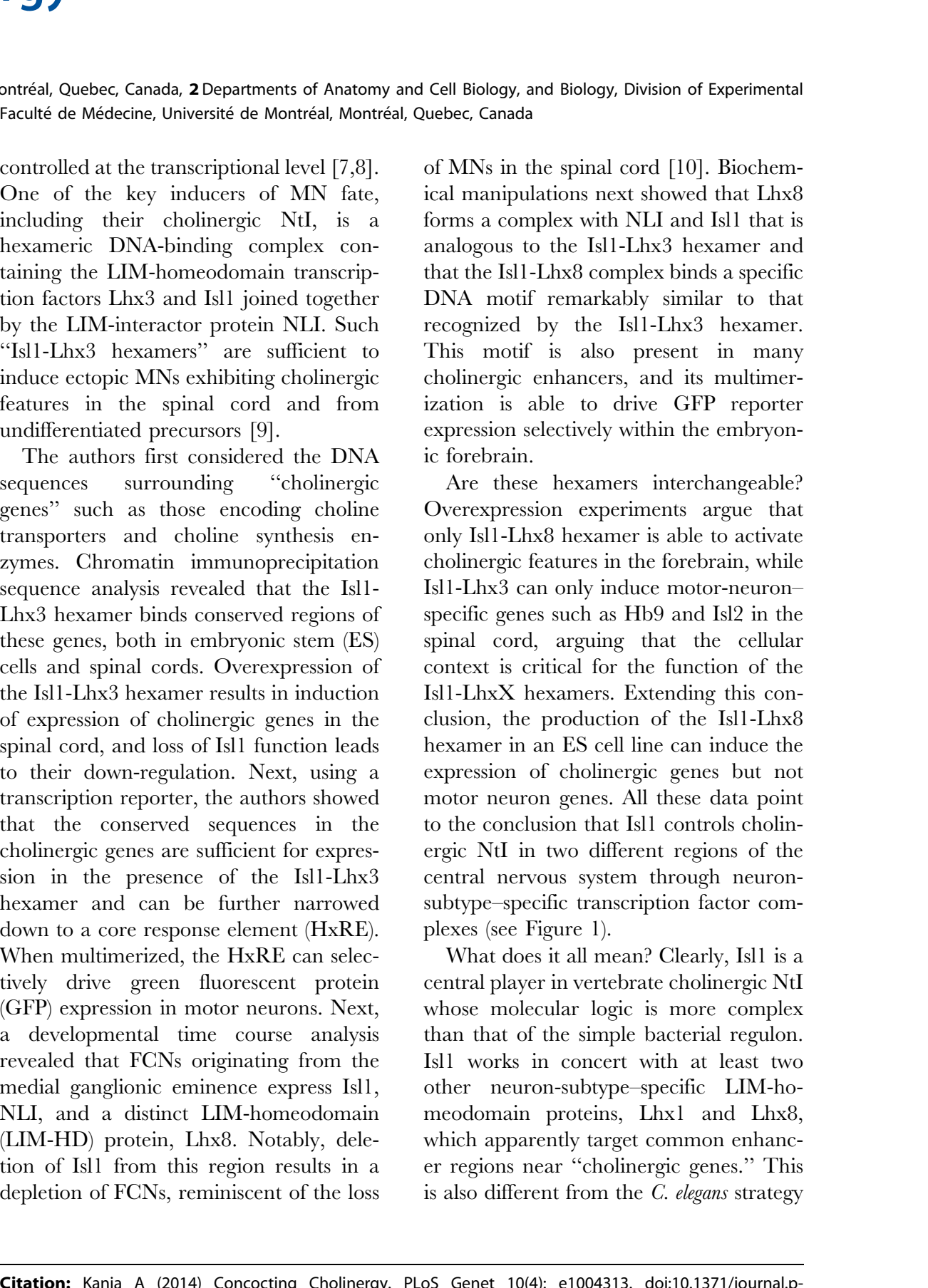

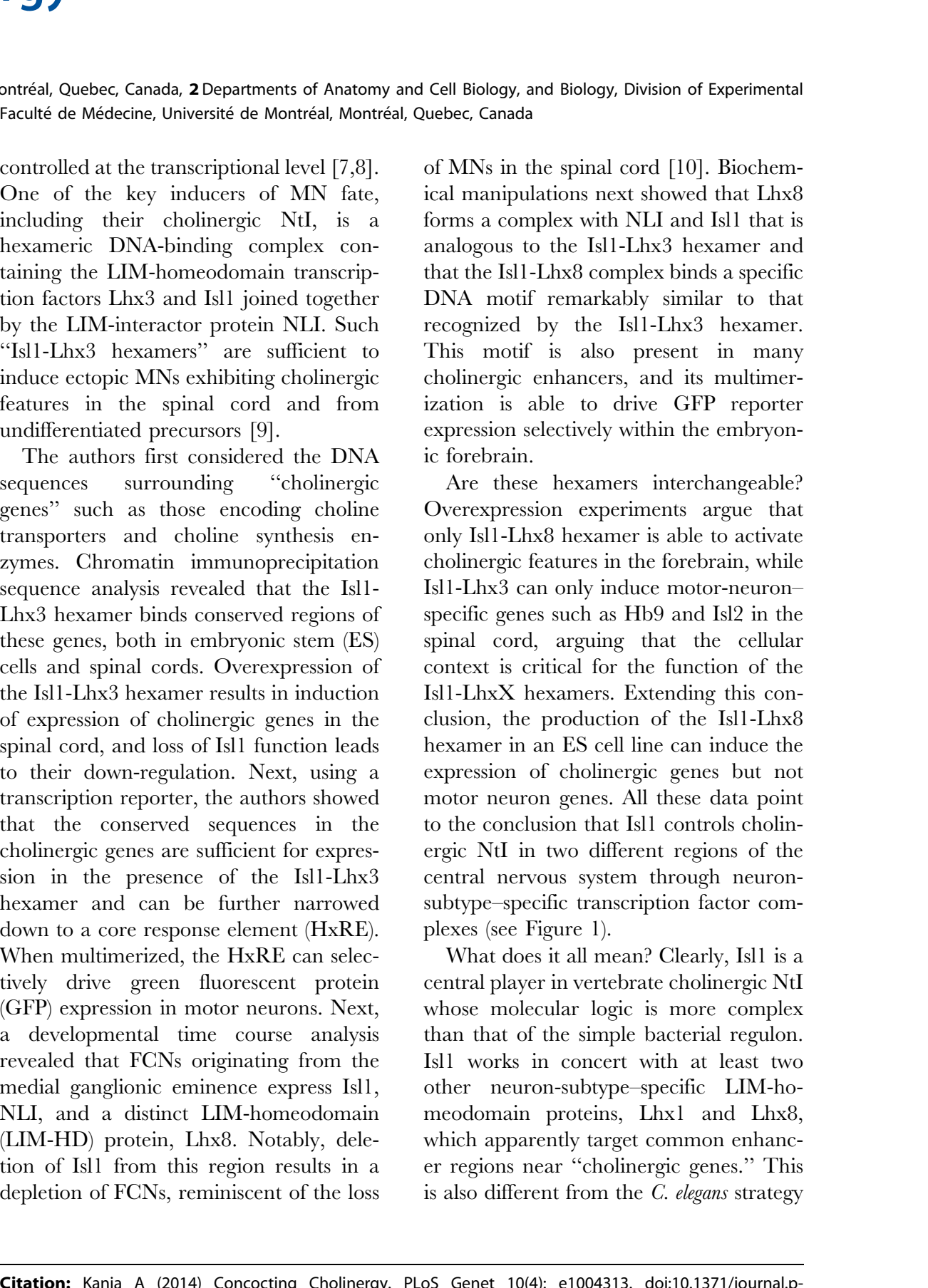

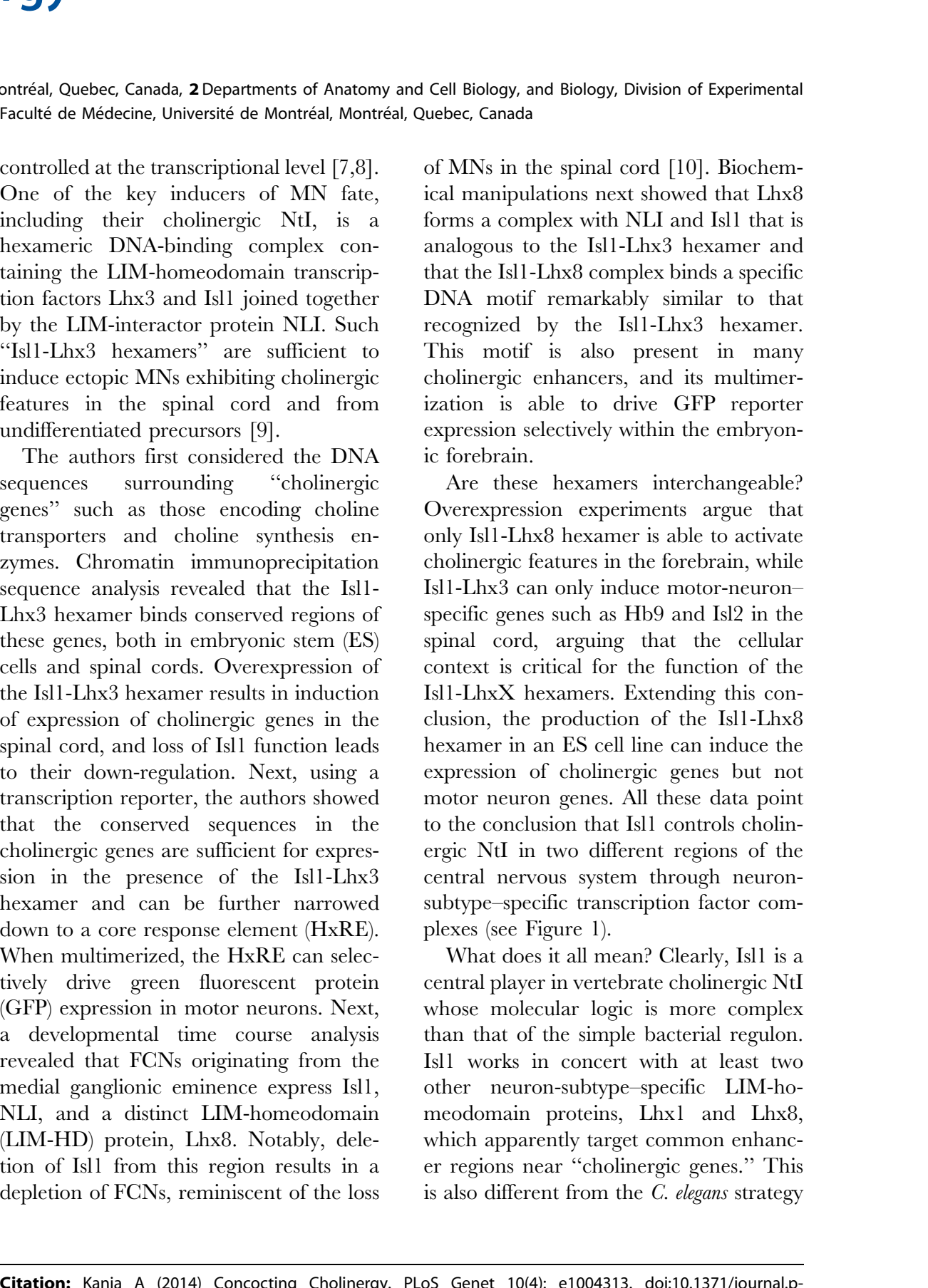

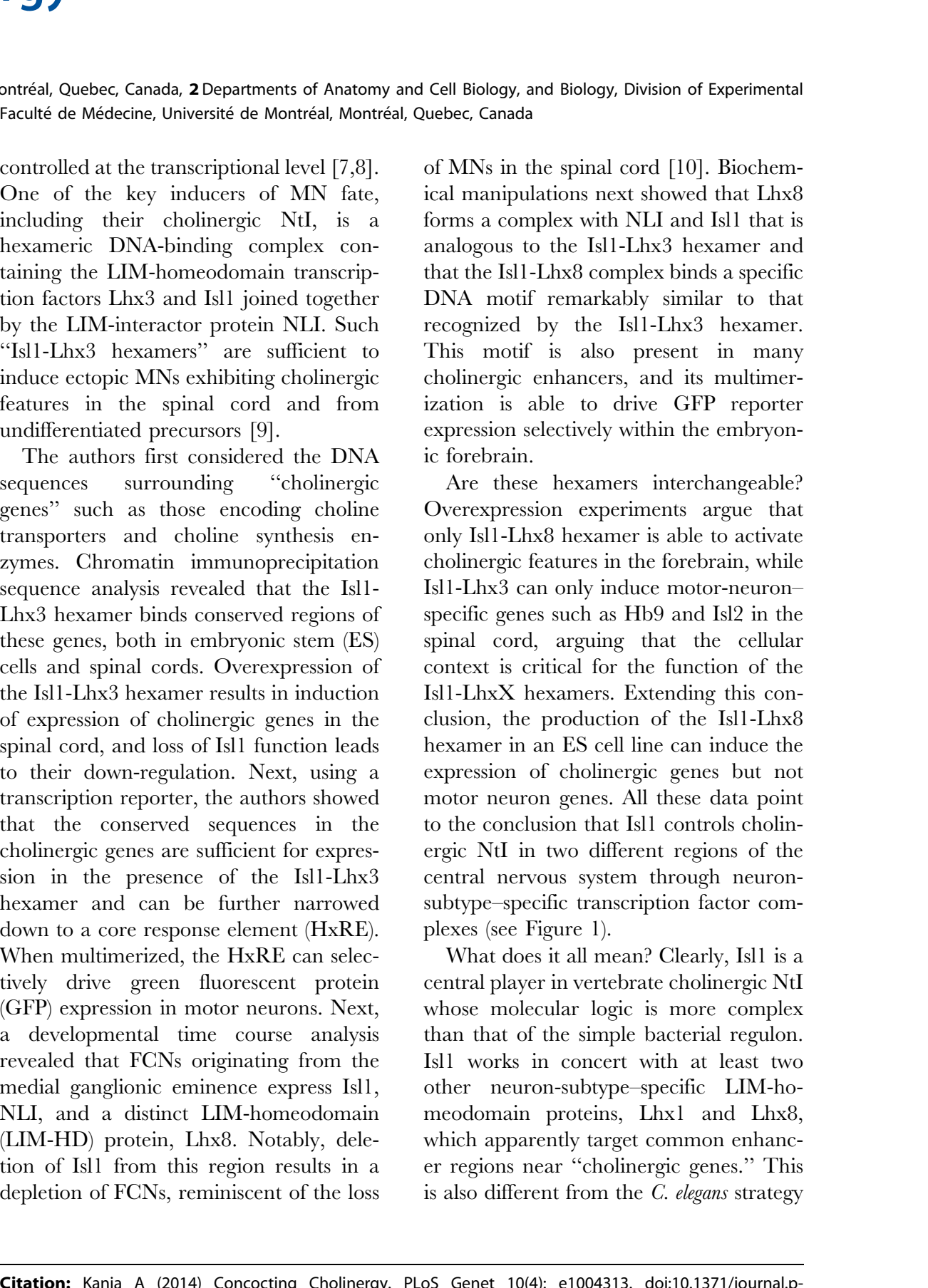

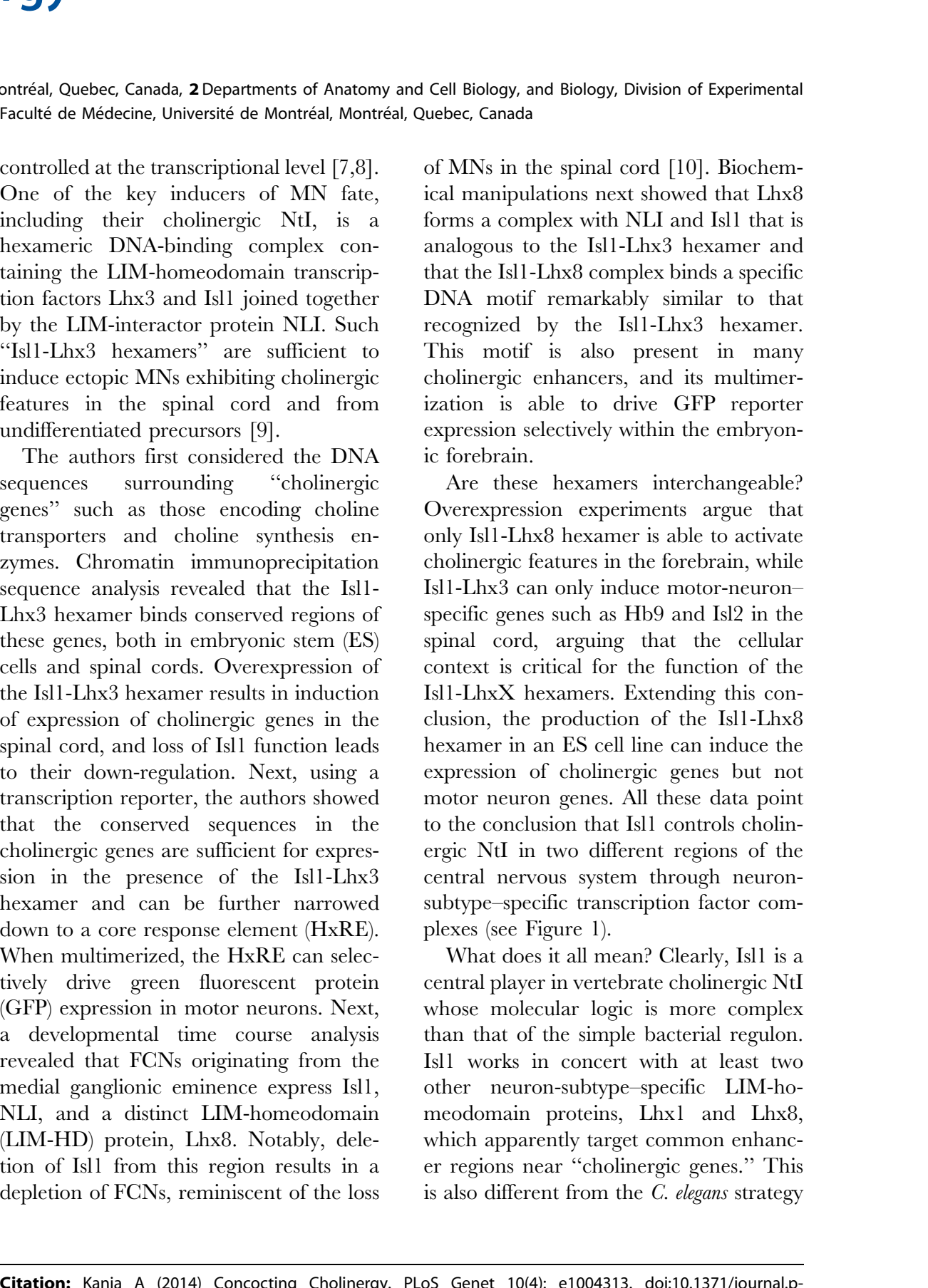

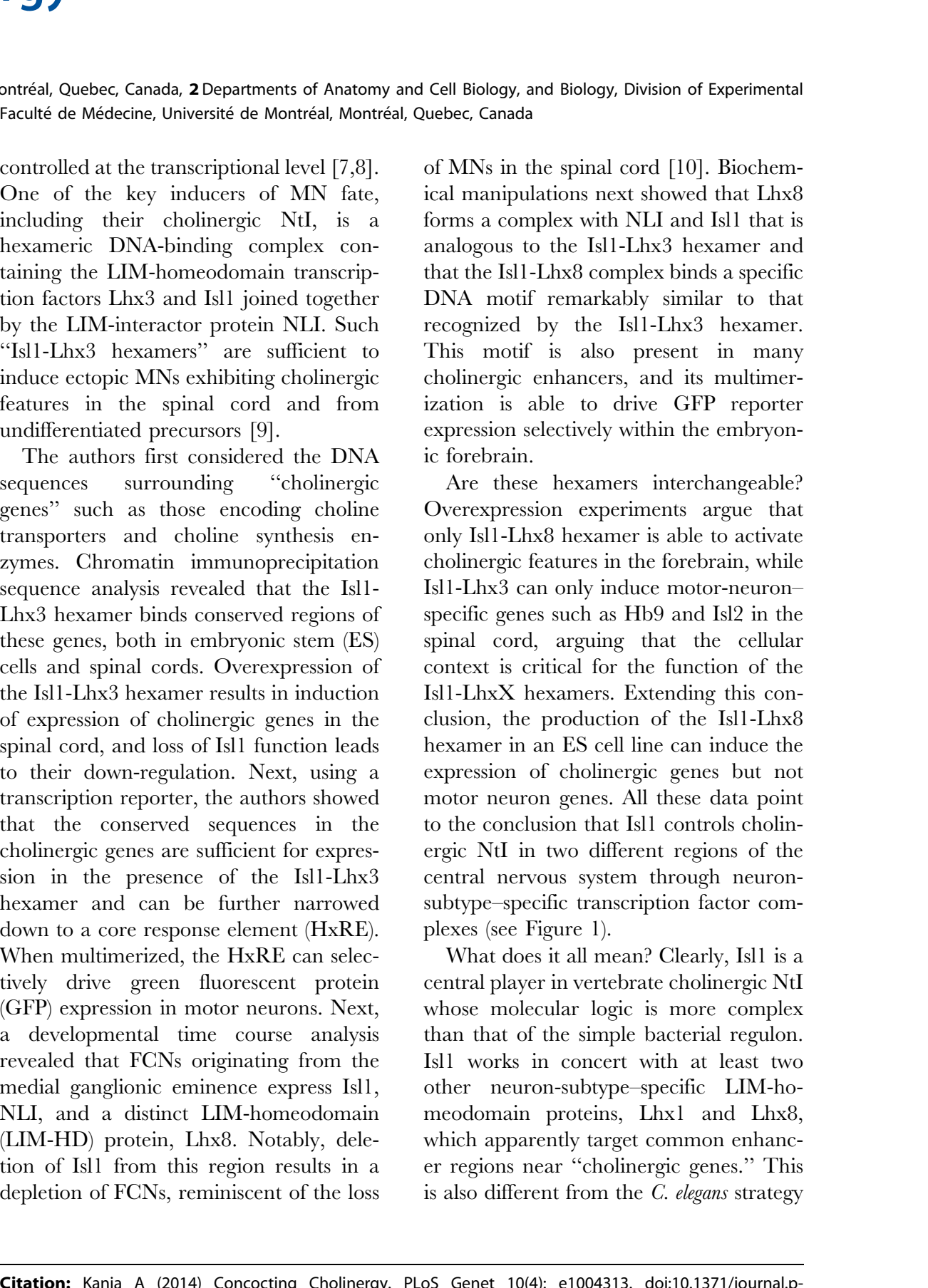

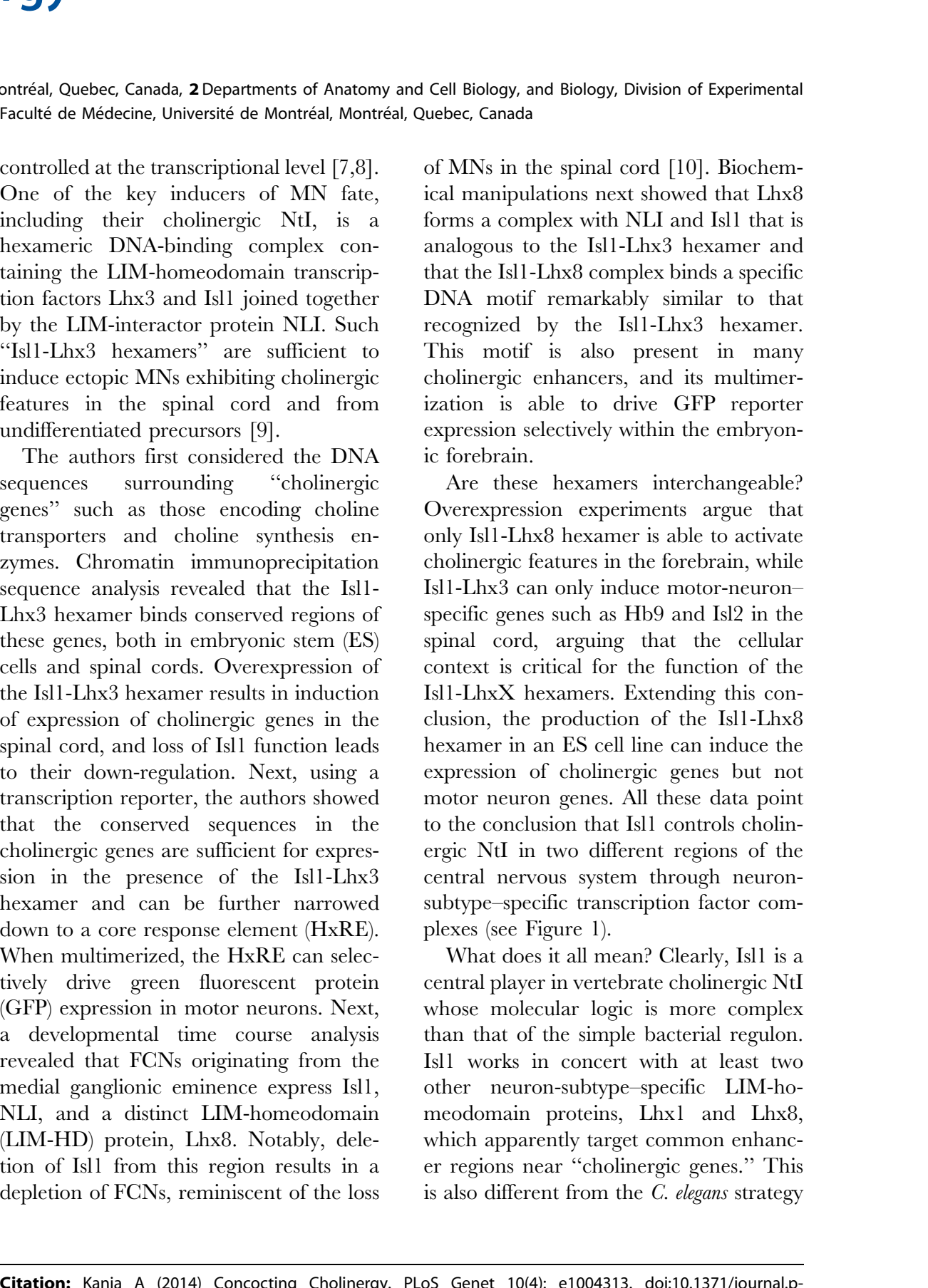

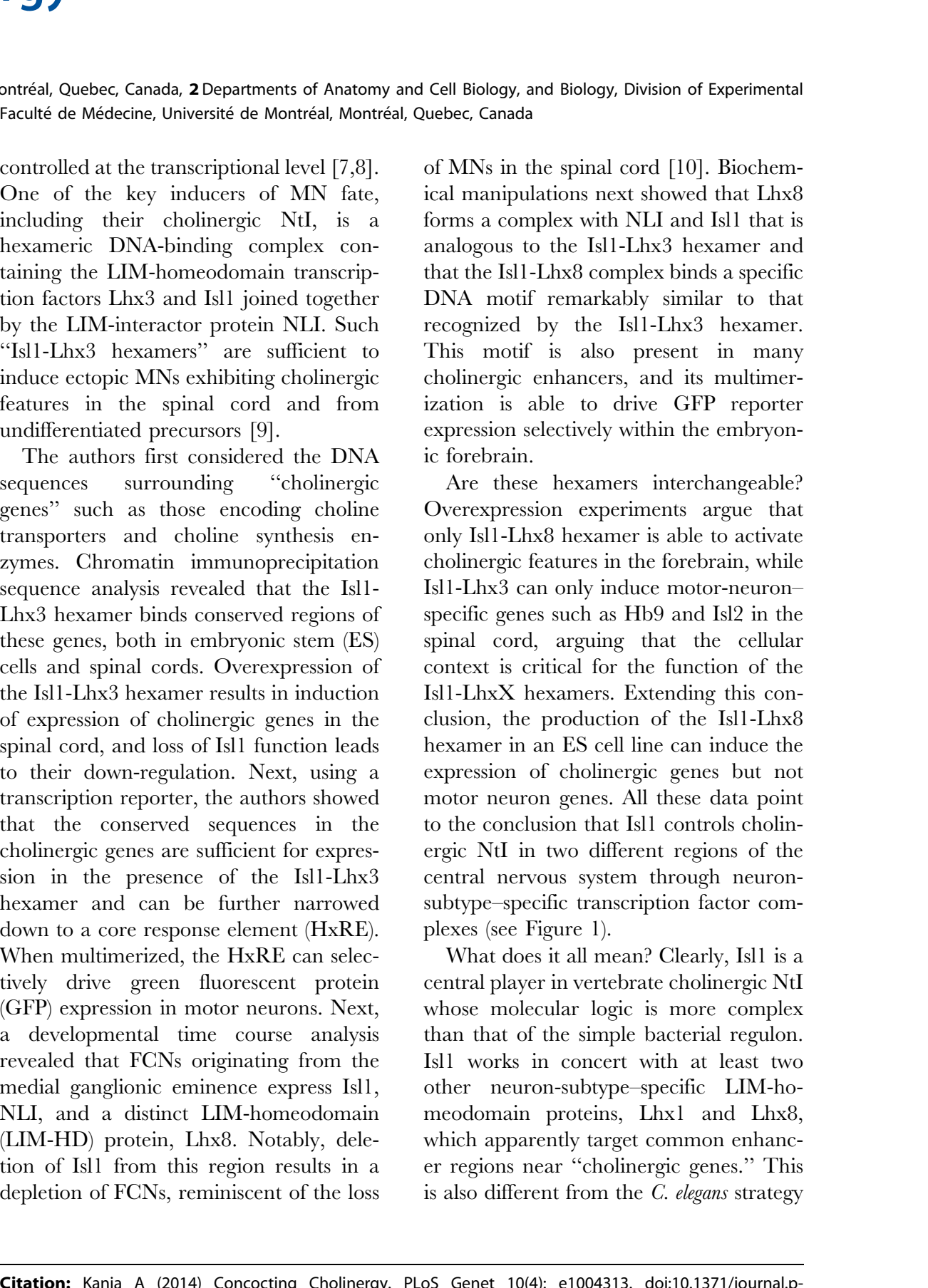

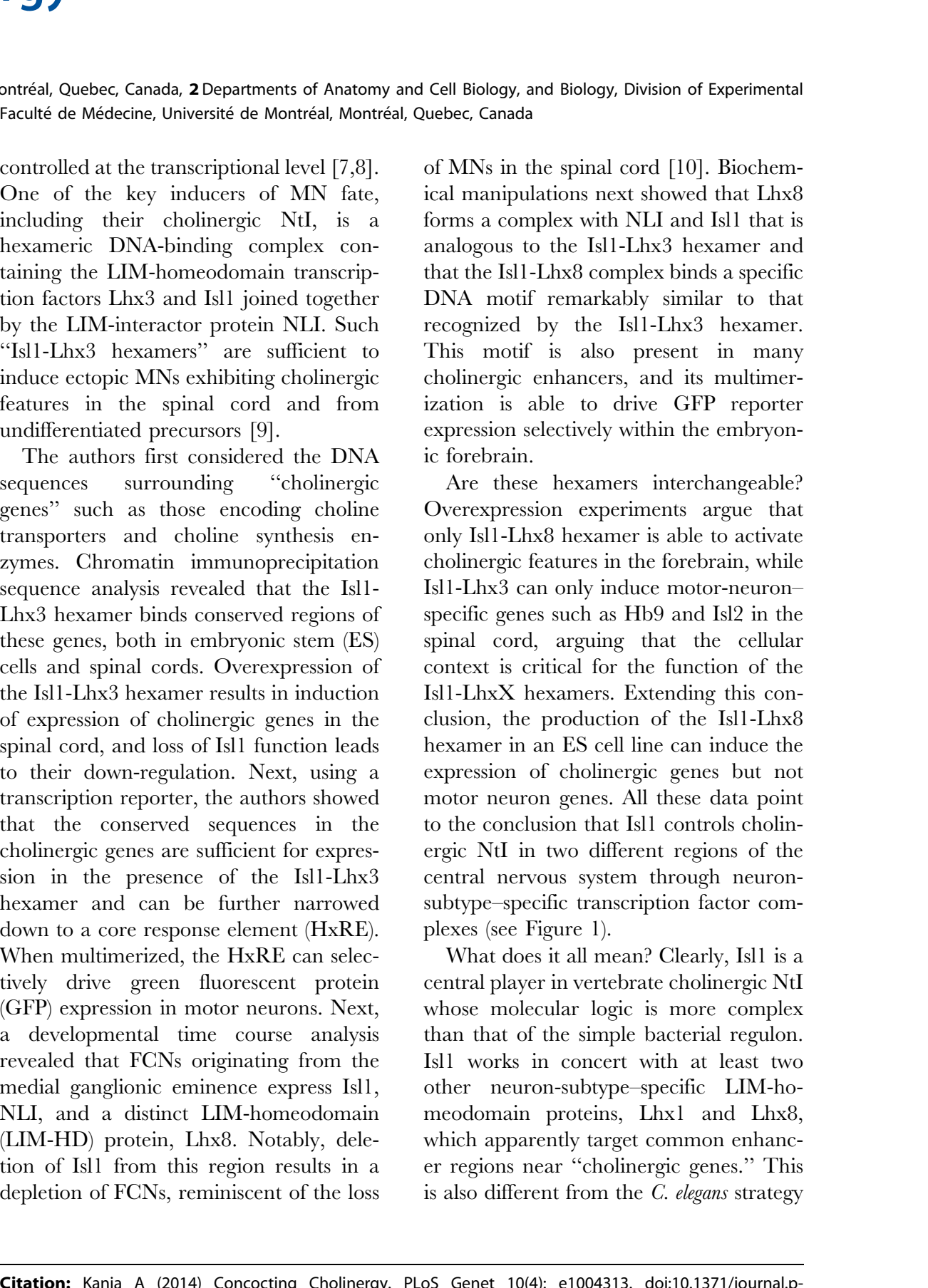

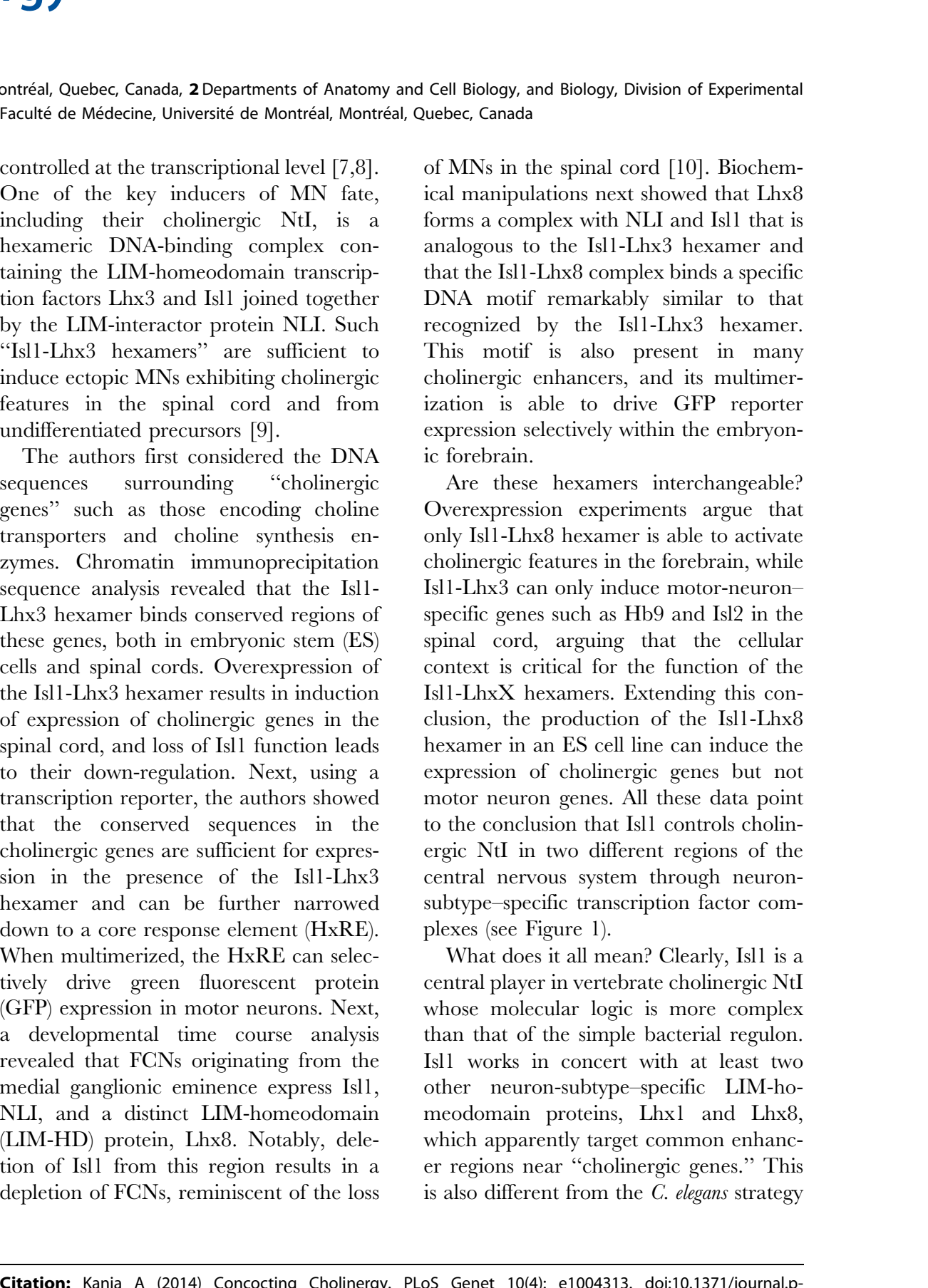

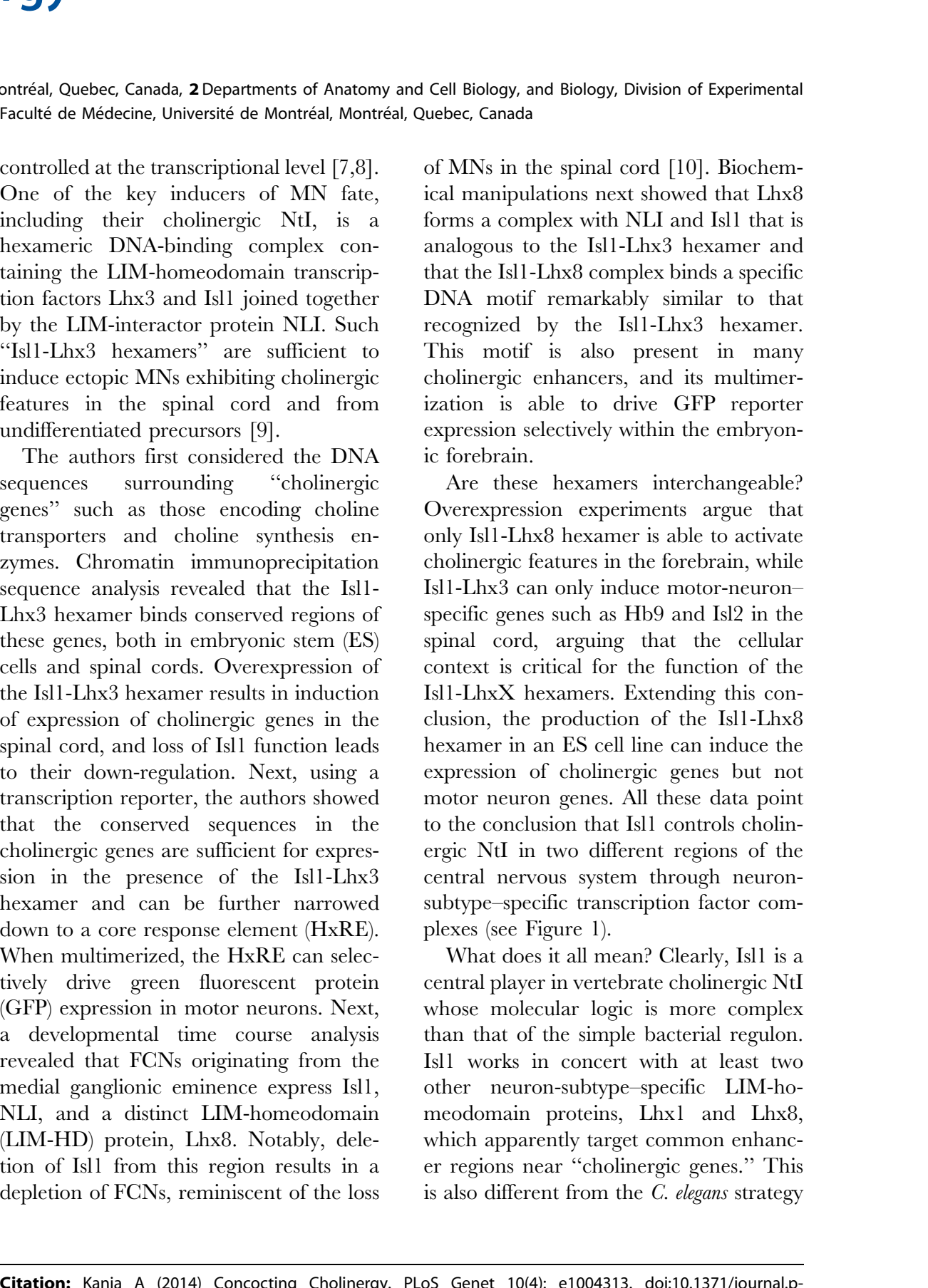

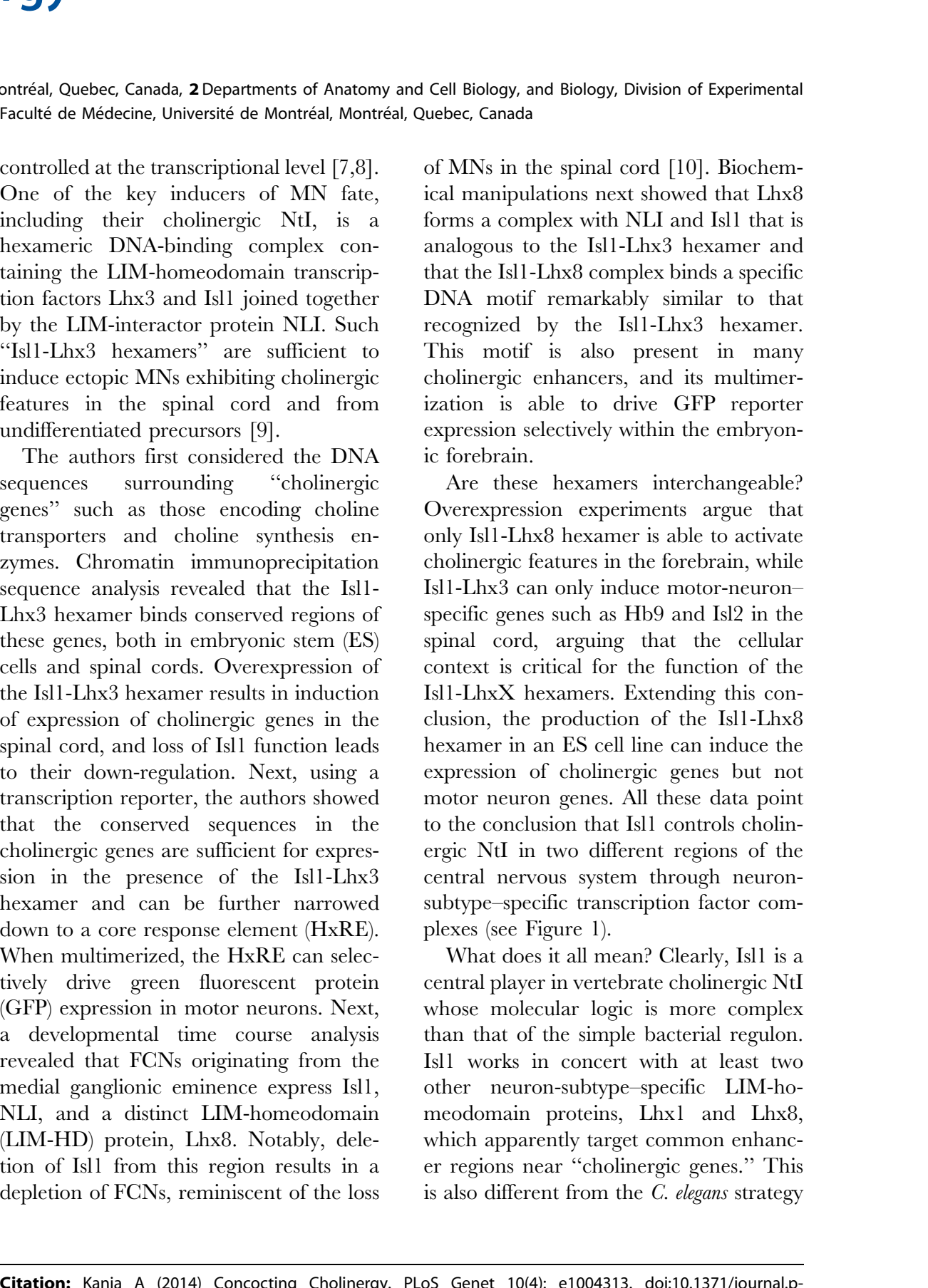

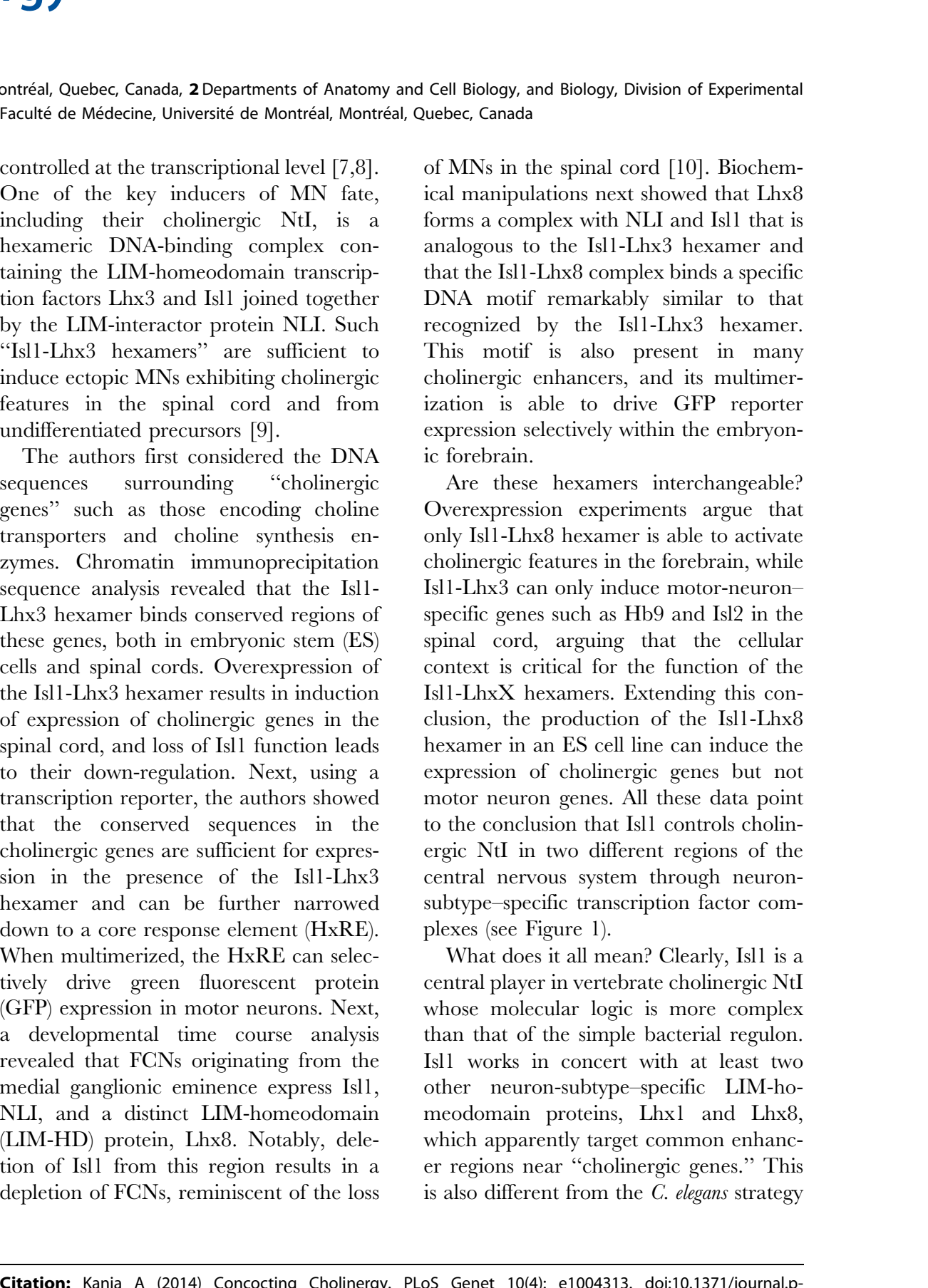

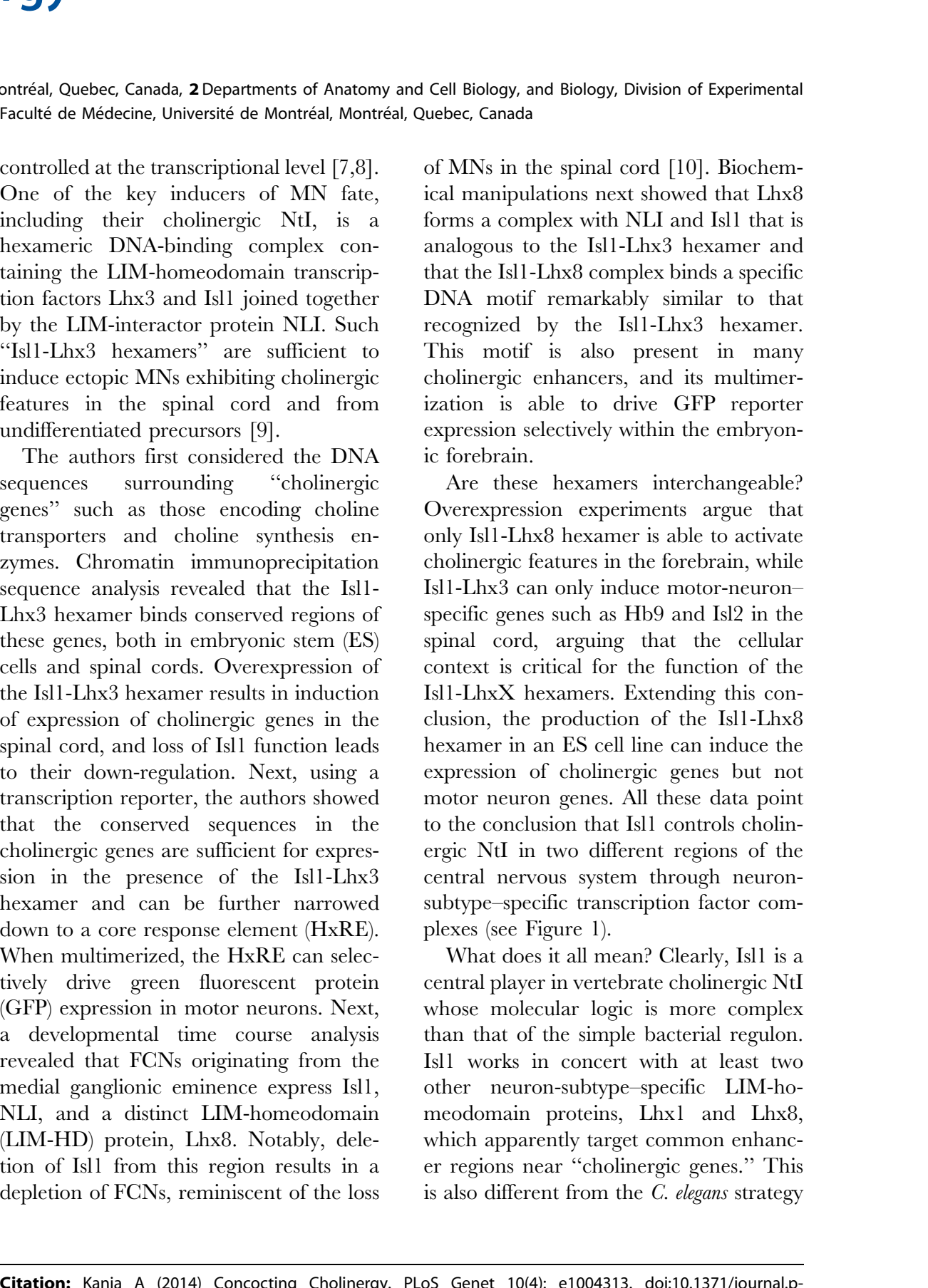

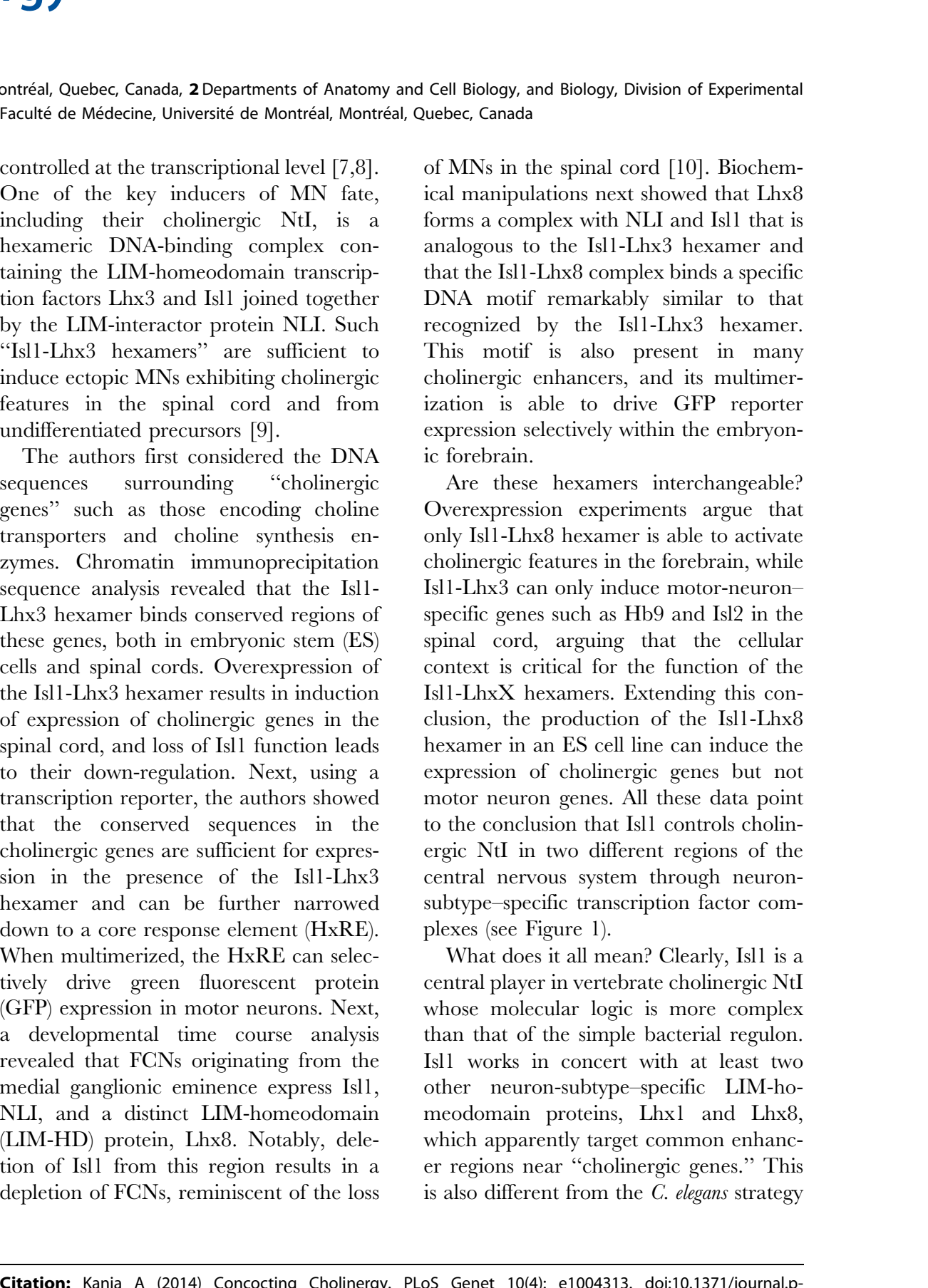

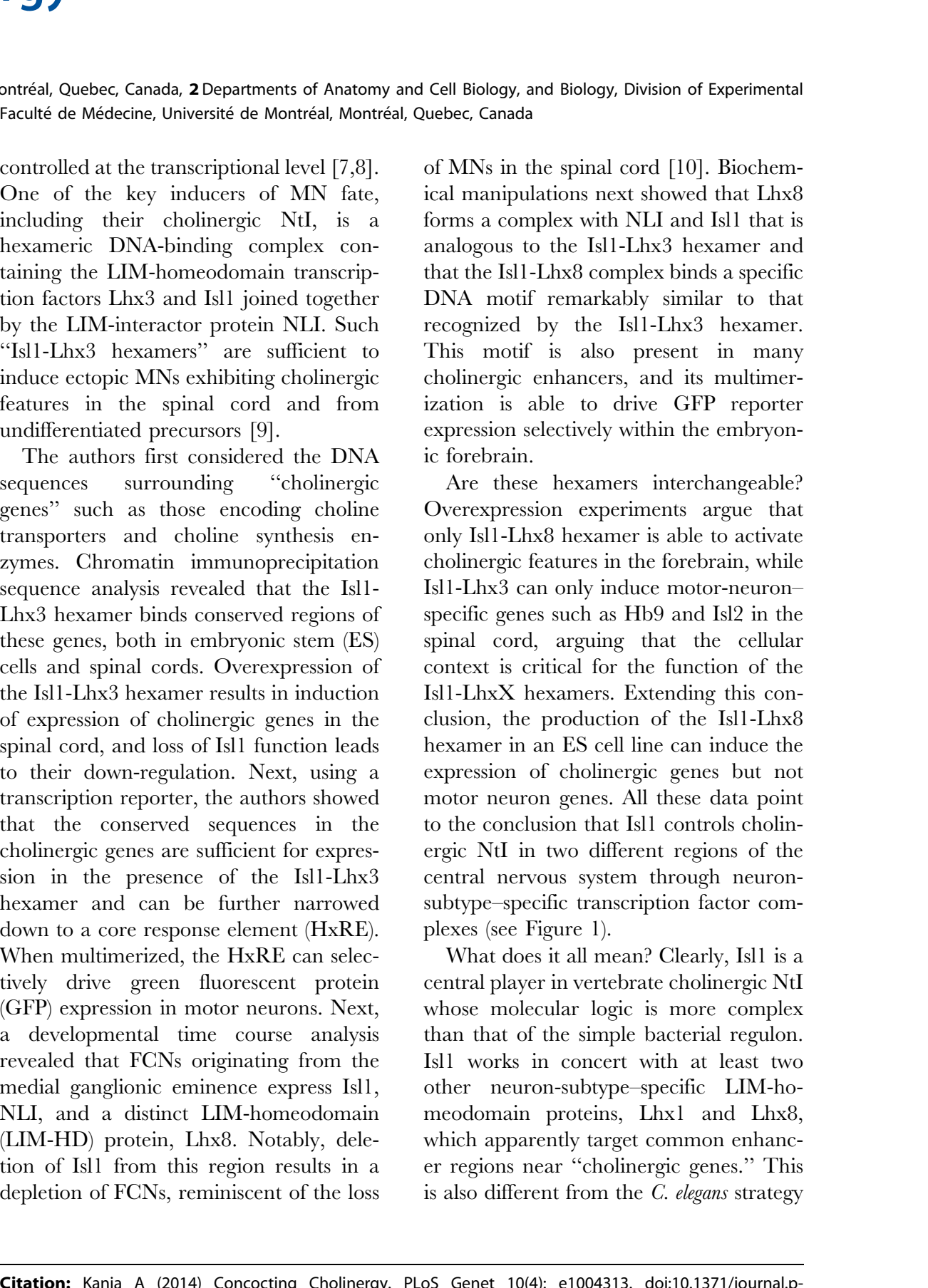

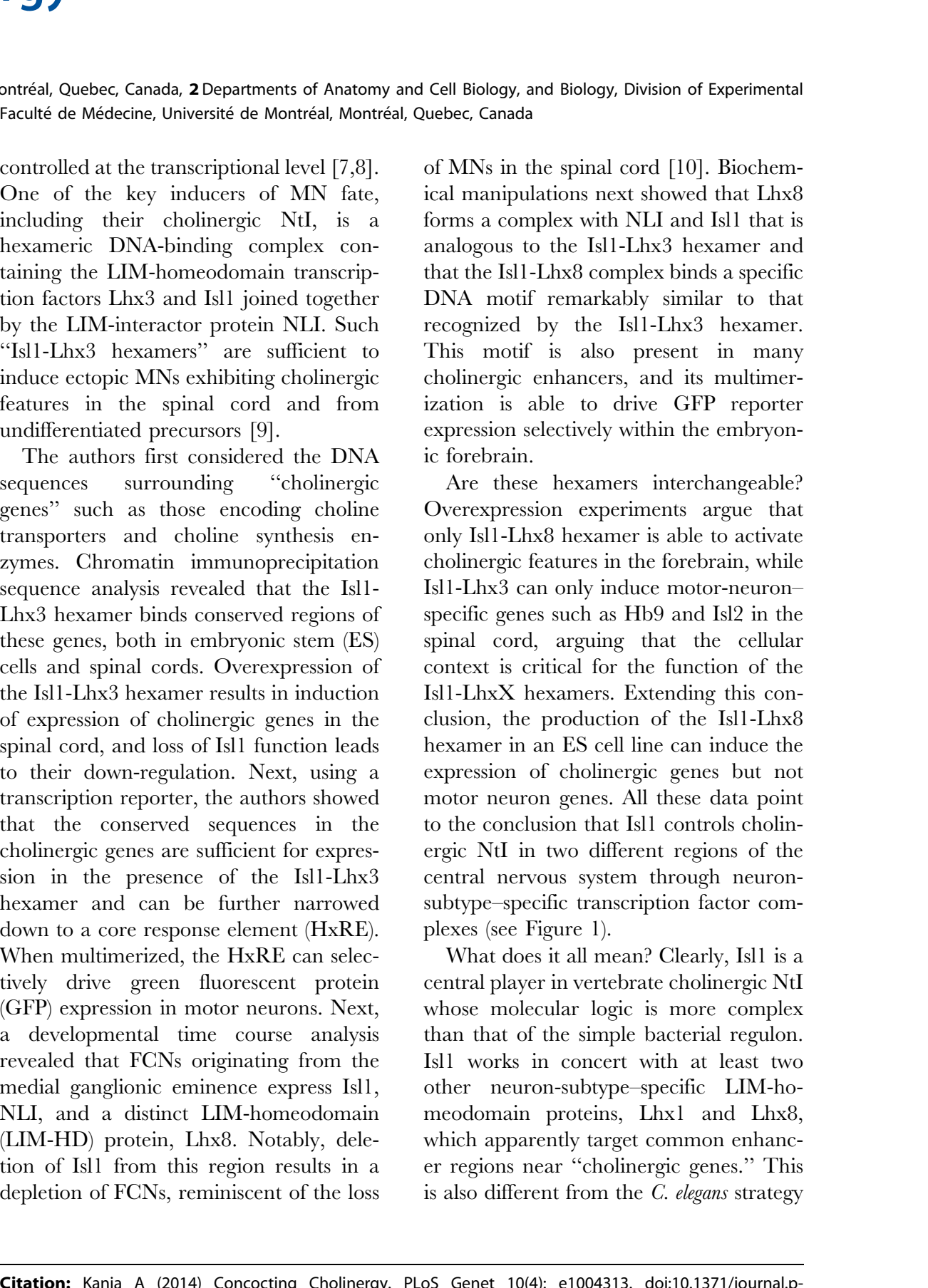

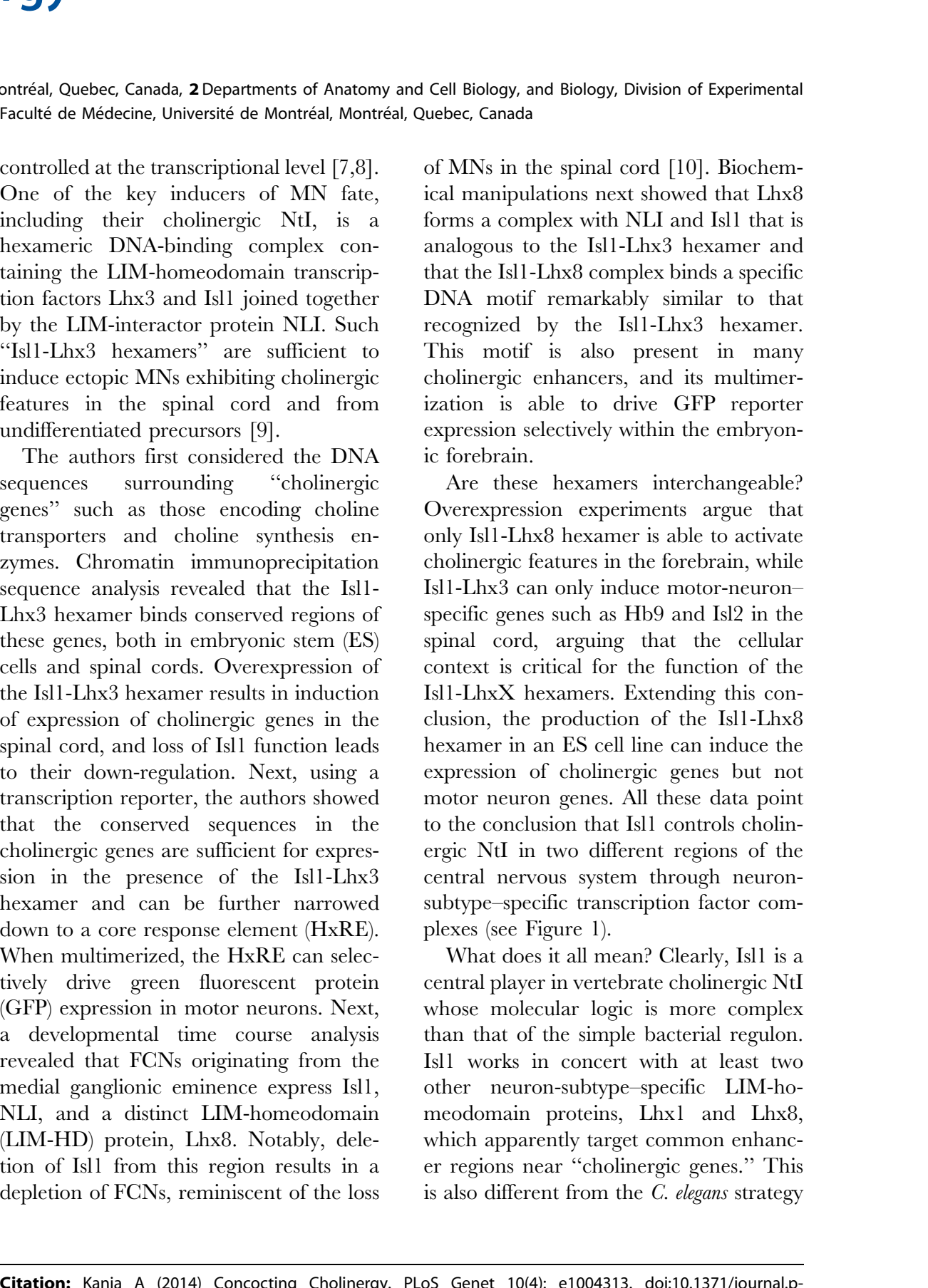

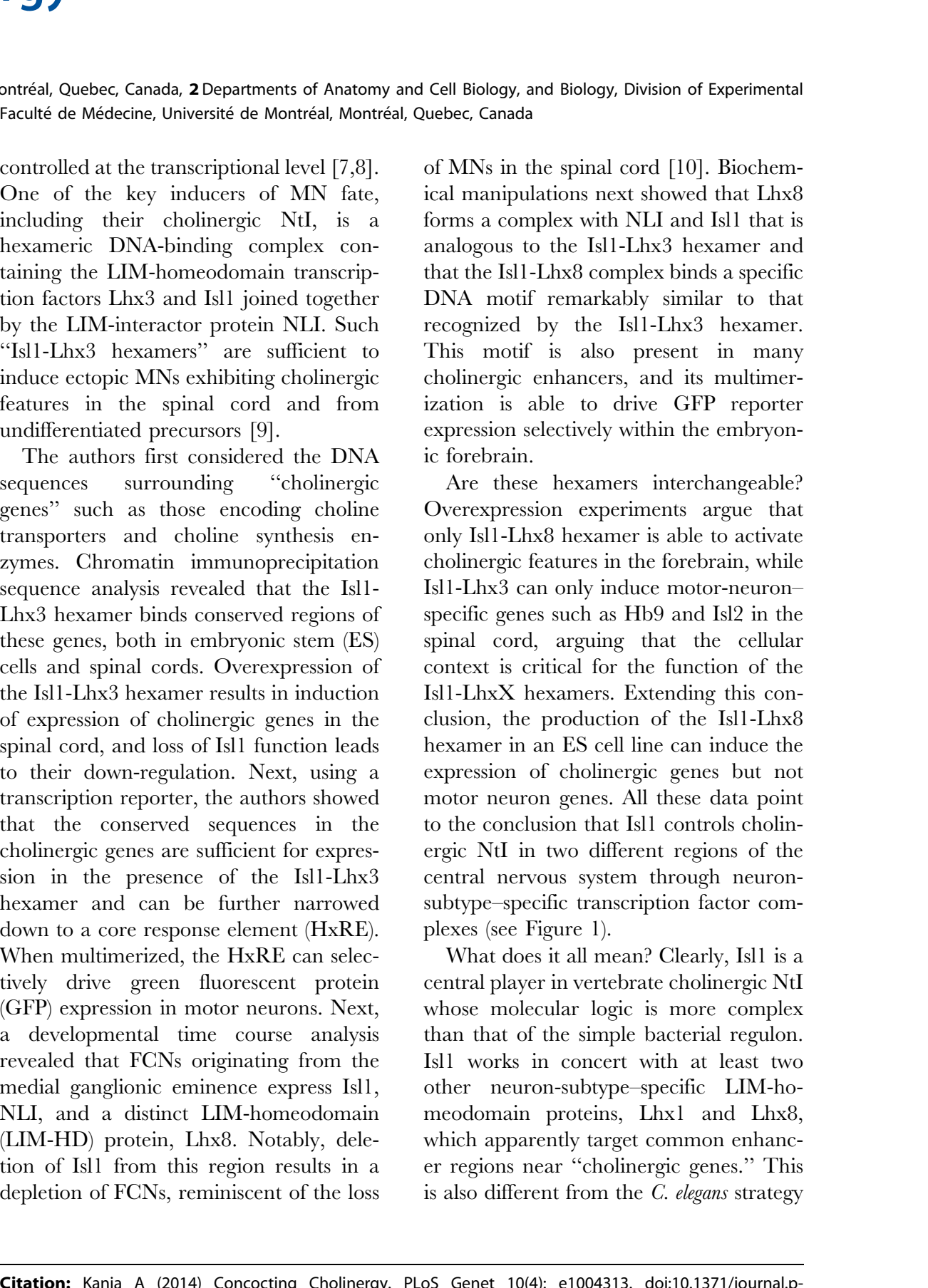

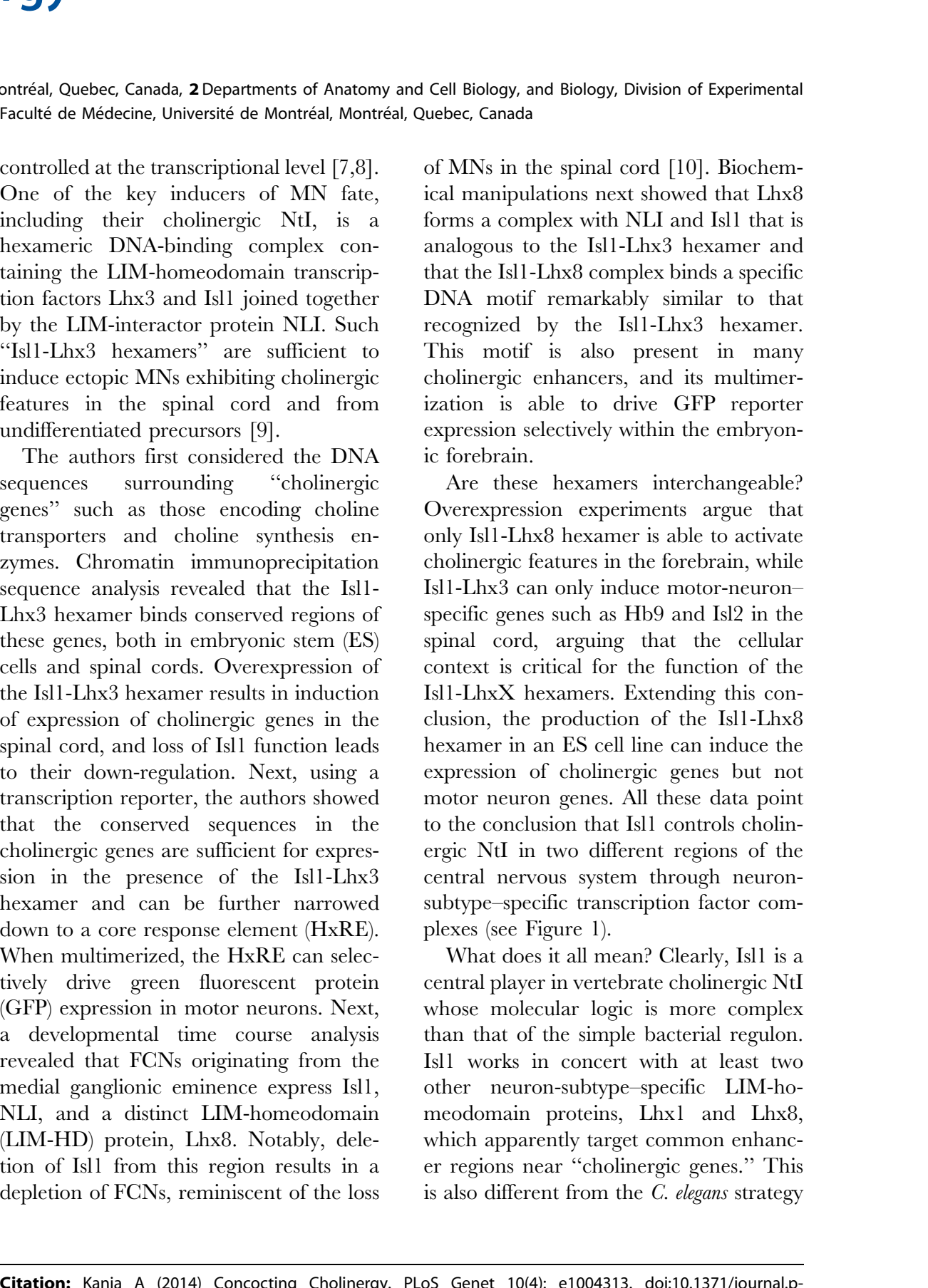

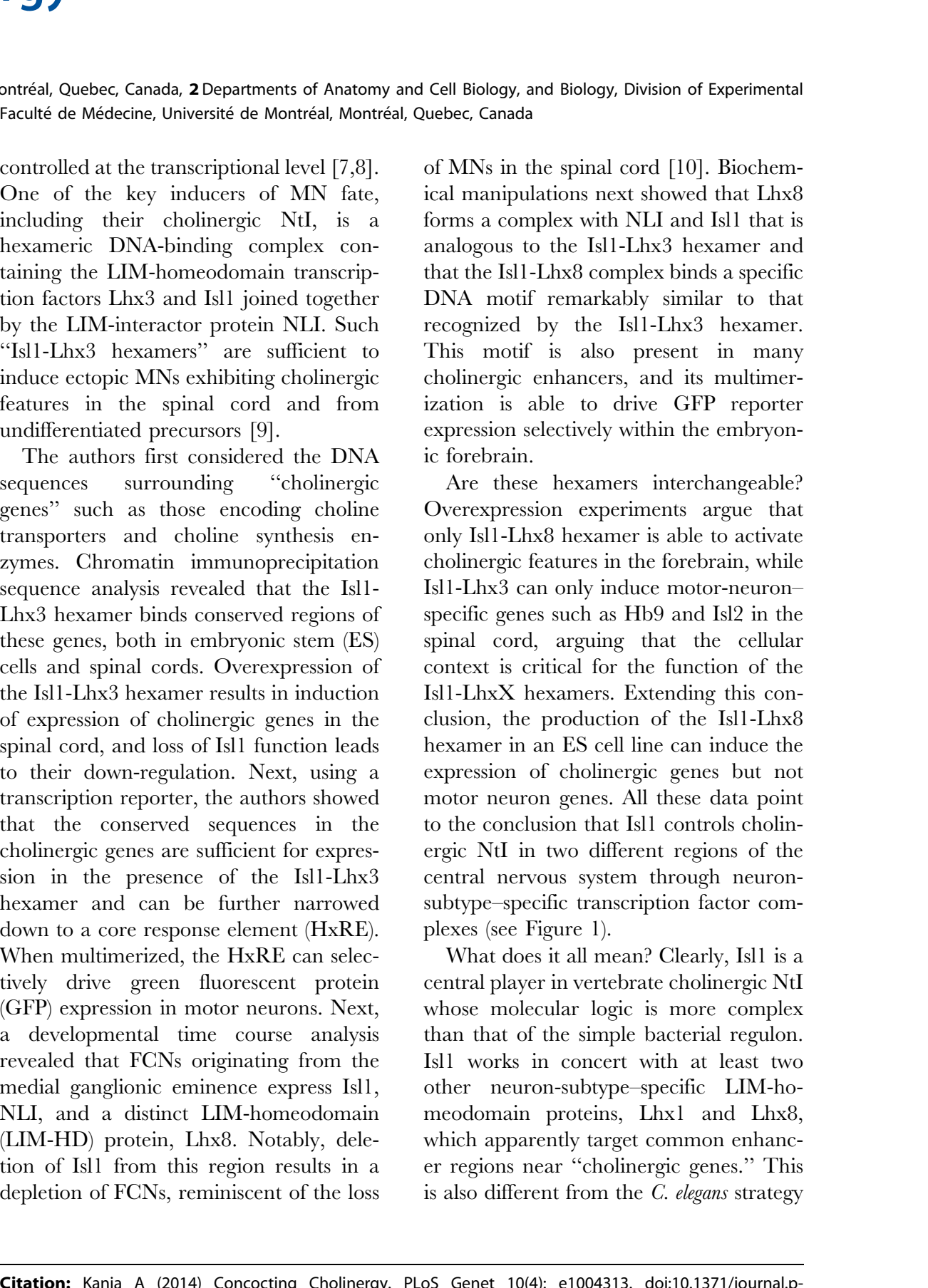

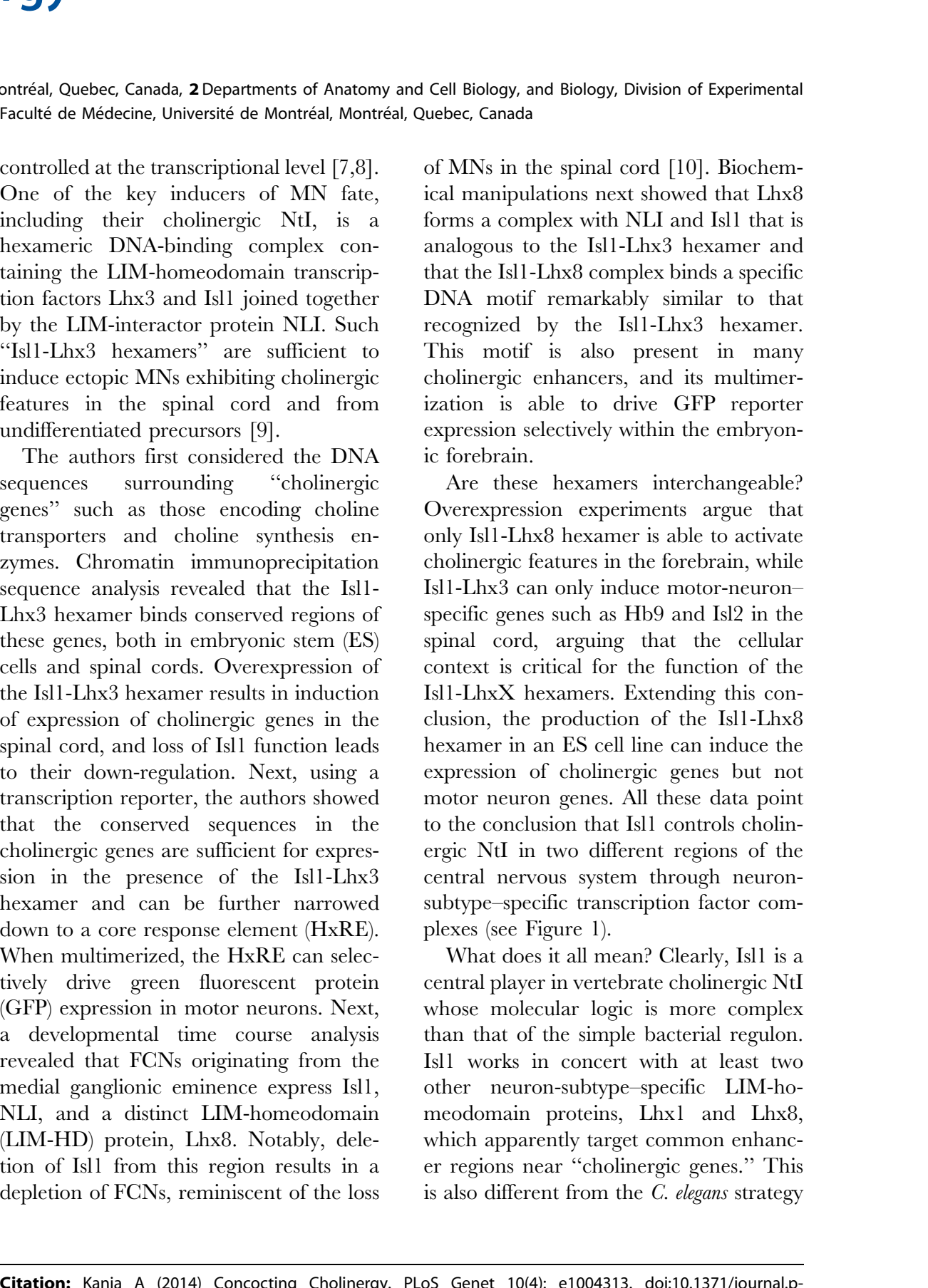

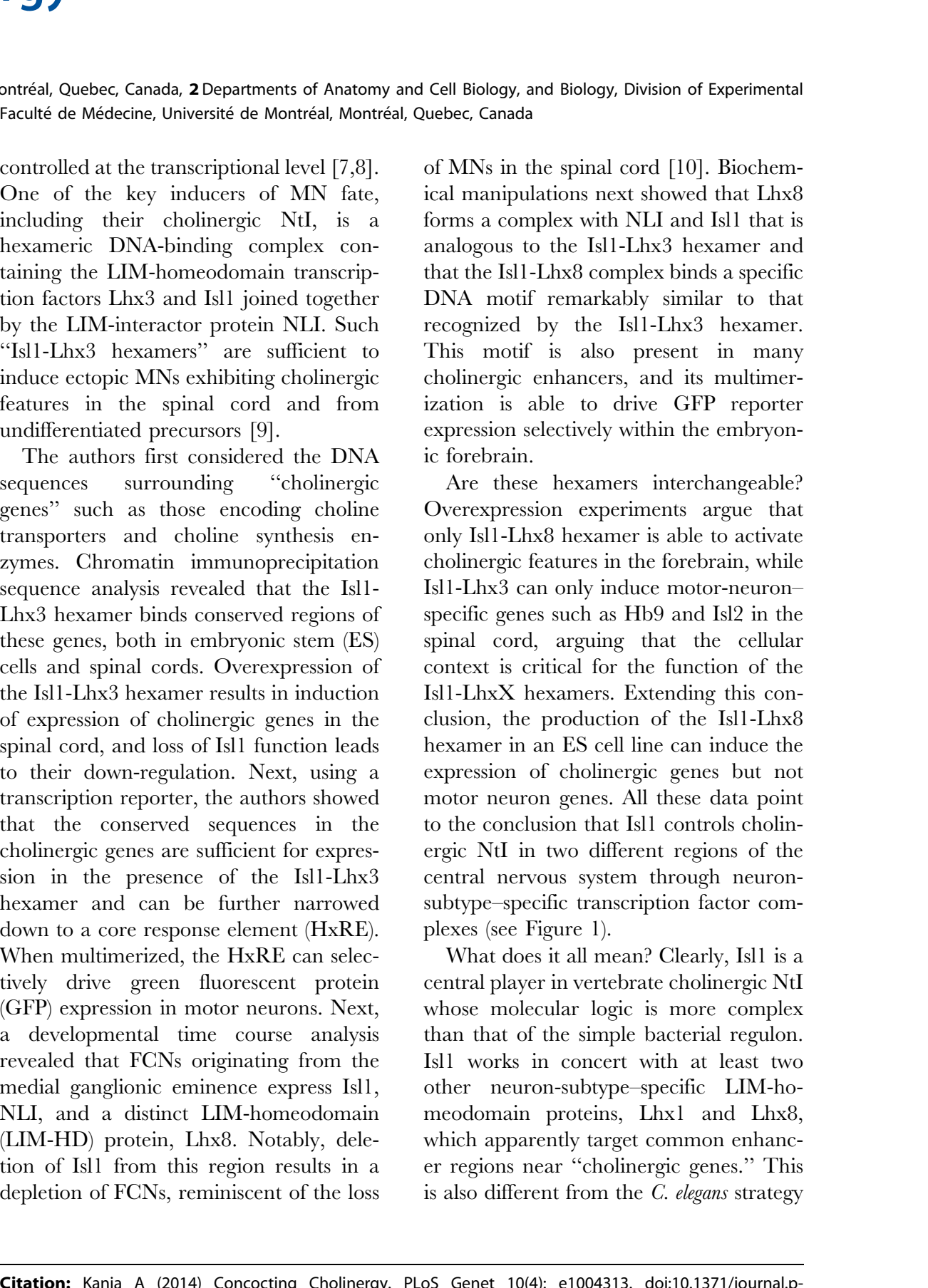

Citation: Kania A (2014) Concocting Cholinergy. PLoS Genet 10(4): e1004313. doi:10.1371/journal.pgen. 1004313

Editor: Bennett Novitch, University of California Los Angeles, United States of America

Published April 24, 2014

Copyright: (C) 2014 Artur Kania. This is an open-access article distributed under the terms of the Creative Commons Attribution License, which permits unrestricted use, distribution, and reproduction in any medium, provided the original author and source are credited.

Funding: AK is supported by the Canadian Institutes of Health Research, National Sciences and Engineering Research Council of Canada, Québec Pain Research Network, Brain Canada and the W. Garfield Weston Foundation. The funders had no role in the preparation of the article.

Competing Interests: The author has declared that no competing interests exist.

*E-mail: artur.kania@ircm.qc.ca 

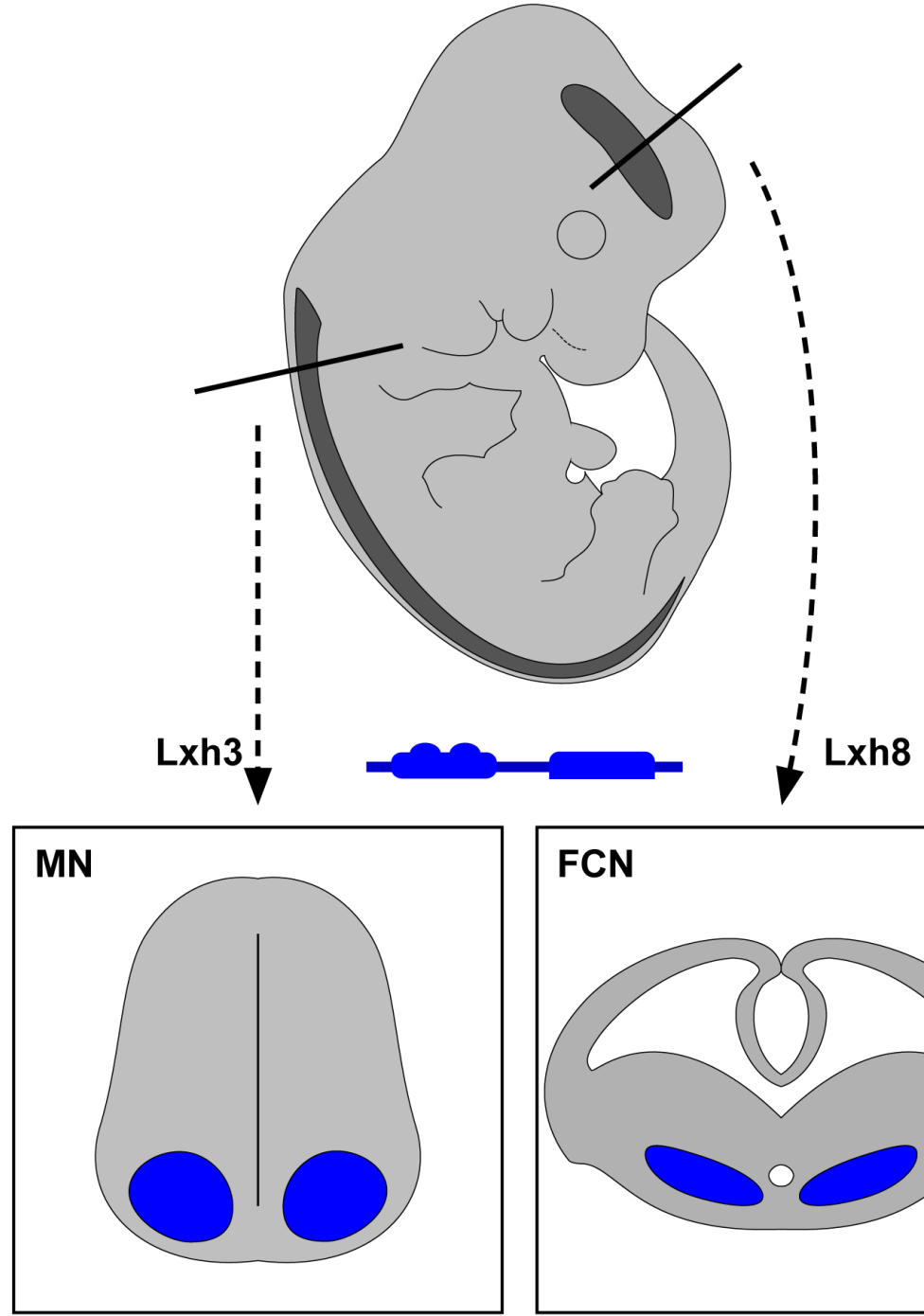

\section{FCN}
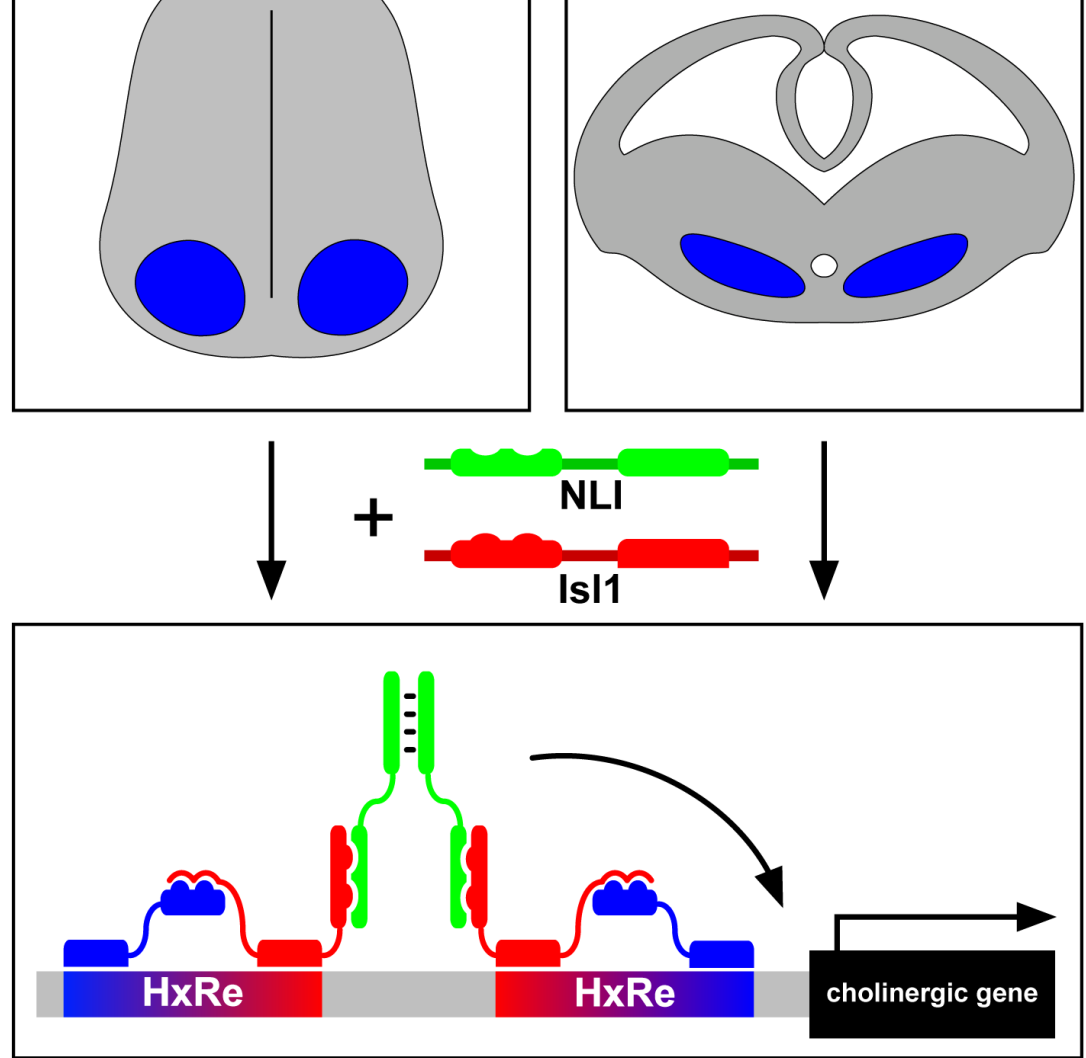

Figure 1. LIM-homeodomain proteins Lhx3 and Lhx8 induce the cholinergic neurotransmitter identity in spinal motor neurons and forebrain cholinergic neurons through IsI1 and NLI hexamer complex transcriptional activity. doi:10.1371/journal.pgen.1004313.g001

in which the UNC-3 transcription factor is sufficient to coregulate all "cholinergic genes" [4]. The most pressing question stemming from this study is the identity of the sequences bound by Isll-Lhx8 and Isl1-Lhx3. Some preliminary and unpublished observations suggest that these are distinct. One corollary would be that there are other cholinergic neuron-subtypespecific Isll-Lhx complexes and that each of these has a binding sequence near cholinergic genes. This would make for quite a baroque model of vertebrate cholinergic NtI. Another possibility could be that there are neuron-type-specific Isll-Lhx hexamers but that these bind to the same DNA sequences. They would only be able to turn on cholinergic genes through the interaction of the Isll partner (Lhx, Lhx8, etc) with another cell-type-specific transcription factor binding to nearby sequences.

Arguably, NtI must be tightly regulated so that neurons do not express inappropriate neurotransmitters and adhere (mostly) to Dale's principle that neurons use a single mode of transmission [11]. One scheme could involve active suppression of "competing" NtIs, in which, for example, Isl1Lhx8 could bind promoters of glutamatergic and GABAergic genes and actively shut them down. This does not appear to be a strategy in $C$. elegans, but vertebrate NtI could be more tortuous [12]. In the broader context, this study provides some attractive models in which to examine the intersection between $\mathrm{NtI}$ and other aspects of neuronal identity, such as dendrite morphology or soma location. To what extent are all these linked? Could they really be thought of as separate modules or would a selection of a particular NtI favour some morphological features? This could be regulated either directly at a transcriptional level, in which Isll-Lhx8, for example, might influence the expression of some FCN "structural" genes, or through homeostatic mechanisms in which the use of a particular neurotransmitter has global consequences on the electrical properties of a neuron. Finally, another important general question is that of the maintenance of neuronal identity, including NtI. Could the same transcriptional complexes that are turning on cholinergy also be required for maintaining it? Could $\mathrm{Alz}$ heimer disease and amyotrophic lateral sclerosis, two human pathologies affecting cholinergic neurons, involve a loss of Isl1Lhx3 and Isll-Lhx8 function? Some answers to this question will certainly come from a deeper understanding of molecular strategies controlling the intersection of $\mathrm{NtI}$ with other aspects of neuronal identity.

\section{Acknowledgments}

The author is grateful to Ben Novitch for critical comments and Farin Bourojeni for illustration. 


\section{References}

1. Cho H-H, Cargnin F, Kim Y, Lee B, Kwon R-J, et al. (2014) Isll directly controls a cholinergic neuronal identity in the developing forebrain and spinal cord by forming cell type-specific complexes. PLoS Genet 10: e1004280. doi: 10.1371/ journal.pgen. 1004280

2. Epstein W, Beckwith JR (1968) Regulation of Gene Expression. Ann Rev Biochemistry 37: 411-436.

3. Doitsidou M, Flames N, Topalidou I, Abe N, Felton T, et al. (2013) A combinatorial regulatory signature controls terminal differentiation of the dopaminergic nervous system in C. elegans. Genes Dev 27: 1391-1405.

4. Kratsios P, Stolfi A, Levine M, Hobert O (2011) Coordinated regulation of cholinergic motor neuron traits through a conserved terminal selector gene. Nat Neurosci 15: 205-214.

5. Serrano-Saiz E, Poole RJ, Felton T, Zhang F, De La Cruz ED, et al. (2013) Modular control of glutamatergic neuronal identity in C. elegans by distinct homeodomain proteins. Cell 155: 659-673.

6. Woolf NJ (1991) Cholinergic systems in mammalian brain and spinal cord. Prog Neurobiol 37: 475-524.

7. Alaynick WA, Jessell TM, Pfaff SL (2011) SnapShot: spinal cord development. Cell 146: 178-178.e1.

8. Dalla Torre di Sanguinetto SA, Dasen JS, Arber S (2008) Transcriptional mechanisms controlling motor neuron diversity and connectivity. Curr Opin Neurobiol 18: 36-43.
9. Thaler JP, Lee S-K, Jurata LW, Gill GN, Pfaff SL (2002) LIM factor Lhx3 contributes to the specification of motor neuron and interneuron identity through cell-type-specific protein-protein interactions. Cell 110: 237-249.

10. Pfaff SL, Mendelsohn M, Stewart CL, Edlund T, Jessell TM (1996) Requirement for LIM homeobox gene Isll in motor neuron generation reveals a motor neuron-dependent step in interneuron differentiation. Cell 84: 309-320.

11. Burnstock G (2004) Cotransmission. Curr Opin Pharmacol 4: 47-52.

12. Hobert O, Carrera I, Stefanakis N (2010) The molecular and gene regulatory signature of a neuron. Trends Neurosci 33: 435445 